NADIA VILELA

\title{
Variação no desempenho auditivo em crianças com transtorno fonológico e do processamento auditivo após programa de estimulação
}


NADIA VILELA

\section{Variação no desempenho auditivo em crianças com transtorno fonológico e do processamento auditivo após programa de estimulação}

Dissertação apresentada à Faculdade de Medicina da Universidade de São Paulo para obtenção do título de Mestre em Ciências.

Programa: Ciências da Reabilitação

Área de Concentração: Comunicação Humana Orientadora: Profa. Dra. Renata Mota Mamede Carvallo

São Paulo

2011 
Dados Internacionais de Catalogação na Publicação (CIP)

Preparada pela Biblioteca da

Faculdade de Medicina da Universidade de São Paulo

Creprodução autorizada pelo autor

Vilela, Nadia

Variação no desempenho auditivo em crianças com transtorno fonológico e do processamento auditivo após programa de estimulação / Nadia Vilela. -- São Paulo, 2011.

Dissertação(mestrado)--Faculdade de Medicina da Universidade de São Paulo. Programa de Ciências da Reabilitação. Área de concentração: Comunicação Humana.

Orientadora: Renata Mota Mamede Carvallo.

Descritores: 1.Testes auditivos 2.Percepção auditiva 3.Audição 4.Transtornos da audição/reabilitação 5.Transtornos da articulação 6.Plasticidade neuronal 7.Criança 
Ao meu pai, por tudo e para sempre:

Era o presente ter você perto, é um presente ter você dentro. 
AGRADECIMENTOS 
Aos meus pais, Flavio (in memorian) e Monika, e ao meu irmão Daniel, por darem sempre a certeza do amor que sentem por mim.

Ao Sérgio, por ser a pessoa, o marido e o pai incrível que é.

Aos meus dois filhos Rafael e Vitor, os melhores presentes que a vida me deu, que aguentaram firme os meus muitos momentos de ausência.

À minha mais que querida orientadora Profa. Dra. Renata Mota Mamede Carvallo, por toda a confiança depositada em mim, pela paciência, disponibilidade, sensibilidade, carinho, delicadeza e por ser esta pessoa maravilhosa que todos queremos sempre por perto.

À Ivone Neves-Lobo e Caio Petrônio pela incansável participação na confecção do CD.

À Eliane Schochat, Haydée Fiszbein Wertzner, Alessandra Gianella Samelli e Ivone Neves-Lobo pelas importantes contribuições durante a Qualificação.

À querida Geny Aleixo pelo carinho e pelo olhar clínico e milimétrico sobre o português.

Às amigas-amadas: Teca, Júlia Paula, "mãe" Júlia e Clê, que me acalmaram nas horas em que achei que não chegaria ao final.

Às fonoaudiólogas queridas que foram importantes demais durante todo o processo: Gabriela Sanches, mais que amiga, uma irmã; Luciana Pagan que teve participação fundamental; Juliana Urosas, pela companhia e por todas as dicas de informática; Jordana Soares, pela calma e bondade; Camila Rabelo pelas palavras carinhosas; Tatiane Barrozo, pela presença; Kilza Arruda, por todas as "figurinhas trocadas" e por ser assim tão 
"arretada"; Márcia Castro, pela incrível sintonia em tempo recorde; Renata Ramos, pela disponibilidade em colaborar.

À Profa. Carmen Saldiva pelas contribuições na análise estatística. Aos funcionários do Centro em Docência e Pesquisa da FMUSP. À FAPESP pelo apoio financeiro à pesquisa.

E, finalmente, aos participantes da pesquisa pelo voto de confiança. 
Esta dissertação está de acordo com as seguintes normas, em vigor no momento desta publicação:

Referências: adaptado de International Commitee of Medical Journals Editors (Vancouver)

Universidade de São Paulo. Faculdade de Medicina. Divisão de Biblioteca e Documentação. Guia de apresentação de dissertações, teses e monografias. Elaborado por Anneliese Carneiro da Cunha, Maria Julia de A. L. Freddi, Maria F. Crestana, Marinalva de Souza Aragão, Suely Campos Cardoso, Valéria Vilhena. $3^{\text {a }}$ ed. - São Paulo: Divisão de Biblioteca e Documentação - 2011.

Abreviaturas dos títulos dos periódicos de acordo com List of Journals Indexed in Index Medicus. 


\section{Sumário}

Lista de Quadros

Lista de Figuras

Lista de Tabelas

Lista de Abreviaturas, Siglas e Símbolos

Resumo

Summary

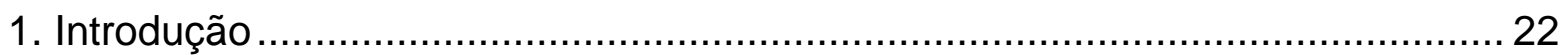

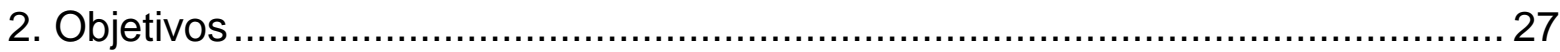

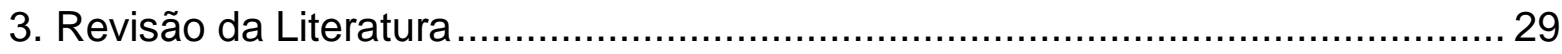

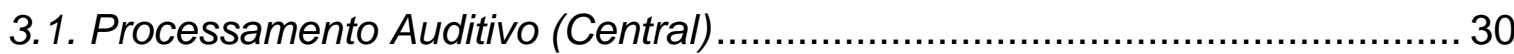

3.2. Treino Auditivo e Plasticidade Neural......................................................... 35

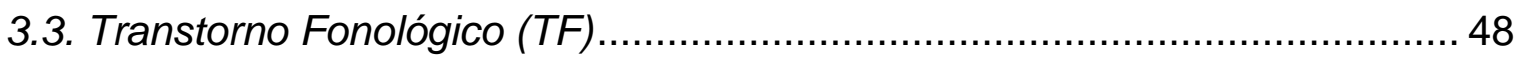

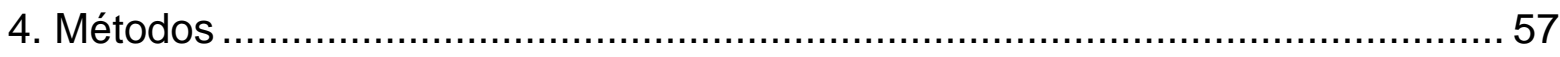

4.1. Elaboração e confecção de material para realização de TAl .......................57

4.1.1. Material utilizado para a captação dos estímulos .................................. 61

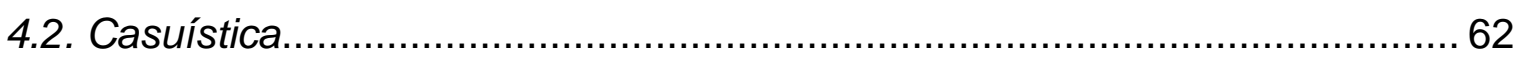

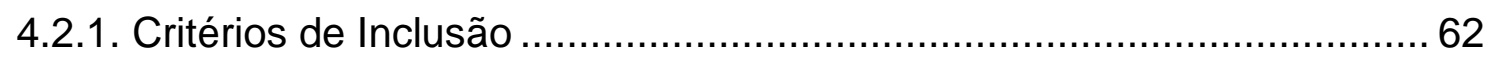

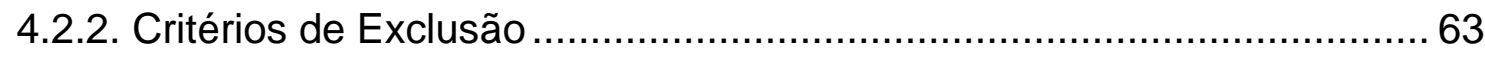

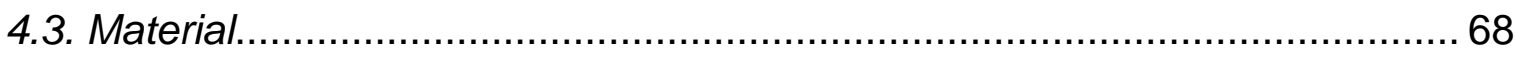

4.3.1. Avaliação Audiológica e do Processamento Auditivo (Central) ............. 68

4.3.2. Material utilizado para Treino Auditivo Formal (TAF) ............................ 74

4.3.3. Material utilizado para Treino Auditivo Informal (TAI) .......................... 78

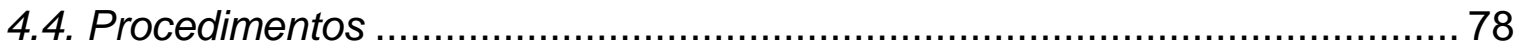

4.4.1. Procedimentos para inclusão nos Grupos ……………………….... 78

4.4.2. Procedimentos após a inclusão em cada grupo ................................... 80 


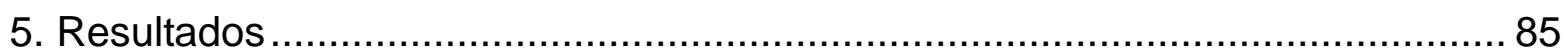

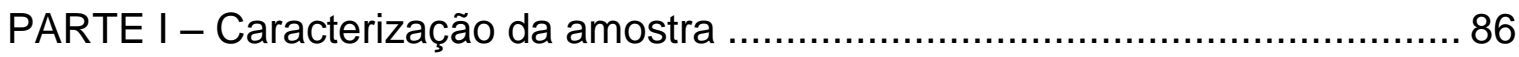

PARTE II - Resultados obtidos nos testes aplicados para a avaliação do PA(C) pré e pós-treino auditivo ........................................................................ 91

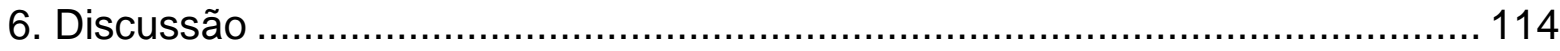

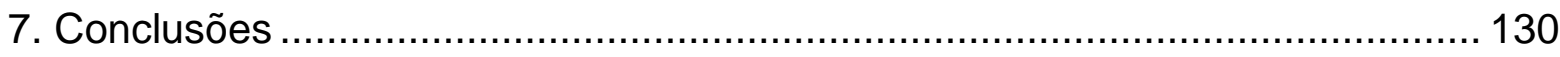

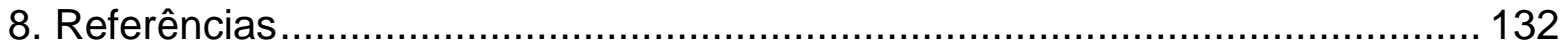

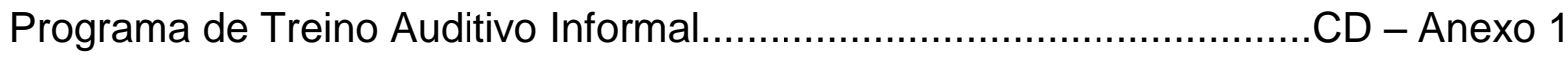

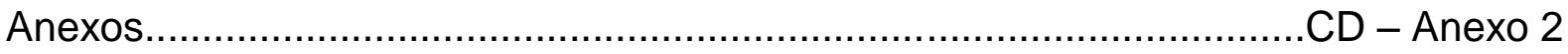




\section{Lista de Quadros}

Quadro 1 - Idades para o domínio dos fonemas 53

Quadro 2 - Aquisição de Grupo Consonantal em posição inicial e final, por idade ................................................................................. 54

Quadro 3 - Descrição das faixas contidas no CD para o TAI .................................60 


\section{Lista de Figuras}

Figura 1 - Organograma com os passos adotados a partir dos resultados das avaliações do $\mathrm{PA}(\mathrm{C})$

Figura 2 - Valores individuais e medianos do PCC-R (\%) na imitação nos grupos Controle, TAF e TAI

Figura 3 - Valores individuais e medianos do PCC-R (\%) na nomeação nos grupos Controle, TAF e TAI

Figura 4 - Perfis individuais da porcentagem de acertos no IF por grupo e avaliação - orelha direita

Figura 5 - Médias \pm erros padrão da porcentagem de acertos no IF por grupo e avaliação - orelha direita

Figura 6 - Perfis individuais da porcentagem de acertos no IF por grupo e avaliação - orelha esquerda....

Figura 7 - Médias \pm erros padrão da porcentagem de acertos no IF por grupo e avaliação - orelha esquerda

Figura 8 - Perfis individuais da porcentagem de acertos no DD por grupo e avaliação - orelha direita

Figura 9 - Médias \pm erro padrão da porcentagem de acertos no DD por grupo e avaliação - orelha direita.

Figura 10 - Perfis individuais da porcentagem de acertos no DD por grupo e avaliação - orelha esquerda.

Figura 11 - Médias \pm erro padrão da porcentagem de acertos no DD por grupo e avaliação - orelha esquerda

Figura 12 - Perfis individuais da porcentagem de acertos no PF por grupo e avaliação

Figura 13 - Médias \pm erros padrão da porcentagem de acertos no PF por grupo e avaliação.

Figura 14 - Perfis individuais da porcentagem de acertos no PD por grupo e avaliação

Figura 15 - Médias \pm erros padrão da porcentagem de acertos no PD por grupo e avaliação.

Figura 16 - Perfis individuais do Limiar no GIN (ms) por grupo e avaliação 
Figura 17 - Valores individuais e medianos do Limiar no GIN (ms) por grupo

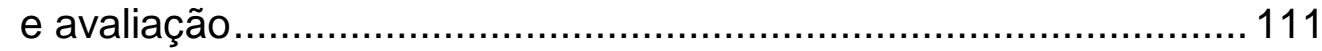




\section{Lista de Tabelas}

Tabela 1 - Estatísticas descritivas para a Idade (anos). 86

Tabela 2 - Estatísticas descritivas para o PCC-R (\%) na imitação e na nomeação

Tabela 3 - P-valores obtidos na comparação das distribuições do PCC-R nos três grupos, duas a duas, ajustados pelo procedimento de Bonferroni

Tabela 4 - Estatísticas descritivas para o PCC-R (\%) na imitação e na nomeação reunindo os grupos com TPA(C) $(T A F+T A I)$

Tabela 5 - Estatísticas descritivas para a porcentagem de acertos no IF por grupo e avaliação - orelha direita

Tabela 6 - Estatísticas descritivas para a porcentagem de acertos no IF por grupo e avaliação - orelha esquerda

Tabela 7 - Estatísticas descritivas para a porcentagem de acertos no DD por grupo e avaliação - orelha direita

Tabela 8 - Estatísticas descritivas para a porcentagem de acertos no DD por grupo e avaliação - orelha esquerda

Tabela 9 - Estatísticas descritivas para a porcentagem de acertos no PF por grupo e avaliação.

Tabela 10 - Estatísticas descritivas para a porcentagem de acertos no PD por grupo e avaliação

Tabela 11 - Estatísticas descritivas para a Limiar no GIN (ms) por grupo e avaliação 


\section{Lista de Abreviaturas, Siglas e Símbolos}

$\begin{array}{ll}\text { ASHA } & \text { American Speech-Language-Hearing Association } \\ \text { C } & \text { grupo Controle } \\ \text { CD } & \text { Compact Disc } \\ \text { CM } & \text { Caixinha de Música } \\ \text { CS } & \text { Categoria Semântica } \\ \text { dB } & \text { Decibel } \\ \text { dBA } & \text { Escala de dB corrigido para leitura do decibelímetro } \\ \text { dBNA } & \text { Decibel Nível de Audição } \\ \text { dBNS } & \text { Decibel Nível de Sensação } \\ \text { DC } & \text { Direito Competitivo } \\ \text { DD } & \text { Dicótico de Dígitos } \\ \text { EC } & \text { Esquerdo Competitivo } \\ \text { FF+MV } & \text { Figura-fundo e memória verbal } \\ \text { FFNV } & \text { Figura-fundo não-verbal } \\ \text { FFV } & \text { Figura-fundo verbal } \\ \text { FFW - L } & \text { Fast ForWord Language } \\ \text { FM } & \text { Frequência Modulada } \\ \text { F+MV } & \text { Fechamento e memória } \\ \text { FNV } & \text { Fechamento Não-Verbal } \\ \text { Freq. } & \text { Frequência } \\ \text { FV } & \text { Fechamento Verbal } \\ \text { Fx. } & \text { Faixa } \\ \text { GIN } & \text { Gaps in Noise } \\ \text { Hab. } & \text { Habilidade } \\ \text { HN } & \text { História Narrada } \\ \text { Hz } & \text { Hertz } \\ \text { IF } & \text { Identificação de Figuras } \\ \text { IIE } & \text { Intervalo inter-estímulo } \\ \text { Khz } & \text { Kilohertz } \\ \text { LRF } & \text { Limiar de Reconhecimento de Fala } \\ \text { ms } & \text { milessegundos } \\ \end{array}$




\begin{tabular}{|c|c|}
\hline $\mathrm{MCl}$ & Mensagem Competitiva Ipsilateral \\
\hline OE & Orelha Esquerda \\
\hline OD & Orelha Direita \\
\hline OT & Ordenação temporal \\
\hline $\mathrm{PA}(\mathrm{C})$ & Processamento Auditivo (Central) \\
\hline $\mathrm{PA}(\mathrm{C}) 1$ & $1^{\mathrm{a}}$ avaliação do Processamento Auditivo (Central) \\
\hline $\mathrm{PA}(\mathrm{C}) 2$ & $2^{\mathrm{a}}$ avaliação do Processamento Auditivo (Central) \\
\hline $\mathrm{PA}(\mathrm{C}) 3$ & $3^{a}$ avaliação do Processamento Auditivo (Central) \\
\hline PCC & Percentage of Consonants Correct \\
\hline$P C C-R$ & Percentage of Consonants Correct - Revised \\
\hline PD & Teste de Padrão Temporal de Duração \\
\hline PF & Teste de Padrão Temporal de Frequência \\
\hline RB & Ruído Branco \\
\hline $\mathrm{RC}$ & Ruído Competitivo \\
\hline$S / R$ & Sinal Ruído \\
\hline $\mathrm{TIH}$ & Transferência inter-hemisférica \\
\hline $\operatorname{TPA}(\mathrm{C})$ & Transtorno do Processamento Auditivo (Central) \\
\hline TA & Treino Auditivo \\
\hline TAF & Treino Auditivo Formal \\
\hline TAl & Treino Auditivo Informal \\
\hline TF & Transtorno Fonológico \\
\hline SNAC & Sistema Nervoso Auditivo Central \\
\hline SNC & Sistema Nervoso Central \\
\hline
\end{tabular}


Vilela, N. Variação no desempenho auditivo em crianças com transtorno fonológico e do processamento auditivo após programa de estimulação [dissertação]. São Paulo: Faculdade de Medicina, Universidade de São Paulo; 2011.

INTRODUÇÃO: O treino auditivo tem sido uma importante ferramenta para estimular indivíduos com transtorno do processamento auditivo (central) $(\operatorname{TPA}(\mathrm{C}))$. Além disso, não é rara a presença de TPA(C) em crianças com transtorno fonológico. OBJETIVOS: Elaborar programa de estimulação auditiva, assim como comparar o desempenho em testes comportamentais do processamento auditivo (central) $(\mathrm{PA}(\mathrm{C})$ ) em crianças com transtorno fonológico que passaram por treino auditivo formal e informal. MÉTODO: Foi desenvolvido programa de estimulação auditiva com objetivo de obter material controlado para o treino auditivo informal. Foram avaliados 15 indivíduos com transtorno fonológico (limiares tonais $\leq 20$ dBNA nas freqüências de 0,50 a $4 \mathrm{kHz}$ e idade entre 7:0 e 10:11 anos) por meio dos testes Identificação de Figuras com Ruído Competitivo Ipsilateral, Dicótico de Dígitos, Padrão Temporal de Freqüência e Padrão Temporal de Duração, formando três grupos: Grupo Controle (grupo C) composto por cinco sujeitos (com média de 9,1 anos) com alteração em apenas um teste comportamental do PA(C); Grupo Treino Auditivo Formal (grupo TAF) com cinco sujeitos (com média de 8,3 anos) com alteração em pelo menos dois testes do PA(C); e Grupo Treino Auditivo Informal (grupo TAI), com cinco sujeitos (com média de 8,1 anos), com alteração em pelo menos dois testes. Todos os participantes foram avaliados quanto ao grau de severidade do transtorno fonológico e realizaram duas avaliações do PA(C), com intervalo de seis a oito semanas, sem receber qualquer intervenção fonoaudiológica. Após a segunda avaliação do $\mathrm{PA}(\mathrm{C})$, as crianças do grupo TAF foram submetidas a oito sessões de treino auditivo formal e as crianças do grupo TAl receberam oito sessões de treino auditivo informal. Após o TAF e TAI, as crianças foram reavaliadas quanto ao PA(C). RESULTADOS: O grau de severidade do transtorno fonológico foi diferente entre o grupo Controle e os grupos TAF e TAI ( $p=0,007)$. Após oito sessões de TAl houve melhora em 
todos os testes aplicados, exceto para o teste Dicótico de Dígitos na orelha direita. Entre a primeira e a terceira avaliação do $\mathrm{PA}(\mathrm{C})$, observou-se diferença estatística no grupo TAI para o teste Identificação de Figuras na orelha direita e esquerda $(p=0,02)$. Houve melhora no desempenho auditivo pré e pós treino nos grupos TAF e TAl, embora sem diferença estatística. CONCLUSÃO: A gravidade do transtorno pareceu ter relação com a presença de TPA(C). A aplicação de oito sessões de TAl também foi capaz de provocar melhora no desempenho das crianças com TPA(C) e transtorno fonológico.

Descritores: Testes auditivos; Percepção auditiva; Audição; Transtornos da Audição/reabilitação; Transtornos da articulação; Plasticidade neuronal; Criança. 
Vilela, N. Variation in auditory performance in children with phonological and auditory processing disorders after stimulation program [dissertation]. São Paulo: School of Medicine, University of São Paulo, 2011.

BACKGROUND: The auditory training has been being an important tool to stimulate individuals with (Central) Auditory Processing Disorder ((C)APD). Moreover, the presence of (C)APD in children with phonological disorders is not uncommon. PURPOSE: The development of an auditory stimulation program, and the comparison of the performance in behavioral tests of (central) auditory processing ((C)AP) in children with phonological disorders who have undergone formal and informal auditory training. METHODS: A program of auditory stimulation was developed in order to obtain controlled material for informal auditory training. Fifteen subjects with phonological disorder ( $\leq 20 \mathrm{~dB} \mathrm{HL}$ tone thresholds at frequencies from 0.50 to $4 \mathrm{kHz}$ and age between 7:0 and 10:11 years) were evaluated through the Figure Identification test with ipsilateral competitive noise, Dichotic Digits test, Pitch Pattern Sequence and Duration Pattern Sequence test, forming three groups: The Control Group (C group) consisting of five subjects (average 9.1 years) with alteration in only one behavioral test of the (C)AP; the Formal Auditory Training Group (FT group) with five subjects (average 8.3 years) with alteration in at least two (C)AP tests; and the Informal Auditory Training Group (IT group), with five subjects (average 8.1 years) with alteration in at least two tests. All participants were assessed for degree of severity of phonological disorders and conducted two evaluations of the (C)PA at intervals of six to eight weeks without receiving any therapy. After the second evaluation of the (C)AP, the children of the FT group underwent eight formal auditory training sessions and the children of the IT group received eight sessions of informal auditory training. After the FT and IT, the children have been re-evaluated on the (C)AP. RESULTS: The severity of phonological disorder was different between the control group and the FT and IT groups $(p=0,007)$. After eight sessions of IT there was an improvement in all tests, except for the Dichotic Digits test in the right ear. Between the first and the 
third evaluation of (C)AP, a statistical difference was observed in the IT group for the figure identification test in the right and left ears $(p=0,02)$. Improvement occurred in auditory performance before and after training in the FT and IT groups, although no statistical difference was observed. CONCLUSION: The severity of the disorder seems to be related to the presence of (C)APD. The application of eight sessions of IT was also able to induce improvement in the performance of children with (C)AP and phonological disorders.

Descriptors: Hearing Tests; Auditory Perception; Hearing; Hearing Disorders/rehabilitation; Articulation Disorders; Neuronal Plasticity; Child. 
INTRODUÇÃO 


\section{INTRODUÇÃO}

A avaliação do Sistema Auditivo Central desperta o interesse de pesquisadores desde meados da década de 1950 (Broadbent, 1952 e 1954; Bocca et al., 1954; e Baran, Musiek, 2001).

Segundo a American Speech-Language-Hearing Association - ASHA (1996), o processamento auditivo (central) $(\mathrm{PA}(\mathrm{C})$ ) envolve os mecanismos do sistema auditivo, com os quais o sistema nervoso lida com a informação sonora, seja ela verbal ou não verbal. Quando o indivíduo apresenta a sensibilidade auditiva preservada, mas dificuldade em uma ou mais habilidades auditivas necessárias para o processamento auditivo é caracterizado um transtorno do processamento auditivo (central) (TPA(C)).

Para Chermak e Musiek (2002) é possível melhorar as funções do sistema auditivo na resolução de sinais acústicos a partir do treino das habilidades auditivas, denominado treino auditivo (TA). Segundo eles, o TA pode ser realizado de maneira formal (TAF) e informal (TAI). Para o TAF são propostas atividades acusticamente controladas e aplicadas em cabina acústica por profissional habilitado. O TAl também envolve a estimulação de habilidades auditivas, mas sem exigir controle acústico do ambiente e dos estímulos apresentados. Para os autores o TAF e o TAl são complementares e garantem a eficácia do tratamento. Além disso, o TAI 
permite que as habilidades auditivas estimuladas sejam utilizadas em situações do cotidiano e, desta forma, mais facilmente generalizadas.

Musiek et al. (1999), explicam que o TAl surgiu como uma possibilidade de treino para pacientes que não poderiam realizar o TA na clínica e, com isso, passaram a receber orientações para que o treino fosse complementado em casa ou na escola, sem a necessidade da presença de um audiologista ou de equipamentos específicos.

Estas duas formas de intervenção se baseiam na plasticidade neural, que é a capacidade do sistema nervoso central (SNC) sofrer mudanças neurofisiológicas a partir de experiências sensoriais (Kraus et al.,1995; Allum-Mecklenburg,1996; Musiek, Berge, 1998; Kraus, 1999; King, 1999; Grafman, 2000; Fujioka, 2006; e Tremblay,2007).

Mesmo sendo notável a melhora que o treino formal das habilidades auditivas proporciona, é preciso salientar que este é um tipo de intervenção que requer uma quantidade de equipamentos onerosa e que esta, infelizmente, não se apresenta em todos os serviços de fonoaudiologia.

Já o TA realizado de modo informal não requer utilização de equipamentos específicos ou ambientes acusticamente controlados, podendo, desta forma, ser utilizado em maior escala e com menor custo.

Considerando o desenvolvimento de fala e linguagem, Ingram (1976) coloca que com a percepção auditiva e a produção dos sons da fala, a criança aprende as regras do sistema linguístico de sua língua materna e se apropria de um sistema fonológico de contrastes. 
O Transtorno Fonológico (TF), por sua vez, pode ser descrito como uma alteração de fala, com ocorrência de substituições, omissões e/ou distorções dos sons (Wertzner, 2002 e Wertzner et al., 2007),

McArthur e Bishop (2004 e 2005) mencionam teorias para explicar as alterações de fala, que descrevem dificuldades em discriminar estímulos verbais de estímulos não-verbais e dificuldades em perceber mudanças acústicas (padrões temporais).

Para McArthur et al. (2009), pode haver estreita relação entre o $\operatorname{TPA}(C)$ e a alteração de fala pelo fato de o primeiro interferir na formação estável da representação dos fonemas no cérebro e na percepção de fala, dificultando o aprendizado da fonologia, sintaxe e semântica.

Mesmo sendo observados resultados positivos em casos de pacientes que passaram por TAl do $\mathrm{PA}(\mathrm{C})$, ainda são necessários, trabalhos que comparem estas duas formas de intervenção (TA formal e informal do $\mathrm{PA}(\mathrm{C})$ ), com o intuito de delimitar quais são seus reais efeitos, resultados e situações ideais de utilização.

Além disso, para a aplicação do TAI, o fonoaudiólogo ainda não dispõe de extensa literatura que o embase, assim como de material para sua realização em sala de terapia.

Levando-se em conta o que foi anteriormente exposto, consideramos que a verificação formal dos resultados obtidos a partir do treino em sala de terapia trará novas perspectivas a respeito do treino do $\mathrm{PA}(\mathrm{C})$, ampliando as possibilidades de reabilitação de indivíduos que apresentam alteração no processamento auditivo. 
Desta maneira, o principal objetivo deste trabalho foi verificar a variação de desempenho nos testes comportamentais do $\mathrm{PA}(\mathrm{C})$, antes e após a realização do treino auditivo formal e informal. 
OBJETIVOS 


\section{OBjetivos}

\subsection{Objetivo Geral}

O objetivo deste trabalho foi elaborar um programa de estimulação para a realização de treino auditivo em terapia fonoaudiológica, assim como verificar a variação de desempenho em crianças com diagnóstico de TF nos testes comportamentais do $\mathrm{PA}(\mathrm{C})$, antes e depois da realização de TAF e TAl.

\subsection{Objetivos Específicos}

2.2.1 - Descrever o desempenho pré e pós-treino auditivo formal nos testes comportamentais do $\mathrm{PA}(\mathrm{C})$, dos sujeitos do grupo TAF;

2.2.2 - Descrever o desempenho pré e pós-treino auditivo informal nos testes comportamentais do PA(C), dos sujeitos do grupo TAl;

2.2.3 - Comparar o desempenho pré e pós-treino auditivo nos testes comportamentais do $\mathrm{PA}(\mathrm{C})$, dos sujeitos dos grupos TAF e TAI, com o grupo Controle; 


\section{REVISÃo DA LITERATURA}




\section{REVISÃO DA LITERATURA}

Com o intuito de favorecer o encadeamento de ideias e, portanto, facilitar a leitura, este capítulo foi organizado de acordo com os seguintes tópicos:

3.1. Processamento Auditivo (Central);

3.2. Treino Auditivo e Plasticidade Neural;

3.3. Transtorno Fonológico. 


\subsection{Processamento Auditivo (Central)}

Historicamente, a avaliação do Sistema Auditivo Central tem seu início em meados da década de 1950, com o médico italiano Bocca e seus colaboradores (Baran e Musiek, 2001). Esta equipe iniciou suas investigações com pacientes que apresentavam lesões do sistema nervoso auditivo central (SNAC), por entenderem que os testes auditivos periféricos (audiometria tonal e testes de reconhecimento de fala) não eram suficientemente eficazes para avaliar as dificuldades auditivas relatadas por estes pacientes. Para isso, introduziram um teste monoaural de fala distorcida (Bocca et al., 1954).

Broadbent (1952 e 1954) também pode ser considerado um dos precursores da avaliação do $\mathrm{PA}(\mathrm{C})$ por ter pesquisado a atenção seletiva de sujeitos diante de estímulos verbais competitivos, sugerindo com isso, a utilização de estímulos dicóticos para avaliar a atenção e memória.

A partir daí, inúmeros testes foram desenvolvidos, sempre com o objetivo de investigar a integridade das habilidades auditivas necessárias para que a mensagem sonora pudesse ser compreendida (Baran e Musiek, 2001). A importância da avaliação clínica do SNAC vem crescendo desde a década de 1970 (AAA, 2010).

De acordo com a ASHA (1996), processos auditivos centrais são os mecanismos e processos do sistema auditivo responsáveis pela localização, lateralização sonora e discriminação auditiva; reconhecimento de padrões auditivos; aspectos temporais da audição (resolução, mascaramento, 
integração e ordenação); desempenho auditivo na presença de sinais competitivos e desempenho auditivo com sinais acústicos degradados. Este documento ainda salienta que tais mecanismos devem ser considerados para sons verbais e não verbais e que processos neurocognitivos estão também envolvidos nas tarefas de processamento auditivo. Para a ASHA (2005), o PA(C) se refere à eficiência e eficácia com que o SNC utiliza informações auditivas.

Deste modo, o $\mathrm{PA}(\mathrm{C})$ envolve as habilidades auditivas necessárias para a interpretação dos sons que ouvimos. Portanto, apresentar limiares auditivos dentro dos padrões de normalidade não é suficiente para que os sons ouvidos adquiram significado. Para isso, é preciso que o estímulo auditivo seja analisado e interpretado pelo sistema nervoso.

Kraus (1999) coloca que a fala fluente é caracterizada por mudanças acústicas rápidas e que, portanto, a percepção adequada da fala depende da decodificação destas mudanças acústicas.

Para Phillips (2002), um grande número de processos auditivos centrais depende da análise temporal do sinal acústico. A coincidência temporal dos eventos que facilita seu agrupamento perceptivo como um "objeto auditivo", a separação em figura-fundo por processos temporais, a discriminação entre fonemas que diferem apenas no aspecto temporal, a percepção do ritmo, o julgamento de ordenação temporal e a percepção de tom são exemplos que podem ter seus mecanismos bastante relacionados na região central de representação temporal dos sons. No entanto, para este 
autor, é importante compreender que estes fenômenos temporais não são reflexos de um processo único.

Segundo a ASHA (1996) quando uma ou mais habilidades auditivas responsáveis pela interpretação da mensagem e, consequentemente, pela atribuição de significado estão alteradas, está-se diante de um TPA(C). Neste sentido, o TPA(C) se refere a qualquer deficiência observada em um ou mais comportamentos relacionados aos mecanismos do PA(C) (ASHA, 1996). Esta definição também reconhece que, para alguns autores, o TPA(C) pode ser resultado de déficits mais globais, como déficits de linguagem, de memória e de atenção. Em 2005, a ASHA (2005) define o TPA(C) como dificuldades no processamento perceptual da informação auditiva no SNC e na atividade neurobiológica que embasa este processamento.

Chermak e Musiek (1992) acreditam que uma abordagem abrangente deve ser oferecida tão logo o diagnóstico de TPA(C) seja estabelecido, com constante acompanhamento e avaliação dos progressos alcançados, a fim de se obter bons resultados com o tratamento.

Para Carvallo (1997), a avaliação do $\mathrm{PA}(C)$ auxilia a análise e evolução do indivíduo em um programa de reabilitação fonoaudiológica no que diz respeito ao aspecto gnósico auditivo. Além disso, a identificação de uma alteração do $\mathrm{PA}(\mathrm{C})$, associada ao treino auditivo, pode auxiliar na minimização ou até mesmo impedir que ocorram distúrbios da comunicação ao longo da vida da criança. 
Para Wertz et al. (2002) o principal objetivo da avaliação e diagnóstico de uma alteração no $\mathrm{PA}(\mathrm{C})$ é poder determinar a forma mais adequada de tratamento. Para estes autores, a efetividade e precisão do tratamento só são possíveis se o diagnóstico for específico.

Para alguns autores ainda são poucos os estudos que comprovam a eficácia da intervenção fonoaudiológica no $\operatorname{TPA}(\mathrm{C})$ e ainda falta entendimento sobre os parâmetros que governam a mudança de performance em relação ao PA(C) (Bellis, 2002; Baran, 2002; e Moore, Amitay, 2007).

Neves (2005), em seu trabalho sobre maturação do processamento auditivo, observou que em crianças com dificuldades escolares, embora apresentem melhora nas respostas aos testes do PA(C) com o aumento da idade, tal melhora se dá de forma mais discrepante e não-gradual. Portanto, crianças com dificuldades escolares podem apresentar atraso na maturação de habilidades auditivas.

Levando-se em conta o processamento temporal auditivo, Hirsh (1959), na tentativa de verificar o mínimo tempo necessário para que dois tons distintos fossem ordenados corretamente, observou que, embora $2 \mathrm{~ms}$ de intervalo tenham sido suficientes para que os indivíduos fossem capazes de perceber a presença de dois tons, para que a ordenação destes sons fosse adequada em $75 \%$ das tentativas, eram necessários $17 \mathrm{~ms}$.

No estudo realizado por Schochat et al. (2000), após aplicarem testes de frequência e duração em indivíduos normais entre 7 e 16 anos, concluíram que nas faixas etárias entre 7 e 11 anos e 11 meses há uma 
grande variação no desempenho intra-grupos. Esta variabilidade não foi observada nos indivíduos mais velhos pesquisados.

Muniz et al. (2007), ao avaliarem o processamento auditivo de crianças com e sem desvios fonológicos, concluíram que as crianças com desvios podem apresentar alteração do processamento temporal e necessitam maior tempo para detecção de intervalos entre estímulos.

Murphy e Schochat (2007), investigando também o processamento temporal de crianças de 9 a 12 anos, concluíram que a variação entre 50 a 250ms para o intervalo inter-estímulo não foi estatisticamente significante ao se considerar a média de acertos; por outro lado, a duração do estímulo foi capaz de suscitar respostas melhores quando este era de $200 \mathrm{~ms}$, em detrimento de estímulos mais curtos (100ms).

Frederigue-Lopes et al. (2010) realizaram avaliação do teste padrão temporal de frequência (PF) e o teste padrão temporal de duração (PD) em campo livre a $60 \mathrm{dBNA}$, solicitando respostas verbais e não verbais. Após a análise dos resultados, estes autores concluíram que: 1) no teste PF o desempenho foi significativamente maior com respostas não-verbais em comparação às respostas verbais; 2) no teste PF foi observado aumento significativo do desempenho para a idade e modalidade verbal; 3) no teste PD houve progressão do desempenho com o aumento da idade para ambos os tipos de resposta (verbal e não-verbal); e 4) o desempenho no PF foi significativamente maior que no PD. 


\subsection{Treino Auditivo e Plasticidade Neural}

Tallal et al. (1996) referem que o treino auditivo específico pode ter influência no processamento, evidenciando que as habilidades auditivas podem ser melhoradas com o treino.

Musiek e Berge (1998) referem que o conceito de treino auditivo (TA) é anterior ao século VI. Naquela época, o TA foi principalmente aplicado em clínicas de reabilitação e escolas para deficientes auditivos. Com o passar dos anos, pela falta de comprovação científica, de sua eficácia clínica e do próprio interesse dos profissionais por esta metodologia, o TA passou a ser uma prática rara. Segundo estes autores, o TA com objetivo de melhorar o TPA(C) voltou a despertar interesse e respeito, não somente pelas técnicas e abordagens que têm surgido, mas também porque a neurociência tem provado que diferenças funcionais e estruturais ocorrem no cérebro com treino/estimulação auditivas apropriadas.

Chermak et al. (1998) sugeriram uma intervenção que englobava tanto o TA, como estratégias metalingüísticas e metacognitivas. O TA focava detecção, atenção, discriminação, escuta binaural e transferência interemisférica. As estratégias metalinguísticas enfocavam a coesão do discurso, ampliação do vocabulário, segmentação e discriminação auditiva e prosódia. As estratégias metacognitivas, por sua vez, envolviam a compreensão de tarefas, atenção, identificação de partes importantes da mensagem, auto-monitoramento, auto-questionamento e estratégias para diminuição de erros. 
Musiek et al. (1999) dividiram os procedimentos para o treino auditivo em três categorias: 1) técnicas de treinamento auditivo; 2) procedimentos de melhora do sinal; e 3) intervenção cognitiva e lingüística. Estes autores acreditam que, mesmo considerando que o TA auxilie no $\operatorname{TPA}(\mathrm{C})$, algumas questões permanecem: 1) Qual é o tipo de treino necessário para cada paciente e como isso pode ser determinado? e 2) Qual tipo de TA é o mais indicado e quanto tempo deve durar? Os autores ainda enumeram características que devem ser levadas em conta para o início do TA: 1) O indivíduo precisa ter um problema identificável do $\mathrm{PA}(\mathrm{C})$; 2) $\mathrm{O}$ paciente, assim como seus pais e professores devem estar motivados para 0 tratamento; 3) O indivíduo precisa ter disponibilidade de tempo para dedicação ao treino; 4) Idade apropriada; 5) Em caso de crianças, é necessário o suporte da escola e da família; 6) O paciente não deve apresentar impedimento médico ou comportamental para o treino auditivo.

Para Kraus (1999) a capacidade de o SNC ser modificado a partir da experiência é questão central para a orientação e estratégias terapêuticas. Para esta autora, a percepção de fala pode ser melhorada com o TA e os efeitos desta aprendizagem não estão, necessariamente, limitados ao estímulo treinado, podendo ser transferidos para outros sons que apresentem características similares.

Segundo Chermak e Musiek (2002) o treino das habilidades auditivas pretende melhorar as funções do sistema auditivo na resolução de sinais acústicos. 
Wertz et al. (2002) referem que, historicamente, o tratamento do $\operatorname{TPA}(\mathrm{C})$ vinha sendo realizado de forma tão ampla quanto as teorias que o definiam. Os profissionais que encampavam esta área estavam divididos em dois grupos principalmente: 1) aqueles que atribuíam o $\operatorname{TPA}(C)$ a uma desordem baseada na linguagem, cujos déficits eram vistos em sua dependência lingüística; e 2) aqueles que acreditavam que a alteração era relacionada exclusivamente a uma desordem perceptual da audição. Cognitivamente, a neurociência distingue estas duas abordagens como processamento top-down e processamento bottom-up, respectivamente. Os autores mencionam que Helmer Myklebust foi um dos primeiros autores a considerar que déficits no $\mathrm{PA}(\mathrm{C})$ poderiam explicar alterações de linguagem, em uma abordagem bottom-up. Foi também este autor que estimulou audiologistas a realizarem além da pesquisa da audição periférica, a avaliação auditiva clínica da criança. A abordagem bottom-up presume, portanto, que o treino dos aspectos auditivos alterados melhoraria consequentemente a linguagem. Para os autores que acreditavam que o $\operatorname{TPA}(\mathrm{C})$ era resultado de uma alteração no processamento top-down, o treino era concentrado em aspectos linguísticos e não somente em habilidades auditivas. O objetivo desta visão terapêutica era realizar intervenção com sons, palavras, sentenças e funções comunicativas que auxiliassem a criança em seu desenvolvimento.

Baran (2002) define que a abordagem bottom-up envolve estratégias que melhoram a habilidade do indivíduo em receber e processar o sinal acústico. A abordagem top-down, por sua vez, envolve estratégias que 
facilitam a interpretação de informações auditivas de acordo com regras linguísticas. Para esta autora, as estratégias para o tratamento do TPA(C) devem ser definidas com o objetivo de se alcançar três aspectos: 1) melhora da qualidade do sinal; 2) melhora das habilidades auditivas do indivíduo; e 3) melhora das habilidades cognitivas e de linguagem. Esta autora ainda defende que o tratamento precisa ser individualizado para atingir as necessidades de cada paciente.

Segundo Wertz et al. (2002), foi a partir da década de 1990 que o tratamento do $\operatorname{TPA}(\mathrm{C})$ começou a considerar tanto o processamento topdown, como o processamento bottom-up. No entanto, nesta época, poucos audiologistas utilizavam estratégias terapêuticas em crianças com TPA(C). As duas orientações mais frequentes eram: 1) modificações acústicas na sala de aula da criança; e 2) melhora do sinal por meio de utilização de sistema FM de som. Com o tempo, os autores referem que o tratamento do TPA(C) passou a ser um processo multidisciplinar com o envolvimento de audiologistas, fonoaudiólogos, professores, pais, neuropsicólogos e terapeutas ocupacionais. Os autores ainda mencionam que o aumento da utilização do computador ampliou ainda mais as possibilidades de estratégias terapêuticas no tratamento do TPA(C).

Para Chermak (2002) atividades metalinguísticas também trazem muitos benefícios para o $\mathrm{PA}(\mathrm{C})$ e a linguagem.

Musiek et al. (2002) enfatizam a importância de se selecionar cuidadosamente os testes ou atividades a serem propostos, justificando que 
tarefas fáceis ou difíceis demais provavelmente não trazem os melhores resultados.

Neste sentido, Musiek e Schochat (1998) também sugerem que as atividades propostas durante o treino auditivo procurem obter média de $70 \%$ de acerto, com o objetivo de manter a motivação do paciente.

O treino das habilidades auditivas pode ser realizado de maneira formal ou informal. (Chermak e Musiek, 2002; Chermak, 2002). O TA formal (TAF) das habilidades auditivas, para estes autores, requer a utilização de tarefas acusticamente controladas, envolvendo elementos tonais e de fala e realizados em cabina acústica por um profissional capacitado. Para eles, a vantagem do TAF é a maior especificidade e precisão na escolha do estímulo a ser trabalhado com cada indivíduo. Por outro lado, o TAF demanda a utilização de aparelhagem específica. O TA informal (TAI) se refere a tarefas que requeiram habilidades auditivas com estímulos verbais e não verbais e pode ser realizado em diferentes ambientes (sala de terapia, escola ou em casa) e aplicado por fonoaudiólogos, pais e professores. O TAI surgiu como complemento para o TAF. Para estes autores, a realização conjunta do TAF e do TAI maximiza a eficácia do tratamento e permite que as habilidades auditivas trabalhadas sejam praticadas em situações reais e, desta forma, generalizadas mais facilmente.

Para Musiek et al. (2007) o TA pode ser definido como um conjunto de condições e/ou tarefas acústicas idealizadas para ativar o sistema auditivo, de forma que sua base neural e seus comportamentos auditivos associados são alterados de forma positiva. Para estes autores, são oito os 
princípios que devem fundamentar o TA: 1) os materiais e tarefas precisam se adequar à idade e linguagem do paciente; 2) a motivação precisa ser sempre mantida; 3) as tarefas precisam variar ao longo do treino; 4) o aumento da dificuldade precisa se dar de acordo com o desempenho; 5) é preciso procurar balancear sempre o nível de acerto X erro (70\% X 30\%); 6) o tempo designado ao TA precisa ser suficiente; 7) é preciso monitorar o desempenho e fornecer feed-backs ao indivíduo; e 8) as tarefas devem ser realizadas em intensidade confortável.

Kricos e McCarthy (2007), em sua importante perspectiva histórica sobre TA, referem que este, embora ainda subutilizado e não completamente conhecido, é uma importante ferramenta para o audiologista. As autoras ainda salientam que, a despeito do TA ter despertado pouco interesse em décadas passadas, atualmente tanto a área da psicologia cognitiva como a da neurociência descobriram seu valor no que tange o domínio do diagnóstico e o da reabilitação. Para elas, parece claro que a prática do TA será refinada e que estudos que comprovem sua eficácia serão importantes para reforçar seu valor no aprendizado auditivo e na melhora da comunicação de pessoas de diferentes faixas etárias.

Moore e Amitay (2007) definem a aprendizagem auditiva como qualquer mudança em uma habilidade auditiva do ouvinte ao executar uma tarefa auditiva por meio de experiência observada ou conhecida. Para estes autores, o TA descreve a natureza da experiência que conduz à aprendizagem. Eles ainda acreditam que 0 TA tem 0 potencial de revolucionar a prática profissional em audiologia e alterações de fala e 
linguagem. Em seus estudos, estes autores se surpreenderam com a generalização que ocorre com o TA. Para eles, embora uma parcela do treinamento seja específica ao estímulo treinado, ocorre também transferência substancial entre os estímulos.

Kraus e Chandrasekaran (2010) e Chermak (2010) sugerem que o TA envolvido no aprendizado de música traz muitos benefícios para o indivíduo não só no que diz respeito ao campo da própria música, como também no que se refere ao processamento de fala. Desta maneira, o aprendizado musical pode acarretar também melhora significativa do processamento de linguagem. Para estes autores, a música é capaz de reforçar várias funções incluindo atenção, aprendizagem, comunicação e memória.

O embasamento teórico do TA está na plasticidade cerebral. Segundo Kraus et al. (1995) e Kraus (1999) a plasticidade é uma característica intrínseca do SNC. É a partir desta característica que somos capazes de aprender a identificar novas vozes, a falar novas línguas e a cantar novas canções. Esta capacidade é observável a partir das mudanças neurofisiológicas que ocorrem por meio da experiência ou após traumas que afetam o SNC. Estes autores também concordam que o funcionamento do córtex auditivo é alterado a partir de treino.

Para Allum-Mecklenburg e Babighian (1996) a plasticidade auditiva se refere à habilidade para a mudança que ocorre no sistema sensório responsável pela transmissão de informações acústicas.

Para Musiek e Berge (1998) o termo plasticidade envolve alteração das células nervosas para melhor se adaptarem às influências ambientais, 
sendo esta alteração frequentemente associada a mudanças comportamentais. Para eles, a plasticidade neuronal pode ocorrer de três maneiras distintas: (a) plasticidade relacionada ao próprio desenvolvimento; (b) plasticidade compensatória; e (c) plasticidade decorrente do aprendizado. Estes autores referem ainda que o TA realizado com o objetivo de melhorar o TPA(C) pode envolver estes três tipos de plasticidade. Estes autores relatam vários estudos com animais que comprovam mudanças na morfologia do centro auditivo e na performance auditiva após o treino ou estimulação.

King (1999) afirma que a melhora na performance em uma determinada habilidade sensória como consequência da prática, é também acompanhada de plasticidade no mapa cortical.

Grafman (2000) define plasticidade neural como as modificações que ocorrem na atividade neural decorrentes do treino de uma habilidade ou exposição constante a um estímulo.

Para Fujioka et al. (2006) experiências de aprendizagem intensiva otimizam os circuitos neurais a partir de mudanças no número de neurônios envolvidos, no tempo de sincronia e no número e força das conexões sinápticas excitatórias e inibitórias. Para estes autores, a mera exposição a um ambiente acústico enriquecido aumenta e melhora o ajustamento de neurônios auditivos.

Thibodeau (2007) coloca que, como resultado da plasticidade cerebral, os processos cognitivos que fundamentam a percepção de certos sinais acústicos podem ser treinados. Esta autora coloca ainda que os 
estímulos do TA podem variar ao longo de duas dimensões: sons naturais $\mathrm{X}$ sons sintéticos e sons verbais $X$ sons não verbais. Segundo ela, sons naturais não verbais (p.ex. sons ambientais) são menos utilizados, por sua reduzida associação cognitiva e consequente dificuldade em manter a atenção da criança. Esta autora e Berlau e Weinberger (2008) consideram que o impacto do TA pode ser aumentado por meio da utilização de estímulos com maior significado para o sujeito.

Tremblay (2007) menciona que o SNAC muda em função da experiência, reorganizando-se ao longo do tempo de acordo com o estímulo auditivo dado. Esta autora refere que a representação fisiológica do som pode ser modificada pelo TA e que as mudanças fisiológicas decorrentes dele podem coincidir com melhora da percepção auditiva. Segundo ela, as mudanças fisiológicas alcançadas com o TA podem ser relacionadas a vários processos, dentre eles: a) maior número de neurônios respondendo à área sensória; b) melhora na sincronia neural; e c) mudança no arranjo neural que maximiza a representação das características de cada estímulo.

Beck et al. (1996), realizaram nove semanas de TA com 21 crianças entre 7 e 10 anos de idade, utilizando atividades que estimularam habilidade de memória, orientação têmporo-espacial, voz, ritmo, sequencialização, leitura e escrita, compreensão de fala no ruído e tônus e mobilidade dos órgãos fonoarticulatórios, notaram que $71,4 \%$ se enquadraram na faixa de normalidade para todas as provas aplicadas pelas autoras.

Tremblay et. al. (1997), demonstraram que após cinco dias de treino auditivo já foi possível perceber melhora no comportamento perceptual e 
também na representação neuronal da fala e que tal melhora poderia ser generalizada para outros estímulos não treinados. Os autores ainda acreditam que as mudanças neurofisiológicas que decorrem do TA podem preceder mudanças comportamentais.

Musiek e Schochat (1998) notaram melhora na performance nos testes do PA(C) em um adolescente de 15 anos. Este paciente foi submetido a três sessões semanais de treinamento auditivo, com uma hora de duração, ao longo de seis semanas, além de duas a três sessões semanais em casa com 15 a 30 minutos de duração. O treino levou em conta testes de intensidade, frequência, duração, percepção de fala dicótica e percepção de fala com ruído competitivo.

Domínguez-Ugidos et al. (2001), em estudos com TA utilizando ruído branco de banda larga destacam que o grau e velocidade de aprendizagem e, consequentemente, de melhora, se relacionam com a complexidade da tarefa, com a semelhança entre as condições e características do treino e os testes e com a familiaridade que o individuo possui com o estímulo.

Putter-Katz et al.(2002) ao compararem as habilidades auditivas de 20 crianças entre 7:11 e 14:4 submetidas a um programa de TAl, observaram melhora no reconhecimento de fala em situações de competição com ruído de fundo e de fala. Segundo estes autores, a intervenção em indivíduos com TPA(C) pode ser classificada em duas categorias: a) melhora do sinal acústico no ambiente; e b) treino específico de habilidades auditivas.

Hayes et al. (2003) avaliaram a plasticidade cerebral de crianças, entre 8 e 12 anos, com dificuldade de aprendizagem ou déficit de atenção, 
após oito semanas de TA e observaram melhora nas respostas dos testes eletrofisiológicos e na performance auditiva.

Zalcman e Schochat (2007), avaliando o desempenho em testes de PA(C) pré e pós treinamento auditivo formal de 30 indivíduos entre 8 e 16 anos, puderam observar melhora em todos os testes aplicados. Estas autoras corroboram a idéia de que o treino auditivo favorece mudanças nas estruturas neurais relacionadas às habilidades auditivas estimuladas.

Moncrieff e Wertz (2008) realizaram TA através de tarefa dicótica em crianças com TPA(C) divididas em dois grupos: 1) aquelas que apresentavam importante déficit na OE; e 2) aquelas com déficits em ambas as orelhas, porém de forma assimétrica. Estas autoras observaram que as crianças com déficits bilaterais não alcançaram o mesmo progresso das crianças com déficits unilaterais e concluíram que esta diferença pode sugerir que fatores não-auditivos como atenção, motivação ou linguagem inibem a melhora em algumas crianças ou que determinados déficits precisam de uma intervenção adicional à que foi oferecida neste estudo.

Murphy (2008), após desenvolver um software para treinamento auditivo, aplicou-o em crianças disléxicas e pôde comprovar melhora de desempenho das habilidades auditivas.

Stevens et al. (2008) utilizaram o software FFW - L (Fast ForWord Language, FFW - L, Scientific Learning Corporation, 1998 - desenvolvido para melhorar a capacidade de percepção de mudanças acústicas rápidas) para investigar a melhora na atenção seletiva de crianças com desenvolvimento normal de linguagem e crianças com déficits específicos de 
linguagem. Os autores concluíram que em todas as crianças houve melhora na atenção seletiva a partir deste treino computadorizado.

Gillam et al. (2008) realizaram um estudo com 216 crianças entre 6 e 9 anos com déficits de linguagem, divididas em quatro grupos distintos de estimulação. O primeiro grupo foi submetido ao FFW - L; o segundo grupo foi submetido a atividades de linguagem; o terceiro grupo a uma intervenção assistida de linguagem no computador; e o quarto grupo recebeu uma intervenção individualizada de linguagem. Todas as crianças passaram por cinco sessões semanais com duração de uma hora e quarenta minutos cada, durante seis semanas. Os autores deste estudo concluíram que houve melhora nas habilidades linguísticas gerais e nas habilidades do processamento temporal, mas que não é possível identificar uma abordagem que tenha sido mais eficaz que as outras.

Samelli e Mecca (2010) realizaram estudo com o objetivo de verificar a eficácia de um programa de treino auditivo informal (TAI). Após realizarem 10 sessões de treino auditivo com 10 pacientes entre 7 e 20 anos, compararam o desempenho destes em testes comportamentais do $\mathrm{PA}(\mathrm{C})$ pré e pós-treino e concluíram que os sujeitos apresentaram melhoras estatisticamente significantes.

Pinheiro e Capellini, (2010) também observaram resultados positivos após a realização de TAl com crianças com e sem distúrbio de aprendizagem. Neste estudo também foi possível concluir que, embora o desempenho pós-treino tenha sido melhor nos dois grupos, as crianças que 
apresentavam distúrbio de aprendizagem tiveram sempre desempenho pior nas tarefas de consciência fonológica e de processamento auditivo. 


\subsection{Transtorno Fonológico (TF)}

Considerando-se o desenvolvimento típico de fala e linguagem, Fey (1992), coloca que a criança precisa ouvir os sons e articulá-los para se apropriar da fonologia de uma determinada língua.

Assim, com a percepção auditiva e a produção dos sons da fala, a criança aprende as regras do sistema linguístico de sua língua materna e se apropria de um sistema fonológico de contrastes (Ingram, 1976).

Wertzner et al. (2007) mencionam que um modelo muito utilizado na análise fonológica é o dos processos fonológicos. Tais processos se referem à simplificação das regras fonológicas da língua e ocorrem durante o desenvolvimento de fala (Wertzner et al. 2006 e 2007). Os processos fonológicos propostos por Wertzner (2004) no teste ABFW são: a) Redução de sílaba (/pato/ - [pa]); b) Harmonia consonantal (/makakU/ - [kakaku]; c) Plosivação de fricativas (/sapU/ - [tapu] ou /vaka/ - [baka]); d) Posteriorização para velar (/tatU/ - [kaku] ou /dosi/ - [gosi]); e) Posteriorização para palatal (/sapU/ - [japu] ou /zebRa/ - [zebra]); f) Frontalização de velares (/karU/ [taru] ou /gatU/ - [datU]).

Segundo Ingram (1976) os processos fonológicos podem ser divididos em três grupos: a) categoria silábica; b) substituição; e c) assimilação. São considerados processos de estrutura silábica a eliminação da consoante final (/'pota/ ou /'poyta/ para [porta]), eliminação da sílaba átona (/'ko/ para [cola]), reduplicação (/pe'pe/ para [pé]), simplificação de encontro consonantal (/baço/ para [braço]) e epêntese (/parato/ para [prato]). Já os 
processos de substituição são: plosivação de fricativas (/'topa/ para [sopa]), simplificação de líquidas (/'boya/ para [bola], /'kaya/ ou /'kala/ para [cara] e ainda /'gayu/ ou /'galu/ para [galho]), frontalização de palatal (/'save/ para [chave]), frontalização de velar (/'datu/ para [gato]), posteriorização para velar (/kapa/ para [tapa]), posteriorização para palatal (/chete/ para /sete/]. Os processos de assimilação envolvem a harmonia consonantal que pode ocorrer por assimilação velar (/baraka/ para [barata]), labial (/mama/ para [mala]), (/nana/ para [nada]) e por sonoridade (/gaza/ para [casa]). Há também o processo de metátese que é resultado da reordenação ou transposição consonantal (/'paRtu/ ou /'patRu/ para [prato] e /pikopa/ para [pipoca]. Alguns processos são muito particulares e, portanto, considerados idiossincráticos.

O desenvolvimento fonológico típico prevê a supressão gradativa dos processos fonológicos. No entanto, quando tais processos permanecem além da idade esperada, tem-se o transtorno fonológico (TF) (Wertzner, 2002 e Wertzner et al., 2006). Para estas autoras, o TF é definido como uma alteração na fala, com produção inadequada dos sons e caracterizado por substituições, omissões e/ou distorções. A gravidade do TF assim como a inteligibilidade de fala pode ser bastante variável. Estas autoras salientam que, embora haja a possibilidade de se caracterizar o TF, sua etiologia ainda não está totalmente clara.

Para Ingram (1976), o TF pode estar relacionado às dificuldades na organização fonológica da língua, à percepção auditiva dos sons da fala ou à produção correta destes. 
Para Fey (1992) as trocas que ocorrem na fala de uma criança podem pautar-se em duas explicações: a) a criança pode apresentar dificuldade em perceber auditivamente os traços distintivos entre dois fonemas; ou b) a discriminação auditiva pode estar adequada, mas o sistema motor da criança não é capaz de realizar a distinção entre os sons.

Gierut (1998) afirma que o TF afeta a produção de fala e/ou a representação mental dos sons de uma determinada língua. Para esta autora, o TF afeta a forma como a informação sonora é armazenada e representada no léxico mental ou na forma como é acessada e recuperada cognitivamente. O TF pode ter um forte impacto tanto na articulação como no conhecimento internalizado do sistema da língua. Esta autora ainda menciona que o TF está entre as alterações fonoaudiológicas mais prevalentes em crianças em idade pré-escolar e escolar. Além disso, estudos retrospectivos identificaram que adultos com histórico de TF, embora não apresentem dificuldades em produzir os sons da fala, demonstram dificuldade em processar informações que dizem respeito à linguagem em geral e ao sistema de som em particular.

Shriberg (1993) relata que os estudos voltados para o transtorno fonológico (inicialmente denominado distúrbio articulatório) datam de 1930.

Wertzner et al. (2006) referem ser as provas de fala espontânea, nomeação e imitação as mais comumente utilizadas para avaliação do TF. A fala espontânea pode ser evocada de forma direta ou indireta. Para a coleta de amostra de fala na forma direta, são colocadas questões que a criança deve responder. Já para a coleta de fala na forma indireta, são ofertados 
materiais ou histórias para estimular a fala da criança. Na prova de imitação, a criança é solicitada a repetir vocábulos ou frases. Para a prova de nomeação, a criança deverá, diante de um estímulo (figura ou objeto), dizer o vocábulo esperado. No Teste de Linguagem Infantil ABFW, Wertzner (2004) sugere as provas de imitação e nomeação para o Português. Wertzner et al. (2006) referem que a utilização destas provas facilita a coleta da amostra, permitindo uma análise mais completa do sistema fonológico consequentemente um diagnóstico mais preciso. Ainda segundo as autoras, na prática fonoaudiológica, é muito importante que se quantifique a gravidade e o impacto do TF.

Neste sentido, Shriberg e Kwiatkowski (1982) propuseram um procedimento denominado percentage of consonants correct (PCC), que verifica o número de consoantes corretas proporcionalmente ao número total de consoantes da amostra. Esta medida leva em consideração todas as distorções, omissões, substituições e inversões presentes na emissão do falante. Desta maneira, de acordo com a faixa de valor desta porcentagem o TF poderia ser classificado em leve (PCC entre 85 e 100\%), levemente moderado (PCC entre 65 e 85\%), moderadamente severo (PCC entre 50 a $65 \%$ ) e severo (PCC abaixo de $50 \%$ ).

Schriberg et al. (1997a) propõem o percentage of consonants correctrevised (PCC-R) que, como o próprio nome sugere, é uma forma revisada para o índice PCC. Nesta nova medida, não são mais considerados os erros por distorção. Assim, o índice PCC-R leva em consideração somente as omissões, substituições e inversões presentes no enunciado avaliado. Tal 
modificação torna possível que indivíduos com diferentes diagnósticos e de diferentes faixas etárias possam ser comparados.

Para Campbell et al. (2007), a justificativa para a utilização do PCC-R em estudos com TF se pauta em dois aspectos: (a) este índice torna possível a comparação entre indivíduos de diferentes faixas etárias; e (b) é menos suscetível aos efeitos da prática que podem influenciar resultados em testes estandardizados aplicados repetidamente.

Shriberg (1997b) sugere a divisão do TF em três grupos. O primeiro grupo, denominado como atraso de fala, refere-se a crianças menores de 9 anos que persistem em processos de eliminação ou substituição não esperadas para sua idade. O segundo grupo, denominado como erros residuais questionáveis, envolve crianças entre 6 e 8 anos e 11 meses que cometem apenas distorções de determinados sons da fala. Já o terceiro grupo, que o autor nomeia como erros residuais, contempla crianças maiores de 9 anos que permanecem com trocas na fala. $O$ grupo de crianças com atraso de fala, pode ser subdividido etiologicamente em cinco grupos: 1) de origem genética; 2) decorrente de otite média de repetição; 3) decorrente de apraxia de desenvolvimento de fala; 4) relacionado ao desenvolvimento psicossocial; e 5) em populações especiais (com alterações craniofaciais ou sensório-motoras, por exemplo). Já o grupo de crianças com erros residuais questionáveis, pode compreender tanto crianças que apresentaram atraso de fala como crianças sem este histórico. O grupo de crianças com erros residuais também pode ser subdividido entre crianças com e sem histórico de atraso de fala. 
Wertzner (2004) estabeleceu as idades previstas para que o domínio dos fonemas do português falado no Brasil ocorra. A seguir apresenta-se um quadro elaborado pela pesquisadora que resume tais idades, descrevendo também as características fonéticas de cada fonema:

Quadro 1 - Idades para o domínio dos fonemas*

\begin{tabular}{|c|c|c|c|c|c|c|}
\hline $\begin{array}{l}\text { Papel das } \\
\text { cavidades } \\
\text { Oral e Nasal }\end{array}$ & $\begin{array}{l}\text { Modo de } \\
\text { Articulação }\end{array}$ & $\begin{array}{l}\text { Zona de } \\
\text { Articulação }\end{array}$ & $\begin{array}{l}\text { Papel } \\
\text { das } \\
\text { Cordas } \\
\text { Vocais }\end{array}$ & Fonema & Inicial & Final \\
\hline \multirow[t]{19}{*}{ Oral } & \multirow[t]{6}{*}{ Oclusivas } & \multirow[t]{2}{*}{ Bilabial } & Surda & $/ \mathrm{p} /$ & $3: 6$ & $3: 6$ \\
\hline & & & Sonora & $/ b /$ & $3: 6$ & $3: 6$ \\
\hline & & \multirow[t]{2}{*}{ Dental ou alveolar } & Surda & $/ \mathrm{t} /$ & $3: 6$ & $3: 6$ \\
\hline & & & Sonora & $/ d /$ & $3: 6$ & $3: 6$ \\
\hline & & \multirow[t]{2}{*}{ Velar } & Surda & $/ \mathrm{k} /$ & $3: 6$ & $3: 6$ \\
\hline & & & Sonora & $\lg /$ & $3: 6$ & $3: 6$ \\
\hline & Constritivas & & & & & \\
\hline & \multirow[t]{7}{*}{ Fricativas } & \multirow[t]{2}{*}{ Labiodental } & Surda & $/ f /$ & $3: 6$ & $3: 6$ \\
\hline & & & Sonora & $/ \mathrm{v} /$ & $3: 6$ & $3: 6$ \\
\hline & & \multirow[t]{3}{*}{ Dental ou alveolar } & Surda & $/ \mathrm{s} /$ & $3: 6$ & $3: 6$ \\
\hline & & & Sonora & $|z|$ & $3: 6$ & $3: 6$ \\
\hline & & & Arqui & /S/ & $4: 0$ & $4: 0$ \\
\hline & & \multirow[t]{2}{*}{ Palatal } & Surda & $/ \mathrm{d} /$ & $3: 6$ & $3: 6$ \\
\hline & & & Sonora & $/ 3 /$ & $3: 6$ & $3: 6$ \\
\hline & \multirow[t]{2}{*}{ Laterais } & Dental & Sonora & $/ / /$ & $3: 6$ & $3: 6$ \\
\hline & & Palatal & Sonora & IN & - & $4: 0$ \\
\hline & \multirow[t]{3}{*}{ Vibrantes } & Simples & Sonora & $/ \mathrm{r} /$ & - & $4: 0$ \\
\hline & & Múltipla & Sonora & $|x|$ & $3: 6$ & $3: 6$ \\
\hline & & & Arqui & $/ \mathrm{R} /$ & $5: 6$ & $5: 0$ \\
\hline \multirow[t]{3}{*}{ Nasal } & & Bilabial & Sonora & $/ \mathrm{m} /$ & $3: 6$ & $3: 6$ \\
\hline & & Dental/alveolar & Sonora & $/ \mathrm{n} /$ & $3: 6$ & $3: 6$ \\
\hline & & Palatal & Sonora & $/ \mathrm{h} /$ & - & $3: 6$ \\
\hline
\end{tabular}

* Quadro extraído de WERTZNER (2004). 
De acordo com Wertzner (2004), também existem determinadas idades em que a aquisição dos encontros consonantais é esperada. Abaixo é possível visualizar estas idades de acordo com o encontro consonantal e sua ocorrência em posição inicial ou final na palavra.

Quadro 2 - Aquisição de Grupo Consonantal em posição inicial e final, por idade*

\begin{tabular}{|c|c|c|}
\hline Encontro Consonantal & Posição Inicial (Idade) & Posição Final (Idade) \\
\hline$/ \mathrm{pr} /$ & $4: 0$ & - \\
$/ \mathrm{br} /$ & $4: 0$ & - \\
$/ \mathrm{tr} /$ & $5: 0$ & - \\
$/ \mathrm{dr} /$ & $4: 6$ & - \\
$/ \mathrm{kr} /$ & $4: 0$ & - \\
$/ \mathrm{gr} /$ & $4: 0$ & - \\
$/ \mathrm{fr} /$ & $4: 6$ & $4: 0$ \\
$/ \mathrm{vr} /$ & - & - \\
$/ \mathrm{pl} /$ & $6: 6$ & - \\
$/ \mathrm{bl} /$ & $5: 6$ & - \\
$/ \mathrm{kl} /$ & $4: 6$ & - \\
$/ \mathrm{gl} /$ & $4: 0$ & - \\
$/ \mathrm{fl} /$ & $4: 6$ & \\
\hline
\end{tabular}

* Quadro extraído de WERTZNER (2004).

À medida que o TF se relaciona com dificuldades na percepção auditiva, pode-se supor haver estreita relação entre o TF e o TPA(C).

McArthur e Bishop (2004 e 2005) referem que a partir do final da década de 1990 passaram a ser aceitas duas teorias para explicar alterações de fala. Tais teorias descrevem dificuldades em discriminar 
estímulos verbais $\mathrm{X}$ estímulos não-verbais e dificuldades em perceber mudanças acústicas (padrões temporais).

Para McArthur et al. (2009), o TPA(C) pode ser uma explicação para a alteração de fala por interferir na formação estável da representação dos fonemas no cérebro e na percepção de fala, dificultando o aprendizado da fonologia, sintaxe e semântica. Os autores ainda relacionam o TPA(C) com as dificuldades de leitura pelo fato de a dificuldade na representação fonêmica piorar o mapeamento dos fonemas em letras.

Mota e Melo Filha (2009) avaliaram a consciência fonológica de indivíduos que tiveram diagnóstico de TF e foram submetidos à terapia fonoaudiológica. Comparado com o grupo de crianças na mesma faixa etária e sem histórico de alterações fonoaudiológicas, o grupo estudo apresentou pior desempenho em tarefas relacionadas à consciência fonológica. É importante salientar, no entanto, que a abordagem terapêutica utilizada com os sujeitos que apresentavam TF, não levou em conta aspectos relacionados à consciência fonológica. 
MÉTOdOS 


\section{MÉTODOS}

Esta pesquisa foi aprovada pela Comissão de Ética para Análise de Projetos de Pesquisa do Hospital das Clínicas da Faculdade de Medicina da Universidade de São Paulo (CAPPesq HC - FMUSP) sob o número de protocolo 0807/08 (ANEXO A - CD ANEXO 2).

Para a definição do tamanho amostral de cada grupo pertencente à pesquisa, foi solicitado parecer estatístico (ANEXO B - CD ANEXO 2).

Todos os responsáveis pelos participantes da pesquisa assinaram o Termo de Consentimento Livre e Esclarecido (ANEXO C - CD ANEXO 2).

Conforme os objetivos descritos anteriormente, para a realização deste estudo foi elaborado material específico visando estimular as habilidades auditivas em sala de terapia. A seguir, serão descritas as etapas para a produção deste material para a realização do TAI.

\subsection{Elaboração e confecção de material para realização de TAI}

Para a confecção do material que foi utilizado durante o treino auditivo informal, vários foram os aspectos levados em consideração.

Em primeiro lugar, houve a necessidade de que o material se apresentasse em formato relativamente controlado para que após a realização do treino, os resultados pudessem ser comparados. Com isso, 
antes ainda de serem elaboradas as atividades que poderiam ser propostas às crianças, decidiu-se qual seria a forma de apresentação do material utilizado para o treino.

A primeira decisão importante foi então a de que as atividades propostas aos sujeitos seriam apresentadas em faixas gravadas em um Compact Disc (CD). Tal decisão pautou-se no fato de que era necessário garantir que os sujeitos expostos ao treino informal do $\mathrm{PA}(\mathrm{C})$ deveriam receber os mesmos estímulos e nas mesmas condições.

No entanto, produzir um material padronizado sem a possibilidade de adaptação às diferentes demandas de cada criança, nos colocava um outro problema: como garantir que as atividades não seriam fáceis ou difíceis demais para os sujeitos da pesquisa?

A solução encontrada foi a de prever atividades com diferentes níveis de dificuldade, possibilitando assim que o treinamento fosse adaptado a cada criança. Desta maneira, todas as atividades foram elaboradas considerando pelo menos dois graus de dificuldade.

Posteriormente, foram elaboradas atividades que, independentemente de estarem gravadas em CD, pudessem ser aplicadas na prática clínica sem a necessidade de equipamentos específicos. Por isso, o objetivo principal não esteve centrado em proporcionar situações em que os estímulos utilizados em cabina acústica fossem simplesmente transferidos para a sala de terapia, mas sim poder fornecer ao fonoaudiólogo subsídios para a aplicação de atividades que favorecessem a estimulação das habilidades auditivas em contexto diverso do da prática audiológica, ampliando com isso as possibilidades de reabilitação de crianças com TPA(C). 
Para a confecção do material objetivou-se contemplar atividades que estimulassem as habilidades auditivas de fechamento, figura-fundo verbal e não verbal e de ordenação temporal e transferência inter-hemisférica, mas também atividades que levassem em conta a ampliação de vocabulário, categorização semântica e memória.

Após a confecção do material foi realizado um teste piloto para que, considerando a faixa etária em questão, as atividades contemplassem o princípio de sucesso versus erro de aproximadamente 70/30 (Musiek e Schochat, 1998). De acordo com as observações realizadas durante o teste piloto, algumas faixas foram modificadas ou adaptadas visando melhorar a qualidade do material a ser apresentado.

O CD produzido é composto de 48 faixas que são explicitadas no quadro a seguir (no CD - ANEXO 1 - Treino Auditivo Informal, há exemplos de todas as faixas que fazem parte deste programa de estimulação auditiva): 
Quadro 3 - Descrição das faixas contidas no CD para o TAl

\begin{tabular}{|c|c|c|c|c|c|c|c|c|}
\hline $\begin{array}{c}\text { Hab. } \\
\text { Auditiva }\end{array}$ & Fx & $\begin{array}{l}\text { Quantidade de } \\
\text { Estímulos }\end{array}$ & S/R & RC & $\begin{array}{c}\text { Duração } \\
(\mathrm{ms})\end{array}$ & $\begin{array}{l}\text { IIE } \\
\text { (ms) }\end{array}$ & $\begin{array}{l}\text { Freq. } \\
(\mathrm{Hz})\end{array}$ & Orientação \\
\hline \multirow{14}{*}{$\begin{array}{l}\text { OT e } \\
\text { TIH. }\end{array}$} & 1 & \multirow{2}{*}{$\begin{array}{l}4 \text { séries de } 2 \\
\text { estímulos }\end{array}$} & \multirow{2}{*}{--} & \multirow{2}{*}{--} & \multirow{2}{*}{200} & 200 & \multirow{7}{*}{$\begin{array}{c}\approx 1000 \\
e \\
\approx 1400\end{array}$} & \multirow{2}{*}{$\begin{array}{l}\text { Diferenciar os } 2 \text { sons } \\
\text { e/ou nomeá-los }\end{array}$} \\
\hline & 2 & & & & & 100 & & \\
\hline & 3 & \multirow{5}{*}{$\begin{array}{l}14 \text { séries de } 3 \\
\text { estímulos }\end{array}$} & \multirow{5}{*}{--} & \multirow{5}{*}{--} & 450 & \multirow{5}{*}{200} & & \multirow{5}{*}{$\begin{array}{l}\text { Ordenar os } \\
\text { estímulos }\end{array}$} \\
\hline & 4 & & & & 350 & & & \\
\hline & 5 & & & & 250 & & & \\
\hline & 6 & & & & 150 & & & \\
\hline & 7 & & & & 100 & & & \\
\hline & 8 & \multirow{2}{*}{$\begin{array}{c}4 \text { séries de } 2 \\
\text { estímulos }\end{array}$} & \multirow{2}{*}{--} & \multirow{2}{*}{--} & \multirow{7}{*}{$\begin{array}{c}400 \\
e \\
200\end{array}$} & 250 & \multirow{7}{*}{$\approx 1000$} & \multirow{2}{*}{$\begin{array}{c}\text { Diferenciar os } 2 \text { sons } \\
\text { e/ou nomeá-los }\end{array}$} \\
\hline & 9 & & & & & 200 & & \\
\hline & 10 & \multirow{5}{*}{$\begin{array}{c}14 \text { séries de } 3 \\
\text { estímulos }\end{array}$} & \multirow{5}{*}{--} & & & 500 & & \\
\hline & 11 & & & & & 400 & & \\
\hline & 12 & & & -- & & 300 & & Ordenar os \\
\hline & 13 & & & & & 200 & & \\
\hline & 14 & & & & & 150 & & \\
\hline & 15 & & +20 & RP & & & & \\
\hline FV & 16 & 100 palavras & +5 & $\mathrm{RB}$ & -0 & - & - & Sinalizar a cada \\
\hline $\mathbf{r V}$ & 17 & $\begin{array}{l}\text { alstribuidas em } 5 \\
\text { CS }\end{array}$ & 0 & CM & -- & -- & -- & ouvida \\
\hline & 18 & & -15 & CIVI & & & & \\
\hline & 19 & 33 ENV & +20 & & & & & Identificar estímulos \\
\hline FNV & 20 & $\begin{array}{c}\text { distribuídos em } 5 \\
\text { CS }\end{array}$ & +5 & RB & -- & -- & -- & $\begin{array}{c}\text { de uma CS e } \\
\text { nomeá-los }\end{array}$ \\
\hline & 21 & 100 palavras & 0 & & & & & Sinalizar a cada \\
\hline FFV & 22 & $\begin{array}{c}\text { distribuídas em } 5 \\
\text { CS }\end{array}$ & -15 & $\mathrm{HN}$ & -- & -- & -- & $\begin{array}{c}\text { palavra de uma CS } \\
\text { ouvida }\end{array}$ \\
\hline & 23 & 33 ENV & 0 & & & & & Identificar estímulos \\
\hline FFNV & 24 & $\begin{array}{c}\text { distribuídos em } 5 \\
\text { CS }\end{array}$ & -15 & $\mathrm{HN}$ & -- & -- & -- & $\begin{array}{c}\text { de uma CS e } \\
\text { nomeá-los }\end{array}$ \\
\hline & 25 & & +20 & & & & & \\
\hline & 26 & 8 séries de 4 & +5 & $\mathrm{RB}$ & & & & \\
\hline & 27 & estímulos $(\mathrm{CS}=)$ & 0 & $C M$ & & & & \\
\hline & 28 & & -15 & CM & & & & \\
\hline & 29 & & +20 & $\mathrm{RP}$ & -- & -- & -- & \\
\hline & 30 & 8 séries de 4 & +5 & $\mathrm{RB}$ & & & & \\
\hline & 31 & estímulos $(C S \neq)$ & 0 & & & & & \\
\hline ᄃ & 32 & & -15 & CM & & & & \\
\hline$r+\operatorname{IVV}$ & 33 & & +20 & & & & & \\
\hline & 34 & 8 séries de 5 & +5 & $\mathrm{RB}$ & & & & \\
\hline & 35 & estímulos $(\mathrm{CS}=)$ & 0 & $C M$ & & & & Repetir a sequência \\
\hline & 36 & & -15 & CM & & & & ouvida na mesma \\
\hline & 37 & & +20 & PR & -- & -- & -- & ordem \\
\hline & 38 & 8 séries de 5 & +5 & $\mathrm{RB}$ & & & & \\
\hline & 39 & estímulos $(C S \neq)$ & 0 & & & & & \\
\hline & 40 & & -15 & CM & & & & \\
\hline & 41 & 8 séries de 4 & 0 & & & & & \\
\hline & 42 & estímulos (CS =) & -15 & & & & & \\
\hline & 43 & & 0 & & -- & -- & -- & \\
\hline$F F+M V$ & 44 & estímulos (CS $\neq$ ) & -15 & $\mathrm{HN}$ & & & & \\
\hline$F F+I M V$ & 45 & 8 séries de 5 & 0 & $\mathrm{HN}$ & & & & \\
\hline & 46 & estímulos (CS =) & -15 & & - & 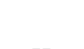 & - & \\
\hline & 47 & 8 séries de 5 & 0 & & -- & -- & -- & \\
\hline & 48 & estímulos $(\mathrm{CS} \neq)$ & -15 & & & & & \\
\hline
\end{tabular}

Legenda: $\mathrm{CM}=$ Caixinha de Música; $\mathrm{CS}=$ Categoria semântica; ENV = Estímulo não verbal; FF + MV = Figura fundo e memória verbal; FFNV = Figura fundo não verbal; FFV = Figura fundo verbal; $F$ + MV = Fechamento e memória verbal; FNV = Fechamento não verbal; Freq. = Frequência; FV = Fechamento Verbal; Fx = Faixa; Hab. = Habilidade; HN = História Narrada; OT = Ordenação Temporal; RB = Ruído Branco; RC = Ruído Competitivo;S/R = Relação Sinal /Ruído; TIH = Transferência inter-hemisférica; 


\subsubsection{Material utilizado para a captacão dos estímulos}

As gravações foram realizadas em ambiente com nível de ruído controlado.

Os equipamentos utilizados na gravação foram:

4.1.1.a Microfone Behringer B1 - Condensador com padrão polar cardióide;

4.1.1.b. Preamp Behringer Mic 200 Tube Ultragain;

4.1.1.c. Interface de Áudio: M-audio 2496 Audiophile;

Após a captação de todos os estímulos, foi utilizado o programa CAKEWALK SONAR para a confecção das faixas. Todas as faixas foram gravadas com taxa de amostragem de $44.1 \mathrm{khz}$ e 24 bits de resolução em formato WAVE e depois de mixadas, foram normalizadas a $-3,5 \mathrm{db}$ (peak normalization).

Para as faixas que envolvem discriminação e ordenação de padrões de frequência, foram utilizados para o som grave a nota B4 do piano (ou nota $\mathrm{Si}$ da $4^{\underline{a}}$ oitava), que equivale à frequência de aproximadamente $1000 \mathrm{~Hz}$ e para o som agudo a nota F5 do piano (ou nota Fá da 5a oitava), que equivale à frequência de aproximadamente $1400 \mathrm{HZ}$. O IIE nestas faixas foi de $450 \mathrm{~ms}, 350 \mathrm{~ms}, 250 \mathrm{~ms}, 150 \mathrm{~ms}$ e $100 \mathrm{~ms}$ (em cada faixa respectivamente). A duração do estímulo foi de $200 \mathrm{~ms}$ para todas as faixas que envolviam a discriminação e ordenação do padrão de frequência.

Para a faixa de discriminação e ordenação de padrões de duração a frequência utilizada foi de aproximadamente $1000 \mathrm{~Hz}$ (nota B4 do piano) e os 
IIEs foram de $500 \mathrm{~ms}, 400 \mathrm{~ms}, 300 \mathrm{~ms}, 200 \mathrm{~ms}$ e $150 \mathrm{~ms}$ (em cada faixa respectivamente), o som curto teve duração de 200ms e o som longo teve duração de $400 \mathrm{~ms}$ para todas as faixas que envolviam a discriminação e ordenação de duração.

Os parâmetros de duração do estímulo e de IIE foram baseados nos achados de Hirsh (1959) e de Murphy e Schochat (2007), mas também foram adaptados a partir do teste piloto que foi realizado com crianças antes do início da pesquisa.

Após a gravação de todas as faixas e com o auxílio de um decibelímetro foi medido o volume em que as faixas deveriam ser apresentadas por meio do notebook para que permanecesse em média a 60dBA. Esta medida foi realizada dentro de cabina acústica (a mesma utilizada para a avaliação do $\mathrm{PA}(\mathrm{C})$ e do TAF) para evitar a interferência de ruídos externos. Foi utilizado decibelímetro digital, da marca Instrutherm, modelo DEC 460, com escala de frequência de $31,5 \mathrm{~Hz}$ a $8 \mathrm{kHz}$ e escala de medição de $30 \mathrm{~dB}$ a $130 \mathrm{~dB}$.

\subsection{Casuística}

\subsubsection{Critérios de Inclusão}

Foram critérios de inclusão nesta pesquisa os seguintes aspectos:

a) faixa etária entre 7 e 10 anos e 11 meses;

b) apresentar diagnóstico de TF;

c) limiares auditivos dentro do padrão de normalidade; 


\subsubsection{Critérios de Exclusão}

Foram critérios de exclusão nesta pesquisa:

a) estar em tratamento fonoaudiológico;

b) apresentar distúrbio de atenção ou hiperatividade diagnosticado;

c) apresentar diagnóstico de alterações neurológicas ou emocionais;

A partir dos critérios de inclusão e exclusão, todas as crianças participantes passaram por uma primeira avaliação comportamental do $\mathrm{PA}(\mathrm{C})$ denominada $\mathrm{PA}(\mathrm{C}) 1$.

A bateria utilizada para esta avaliação contou com os seguintes testes (explicados de forma mais detalhada no capítulo Material):

1) Teste de Identificação de Figuras com Ruído Branco (teste monótico) em Pereira e Schochat (1997);

2) Dicótico de Dígitos (teste dicótico) em Pereira e Schochat (1997);

3) Teste Padrão Temporal de Frequência proposto pela AUDITEC (1997);

4) Teste Padrão Temporal de Duração, proposto pela AUDITEC (1997); e

5) Teste Gaps in Noise (GIN), desenvolvido por Musiek et al. (2005). É importante salientar que este último teste não foi utilizado como critério de normalidade. $O$ interesse por ele esteve em verificar eventuais variações na avaliação pré e pós TAF e TAI do PA(C).

Após a realização da primeira avaliação do $P A(C)$ a criança foi orientada a retornar em seis semanas para que uma nova avaliação fosse feita (denominada $\mathrm{PA}(\mathrm{C}) 2$ ). Ou seja, independentemente do resultado do 
$\mathrm{PA}(\mathrm{C}) 1$, todas as crianças passaram pelo $\mathrm{PA}(\mathrm{C}) 2$, sem ter realizado, neste período, qualquer intervenção fonoaudiológica. O objetivo da realização do $\mathrm{PA}(\mathrm{C}) 2$ foi verificar se o fator tempo seria suficiente para causar variações no desempenho da criança durante a avaliação comportamental do $P A(C)$. $A$ avaliação do $\mathrm{PA}(\mathrm{C}) 2$ também contou com os mesmos testes realizados ao longo da avaliação do $\mathrm{PA}(\mathrm{C}) 1$.

De acordo com os resultados encontrados no $\mathrm{PA}(\mathrm{C}) 1$ e no $\mathrm{PA}(\mathrm{C}) 2$ as crianças foram incluídas nos grupos Controle, TAF e TAI.

Grupo Controle (C) - Crianças com diagnóstico de TF e, no máximo, alteração nos resultados de um dos testes aplicados para a avaliação comportamental do $\mathrm{PA}(\mathrm{C})$, tanto no $\mathrm{PA}(\mathrm{C}) 1$, quanto no $\mathrm{PA}(\mathrm{C}) 2$.

Grupo TAF - Crianças com diagnóstico de TF e alteração nos resultados de pelo menos dois testes aplicados para a avaliação comportamental do $\mathrm{PA}(\mathrm{C})$, tanto no $\mathrm{PA}(\mathrm{C}) 1$, quanto no $\mathrm{PA}(\mathrm{C}) 2$. As crianças pertencentes a este grupo foram submetidas a oito sessões de TAF e após a realização do treino, passaram pela terceira avaliação do $P A(C)$ (denominada $\mathrm{PA}(\mathrm{C}) 3$ ).

Grupo TAl - Crianças com diagnóstico de TF e alteração nos resultados de pelo menos dois testes aplicados para a avaliação comportamental do $\mathrm{PA}(\mathrm{C})$, tanto no $\mathrm{PA}(\mathrm{C}) 1$, quanto no $\mathrm{PA}(\mathrm{C}) 2$. As crianças pertencentes a este grupo realizaram oito sessões de TAl e após o treino, foram submetidas ao $\mathrm{PA}(\mathrm{C}) 3$.

Inicialmente foram avaliadas 23 crianças com idades entre 7:0 e 10:11 anos, sendo 17 do sexo masculino e seis do sexo feminino. 
Destas, oito foram excluídas do estudo por diferentes questões. Quatro crianças apresentaram melhora espontânea do $\mathrm{PA}(\mathrm{C}) 1$ para 0 $\mathrm{PA}(\mathrm{C}) 2$ e desta forma não poderiam mais ser enquadradas em um dos três grupos pré-estabelecidos para esta pesquisa. Duas crianças não tiveram comprovação do diagnóstico de TF ao longo da avaliação, uma apresentava epilepsia (fator de exclusão) e uma não pôde comparecer à segunda avaliação do $\mathrm{PA}(\mathrm{C})$.

Sendo assim, participaram desta pesquisa 15 crianças entre 7:2 e 10:7 anos, com média de idade de 8,47 anos, sendo 11 meninos e quatro meninas. Os grupos foram distribuídos da seguinte forma:

- Grupo Controle: cinco crianças do sexo masculino, com média de idade de 9,1 anos;

- Grupo TAF: cinco crianças, sendo dois indivíduos do sexo feminino e três do sexo masculino e média de idade igual a 8,3 anos;

- Grupo TAl: cinco crianças, sendo duas do sexo feminino e três do sexo masculino, com média de idade equivalente a 8,1 anos;

Todos os participantes da pesquisa foram avaliados pelo Laboratório de Investigação Fonoaudiológica em Fonologia e pelo Laboratório de Investigação Fonoaudiológica em Audição Humana do Departamento de Fonoaudiologia, Fisioterapia e Terapia Ocupacional da Faculdade de Medicina da Universidade de São Paulo. 
Todas as crianças que participaram da pesquisa foram submetidas à anamnese (ANEXO D - CD ANEXO 2) com o responsável e realizaram avaliação audiológica.

Quando os resultados da avaliação audiológica estavam dentro dos padrões de normalidade, a criança passava pela bateria de testes selecionada para avaliação do $\mathrm{PA}(\mathrm{C})$.

A seguir temos um fluxograma que descreve os passos para inclusão em cada grupo da pesquisa, a partir dos resultados da avaliação do $P A(C)$ e do TF. 
Figura 1 - Organograma com os passos adotados a partir dos resultados das avaliações do $\mathrm{PA}(\mathrm{C})$

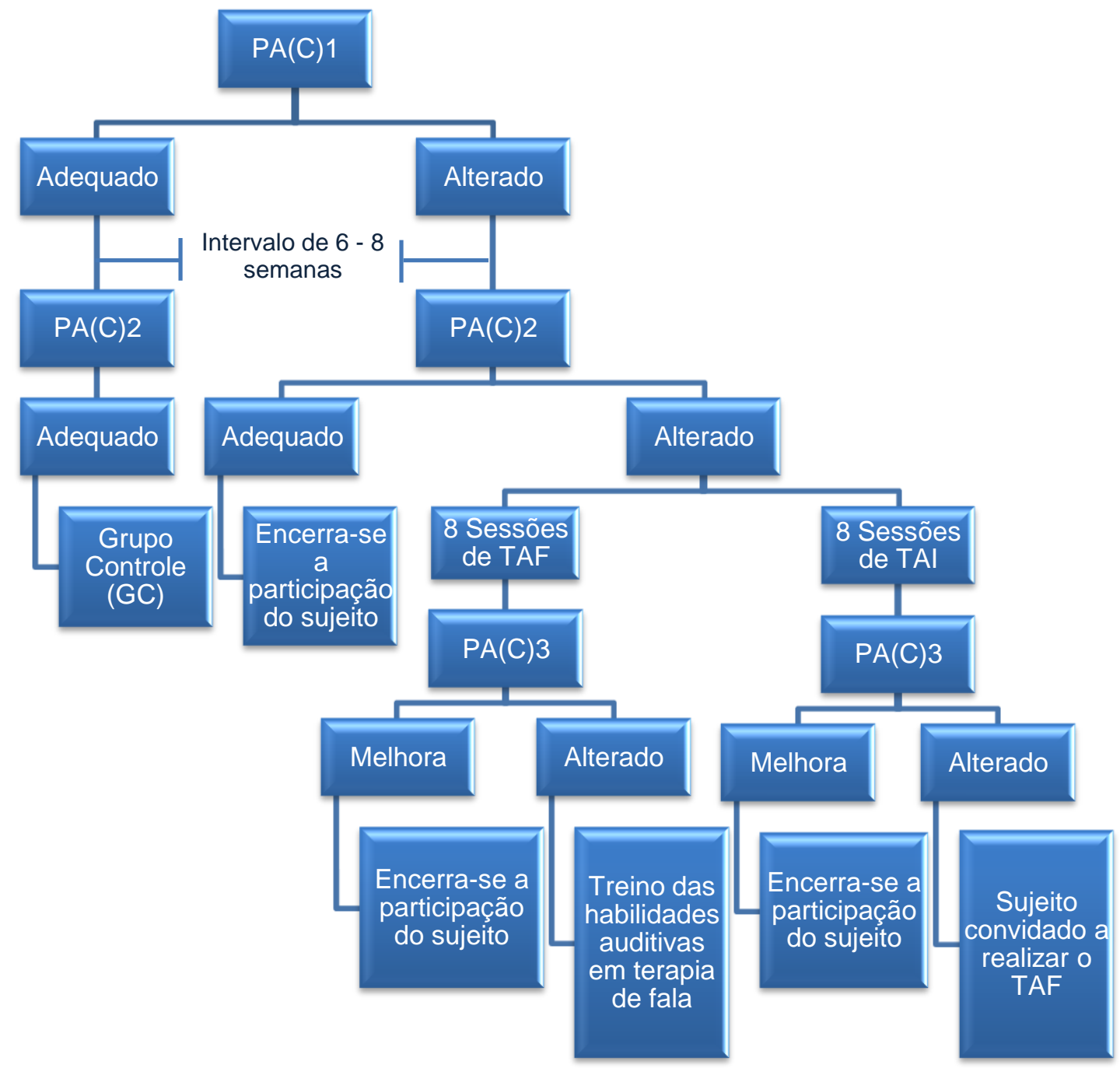

É importante salientar que todas as crianças com alteração do PA(C) que não atingiram os níveis de desempenho esperado para a idade após o TAl foram convidadas a participar de um programa de TAF.

Quando as crianças iniciaram o TAF ou o TAI, os responsáveis foram orientados a responder um questionário sobre atenção, concentração, memória e leitura e escrita. (ANEXO H - CD ANEXO 2). Este mesmo questionário foi aplicado após a última sessão de TAF ou TAI. Desta forma, 
obtivemos dados a respeito da percepção dos responsáveis em relação aos aspectos mencionados, pré e pós TA.

\subsection{Material}

\subsubsection{Avaliação Audiológica e do Processamento Auditivo} (Central)

a.) Protocolo para anamnese utilizado no Laboratório de Investigação Fonoaudiológica em Audição Humana (ANEXO D - CD ANEXO 2).

b.) Otoscópio da marca Heine;

c.) Analisador de Orelha Média Interacoustics AT235h - microprocessado e provido de duas frequências de tom na sonda de imitância: $226 \mathrm{~Hz}$ e $1 \mathrm{KHz}$. O equipamento foi utilizado para as medidas timpanométricas de forma automática e para as medidas dos reflexos acústicos ipsilaterais.

d.) Cabina acústica da marca Siemens aferida de acordo com a norma ANSI S3 1 - 1991;

e.) Audiômetro da marca Grason - Stadler, modelo GSI - 61, cuja faixa de frequência varia de $125 \mathrm{~Hz}$ a $12000 \mathrm{~Hz}$, com variação de intensidade de 10 a 
110 dBNA para o tom puro nas frequências de $125 \mathrm{~Hz}$ e $12000 \mathrm{~Hz}$; de -10 a 115 dBNA para as frequências de $250 \mathrm{~Hz}$ e $8000 \mathrm{~Hz}$; e de -10 a 120 dBNA para as frequências de 500, 750, 1000, 2000, 3000, 4000, 5000 e $6000 \mathrm{~Hz}$. A calibração está de acordo com os padrões ANSI S3 6 - 1989, ANSI S3 43 - 1992, IEC 645 - 1 (1992), IEC 645 - 2 (1993) e ISO 389; UL 544;

f.) Fone de ouvido da marca Telephonics modelo TDH $-50 \mathrm{P}$, com impedância de 80 ohms;

g.) Lista de vocábulos trissílabos para a realização do Limiar de Reconhecimento de Fala (LRF), proposta por Santos e Russo (1986);

h.) CD player da marca Aiwa, modelo HP - A272W, com saída direta para o audiômetro;

i.) CDs contendo testes para avaliação comportamental do $\operatorname{PA}(C)$. A bateria de testes utilizada para avaliação dos sujeitos contou com os testes Identificação de Figuras com Ruído Branco (teste monótico) e Dicótico de Dígitos (teste dicótico) em Pereira e Schochat (1997). Além destes, foram também utilizados os testes Padrão Temporal de Frequência e Padrão Temporal de Duração, propostos pela AUDITEC (1997) e o teste Gaps in Noise (GIN), desenvolvido por Musiek et al. (2005). Conforme mencionado anteriormente, o teste Gaps in Noise (GIN) não foi utilizado como critério de normalidade. $\mathrm{O}$ interesse por este teste esteve em verificar eventuais variações na avaliação pré e pós TAF e TAl do PA(C). 

Auditivo (Central):

- Testes de Escuta Monótica - exigem o reconhecimento de sílabas, palavras ou frases na presença de ruído competitivo ou em situação de fala degradada, apresentados na mesma orelha e ao mesmo tempo (Neves, 2004). Nestes testes, a intensidade da mensagem (sinal) foi apresentada a 40dBNS, em relação ao valor do LRF.

- Identificação de Figuras com Ruído Competitivo Ipsilateral (IF) este teste foi proposto por Jerger et al. (1980) e adaptado para o português por Almeida et al. (1988). Neste teste, a criança ouve ao mesmo tempo, de forma monoaural, palavras mono ou dissílabas que têm o ruído branco, a uma relação sinal/ruído +20 , como mensagem competitiva ipsi lateral. A criança é orientada a apontar em um cartaz a figura correspondente à palavra ouvida. São dadas 10 palavras em cada orelha e posteriormente, calculada a porcentagem de acerto. É preciso que a criança atinja $90 \%$ de acerto para que o resultado do teste seja considerado normal. A habilidade auditiva avaliada neste teste é o fechamento auditivo, que envolve a compreensão da fala, mesmo que um ruído competitivo dificulte a recepção completa da mensagem.

- Testes de Escuta Dicótica - são testes que apresentam mensagens distintas em cada uma das orelhas, de maneira simultânea. Estes testes avaliam o sistema auditivo em situações desfavoráveis de fala, por exigir a compreensão de duas mensagens verbais distintas e simultâneas. Para os 
testes dicóticos, os estímulos foram apresentados na intensidade de 50 dBNS com relação ao LRF de cada orelha. A criança foi orientada a repetir as mensagens que ouvisse.

- Dicótico de Dígitos $(D D)$ - neste teste a criança é exposta a uma sequência de quatro dígitos dissílabos, sendo dois dígitos dados na orelha direita $(\mathrm{OD})$ e os outros dois na orelha esquerda (OE). Além disso, dois dígitos diferentes são dados simultaneamente em cada orelha. A criança pode repetir os quatro dígitos em qualquer ordem. Este teste foi adaptado para o português por Santos e Pereira (1997). A habilidade auditiva avaliada é denominada figura-fundo, que se refere à capacidade de identificar a mensagem principal em detrimento de outra dada simultaneamente. Além disso, também é avaliada a memória de curto prazo, uma vez que o indivíduo precisa reter os quatro dígitos que foram dados. Os valores de normalidade para cada idade estão no quadro abaixo:

\begin{tabular}{ccc}
\hline \multicolumn{3}{c}{ Normalidade } \\
\hline Idade & OD & OE \\
\hline $7-8$ & $85 \%$ & $82 \%$ \\
\hline $9-10$ & $90 \%$ & $90 \%$ \\
\hline 11 ou + & $93 \%$ & $93 \%$ \\
\hline
\end{tabular}

- Teste de Reconhecimentos de Padrões Temporais - estes testes foram produzidos pela Auditec (1997).

- Teste de Padrão Temporal de Frequência (PF) - este teste foi produzido pela Auditec (1997). Neste teste, a criança é orientada a nomear a sequência de tons que escutou entre grave/grosso ou agudo/fino. Em um 
primeiro momento a criança é exposta a um treino com somente dois estímulos. O teste propriamente dito apresenta três estímulos dispostos aleatoriamente. A criança recebe a informação de que não há três estímulos iguais na mesma sequência. A criança é solicitada a ordenar e nomear a sequência de tons que ouviu. Neste teste, as habilidades auditivas investigadas são as de ordenação temporal, que é a capacidade de ordenar os estímulos em relação a padrões acústicos temporais, e transferência inter-hemisférica, que é a habilidade necessária para poder nomear tais estímulos. Os valores de normalidade se baseiam nos achados de Balen (2001) e estão explicitados abaixo:

\begin{tabular}{ccc}
\hline \multicolumn{3}{c}{ Normalidade } \\
\hline Idade & OD & OE \\
\hline 7 & $66,6 \%$ & $51,7 \%$ \\
\hline 8 & $78,6 \%$ & $76,3 \%$ \\
\hline 9 & $77,3 \%$ & $69,65 \%$ \\
\hline 10 & $80 \%$ & $75,76 \%$ \\
\hline 11 & $84,3 \%$ & $83,4 \%$ \\
\hline
\end{tabular}

- Teste de Padrão Temporal de Duração (PD) - Este teste foi produzido pela Auditec (1997). Neste teste, a criança é orientada a nomear a sequência de sons que escutou em curto ou longo. Primeiramente é realizado um treino em que a criança aprende qual é o som curto e qual é o som longo. Neste teste a criança também recebe a informação de que não há três estímulos iguais na mesma sequência. A criança é solicitada a ordenar e nomear a sequência de sons que ouviu. Da mesma maneira que no teste anterior, neste são avaliadas as habilidade auditivas de ordenação temporal e 
transferência inter-hemisférica. Os valores de normalidades se baseiam nos achados de Balen (2001) e estão no quadro abaixo:

\begin{tabular}{ccc}
\hline \multicolumn{3}{c}{ Normalidade } \\
\hline Idade & OD & OE \\
\hline 7 & $39,6 \%$ & $33,6 \%$ \\
\hline 8 & $47,6 \%$ & $43,3 \%$ \\
\hline 9 & $49,6 \%$ & $44,3 \%$ \\
\hline 10 & $63 \%$ & $58,3 \%$ \\
\hline 11 & $71 \%$ & $64 \%$ \\
\hline
\end{tabular}

- Gaps in Noise (GIN) - desenvolvido por Musiek et al. (2005), este teste apresenta de zero a três intervalos de silêncio, com duração de $2 \mathrm{~ms}$, 3ms, $4 \mathrm{~ms}, 5 \mathrm{~ms}, 6 \mathrm{~ms}, 8 \mathrm{~ms}, 10 \mathrm{~ms}, 12 \mathrm{~ms}, 15 \mathrm{~ms}$ e $20 \mathrm{~ms}$, contidos em seis segundos de ruído branco. A habilidade auditiva envolvida neste teste é a de resolução temporal, que reflete o menor tempo necessário para se resolver um evento acústico. O indivíduo é orientado a sinalizar quando perceber que o ruído contínuo foi interrompido por um intervalo de silêncio. Quando ele identifica $66,66 \%$ dos intervalos de mesma duração apresentados (ou seja, quatro intervalos dos seis que são apresentados), este é considerado seu limiar de detecção. Este teste foi aplicado de forma binaural, pelo fato de estudos anteriores (Balen et al., 2009; Perez e Pereira, 2010; Amaral e Colella-Santos, 2010 e Barreira et al., 2011) terem demonstrado não haver diferença estatística entre orelhas e com a intenção de minimizar a possibilidade de eventual cansaço por parte das crianças. É importante frisar que, embora o teste GIN já tenha valores de normalidade estudados para a 
faixa etária de sete anos (Shinn et al., 2009, Balen et al., 2009 e Barreira et al., 2011), como algumas das crianças participantes do estudo não foram capazes de compreender a tarefa solicitada, optou-se por não utilizá-lo como critério de inclusão ou exclusão dos grupos. Desta forma, o interesse por este teste esteve voltado somente para a comparação pré e pós TAF e TAI do $\operatorname{PA}(\mathrm{C})$.

j.) Protocolos específicos para notação dos resultados da avaliação comportamental do PA(C) (ANEXO E - CD ANEXO 2)

\subsubsection{Material utilizado para Treino Auditivo Formal (TAF)}

Para a realização do treino auditivo em cabina acústica, os materiais utilizados são enumerados a seguir:

a.) Cabina acústica da marca Siemens aferida de acordo com a norma ANSI S3 1 - 1991;

b.) Audiômetro da marca Grason - Stadler, modelo GSI - 61, cuja faixa de frequência varia de $125 \mathrm{~Hz}$ a $12000 \mathrm{~Hz}$, com variação de intensidade de 10 a 110 dBNA para o tom puro nas frequências de $125 \mathrm{~Hz}$ e $12000 \mathrm{~Hz}$; de -10 a 115 dBNA para as frequências de $250 \mathrm{~Hz}$ e $8000 \mathrm{~Hz}$; e de -10 a 120 dBNA para as frequências de 500, 750, 1000, 2000, 3000, 4000, 5000 e $6000 \mathrm{~Hz}$. 
A calibração está de acordo com os padrões ANSI S3 6 - 1989, ANSI S3 43 - 1992, IEC 645 - 1 (1992), IEC 645 - 2 (1993) e ISO 389; UL 544;

c.) Fone de ouvido da marca Telephonics modelo TDH - 50P, com impedância de 80 ohms;

d.) CD player da marca Aiwa, modelo HP - A272W, com saída direta para o audiômetro;

e.) Testes contidos nos CDs para avaliação comportamental do Processamento Auditivo (Central) (Pereira e Schochat, 1997) e que foram utilizados como atividades durante a realização do TAF:

- Pediatric Speech Intelligibility Test com mensagem competitiva ipsi lateral (PSI-MCI) - teste monótico. Este teste foi idealizado por Jerger et al.(1980) e adaptado para o português por Almeida et al. (1988). Nesta atividade, a criança deve identificar sentenças simples na presença de mensagem competitiva ipsi-lateral (história narrada). Todas as sentenças possuem uma ilustração correspondente e a criança foi instruída a apontálas. A habilidade auditiva estimulada é a de figura-fundo para sons linguísticos com apoio visual. A relação sinal-ruído variou de acordo com o índice de sucesso da criança durante o treino auditivo formal.

- Teste Dicótico Não-Verbal de escuta direcionada (DNV) (Ortiz e Pereira, 1997). Nesta atividade são apresentados sons não-verbais (sino tocando, cachorro latindo, gato miando, trovão, porta batendo e galo cantando) aos pares e de forma simultânea nas duas orelhas. A habilidade 
auditiva estimulada é a de figura-fundo para sons não-linguísticos e a criança é estimulada a apontar um quadro com ilustrações representativas dos sons cada som ouvido. Em um primeiro momento a criança deve apontar somente o som que julga ter escutado melhor (atenção livre) e nos momentos seguintes, a criança é orientada a apontar somente os sons dados na OD e depois na OE. A regulagem de cada canal do audiômetro variou de acordo com o desempenho da criança durante o treino.

- Staggered Spondaic Word Test (SSW) - teste de dissílabos alternados. Este teste foi proposto por Katz (1962) e adaptado para o português por Borges em 1986 (Borges, 1997). São 40 sequências de quatro palavras dissílabas e paroxítonas, sendo que duas das quatro palavras são apresentadas simultaneamente. Cada sequência é composta de uma palavra apresentada na OD em situação não competitiva (DNC), uma palavra apresentada na OE em situação também não competitiva (ENC) e duas palavras apresentadas simultaneamente nas duas orelhas (DC e EC). Das 40 sequências, 20 são apresentadas inicialmente pela OD e as outras 20 são apresentadas iniciando-se pela OE. Nesta atividade são trabalhadas as habilidades de figura-fundo para sons linguísticos, análise e síntese e memória de curto prazo. Dependendo do desempenho da criança, a dificuldade da tarefa foi aumentada.

- Sons Ambientais Competitivos - CES - Este teste foi desenvolvido por Katz em 1975 (Katz et al., 1992) e convalidado para o Brasil por Schochat (1997). Para esta atividade, a criança é orientada a identificar dois sons diferentes apresentados de forma dicótica, dentre 14 sons distintos. Os sons identificados devem ser apontados em uma lista que contem quatro 
ilustrações representativas dos sons. O teste é composto de 20 apresentações com dois sons em cada. Nesta atividade, a habilidade auditiva estimulada é a de figura-fundo para sons não verbais.

f.) Teste Progressivo Temporal Auditivo idealizado por Borges (2005) com apresentação de paradigmas temporais (grave/agudo e curto/longo), com diferentes (intervalos inter-estímulos (IIEs) e durações de estímulos. Nesta atividade a criança é orientada a ordenar os estímulos dados. A habilidade auditiva estimulada nesta atividade é a de ordenação temporal e transferência inter-hemisférica. Inicialmente, a atividade foi realizada por meio do audiômetro, com os estímulos dados manualmente. A partir do momento em que a criança foi capaz de realizar a ordenação e nomear adequadamente os estímulos, a estimulação passou a ser realizada com o teste.

g.) Instrumentos musicais (sino, agogô, guizo, coco e castanhola) para serem identificados auditivamente em relação à ordem de apresentação. Nesta atividade foi estimulada a habilidade de discriminação e memória para sons não verbais em seqüência. A quantidade de instrumentos apresentados dependeu do desempenho da criança. O guizo e o sino também foram utilizados em tarefas de localização. A criança, de olhos fechados, foi estimulada a localizar a origem do som.

h.) Protocolo para acompanhamento das atividades propostas por sessão de TAF (ANEXO F - CD ANEXO 2). 


\subsubsection{Material utilizado para Treino Auditivo Informal (TAl)}

Para o TAl foi utilizado um notebook, da marca DELL, modelo Inspiron 1525, com um fone de ouvido da marca CSR, modelo HD 3030, para execução do $\mathrm{CD}$, produzido com a finalidade específica de realizar esta pesquisa. A descrição das faixas do $C D$, as orientações para aplicação de cada faixa e os protocolos para notação das respostas estão em anexo (ANEXO G - CD ANEXO 2).

Os sujeitos da pesquisa participantes do Grupo TAl foram submetidos às faixas do $C D$, através de um fone de ouvidos e deveriam responder às solicitações da terapeuta. Ao mesmo tempo a pesquisadora também ouviu os estímulos utilizando outro fone de ouvidos. As respostas foram anotadas em protocolo desenvolvido especificamente para os objetivos da presente pesquisa (ANEXO G - CD ANEXO 2).

\subsection{Procedimentos}

\subsubsection{Procedimentos para inclusão nos Grupos}

Os sujeitos passaram por Avaliação de Linguagem, Avaliação Audiológica e Avaliação Comportamental do Processamento Auditivo (Central) $(\mathrm{PA}(\mathrm{C}))$.

a.) Avaliação de Linguagem - Esta avaliação foi realizada pelo Laboratório de Investigação Fonoaudiológica em Fonologia do 
Departamento de Fonoaudilogia, Fisioterapia e Terapia Ocupacional da Faculdade de Medicina da Universidade de São Paulo. O critério de inclusão para esses sujeitos foi a presença de alterações na prova de Fonologia (Wertzner, 2004) do Teste de Linguagem Infantil ABFW na área de fonologia, caracterizada pela omissão e/ou substituição de fonemas relacionados à presença de processos fonológicos, na presença ou não de alterações na Linguagem Escrita concomitantes e ausência de alterações sintáticas, semânticas ou pragmáticas.

b.) Avaliação Audiológica - Esta avaliação envolveu anamnese realizada com os responsáveis (ANEXO D - CD ANEXO 2), inspeção do meato acústico externo, Audiometria Tonal Liminar (nas frequências de $500 \mathrm{~Hz}, 1 \mathrm{Khz}, 2 \mathrm{Khz}$ e $4 \mathrm{Khz}), \mathrm{LRF}$, e Imitanciometria, com timpanometria e pesquisa dos reflexos acústicos.

c.) Avaliação do Processamento Auditivo (Central) - Nesta avaliação foram utilizados os testes Identificação de Figuras com Ruído Branco (teste monótico), Dicótico de Dígitos (teste dicótico), Padrão de Frequência, Padrão de Duração e o teste Gaps in Noise (GIN). É importante salientar que o teste Gaps in Noise (GIN) não foi utilizado como critério de normalidade. $O$ interesse por este teste esteve em verificar eventuais mudanças de resultados na avaliação pré e pós TAF e informal do $P A(C)$. Os testes de Identificação de Figuras com Ruído Branco (teste monótico), Dicótico de Dígitos são testes comportamentais, adaptados para o português por Pereira e Schochat (1997). Os testes de Padrão de Frequência e de 
Duração foram propostos pela AUDITEC (1997). O teste Gaps in Noise (GIN) foi desenvolvido por Musiek et al. (2005).

De acordo com os resultados apresentados em cada teste, as crianças foram enquadradas nos grupos desta pesquisa.

\subsubsection{Procedimentos após a inclusão em cada grupo}

a.) Grupo Controle - Este grupo passou pela bateria de testes comportamentais do $\operatorname{PA}(C)$ de seis a oito semanas após a primeira avaliação, sem qualquer intervenção entre a primeira e a segunda avaliação do $\operatorname{PA}(\mathrm{C})$;

b.) Grupo TAF - Após a segunda avaliação do PA(C) (que ocorreu de seis a oito semanas após a primeira) com resultados abaixo do esperado para a idade em pelo menos dois testes, as crianças passaram por oito sessões de TAF do $P A(C)$.

\section{b.1) Treino Formal}

Após a inclusão no Grupo TAF, os sujeitos passaram por Programa de Treinamento Auditivo Formal validado por Musiek e Schochat (1998). O Treinamento Auditivo consistiu em oito sessões, com duração de 50 minutos cada. 
O grau de dificuldade de cada tarefa do Treinamento Auditivo em cabina foi determinado de modo manual com o objetivo de alcançar um índice de sucesso versus erro de aproximadamente 70/30 (Musiek e Schochat, 1998). Procurou-se contemplar três habilidades auditivas a cada sessão e sempre foi trabalhada pelo menos uma atividade que envolvesse a habilidade auditiva de resolução temporal.

Após a realização das oito sessões de TAF, as crianças deste grupo passaram por reavaliação comportamental do $\mathrm{PA}(\mathrm{C})$ (denominado $\mathrm{PA}(\mathrm{C}) 3$ );

c.) Grupo TAI - Após a segunda avaliação do $P A(C)$ (que ocorreu de seis a oito semanas após a primeira) com resultados abaixo do esperado para a idade em pelo menos dois testes, as crianças passaram por oito sessões de TAI do PA(C).

\section{c.1.) Treino Informal}

As crianças pertencentes a este grupo realizaram oito sessões de terapia (em caráter semanal), com duração de 50 minutos cada, e foram expostas às faixas do CD Programa para Treino Auditivo Informal (amostras das faixas estão em anexo - CD ANEXO 1 - Programa de Treino Auditivo Informal), de acordo com hierarquia de dificuldade previamente determinada. Antes de cada atividade, as crianças foram apresentadas aos estímulos que seriam utilizados e receberam explicações acerca da tarefa. Depois de garantir que a criança havia compreendido a solicitação, iniciava-se a atividade. 
O quadro com a ordem de apresentação das faixas se encontra em (ANEXO G - CD ANEXO 2). É importante salientar que a ordem de apresentação das faixas do CD foi a mesma para todas as crianças, no entanto para que uma nova atividade fosse proposta era necessário que a criança tivesse realizado, com pelo menos $70 \%$ de acerto, a atividade anterior. Após a realização das oito sessões de TAl, as crianças deste grupo passaram por reavaliação comportamental do $\mathrm{PA}(\mathrm{C})$. Caso os resultados da avaliação do $\mathrm{PA}(\mathrm{C})$ após o TAI se mantivessem alterados, a criança seria convidada a realizar oito sessões de $\operatorname{TAF}$ do $\mathrm{PA}(\mathrm{C})$ (denominado $\mathrm{PA}(\mathrm{C}) 3$ ) ou a treinar as habilidades auditivas alteradas em terapia fonoaudiológica.

\subsection{Métodos de Análise dos Resultados}

A amostra foi caracterizada quanto à idade.

As distribuições do PCC-R nomeação e PCC-R Imitação nos três grupos foram comparadas por meio dos testes de Kruskal-Wallis e MannWhitney (Neter et al., $2005^{1}$ ). O procedimento de Bonferroni foi aplicado para localizar as diferenças apontadas no teste.

Para os testes Identificação de Figuras com Ruído Branco (IF), Dicótico de Dígitos (DD), Padrão Temporal de Frequência (PF) e Padrão Temporal de Duração (PD) foi adotada a seguinte estratégia de análise: considerando inicialmente as duas primeiras avaliações $(P A(C) 1$ e $P A(C) 2)$,

\footnotetext{
${ }^{1}$ Neter, J., Kutner, M.H., Nachtsheim, C.J. e Li, W. - Applied Linear Statistical Models. $5^{\mathrm{a}}$ ed. Chicago: Irwin; 2005.
} 
as médias das respostas nos três grupos ( $\mathrm{C}$, TAF e TAI) e nas duas avaliações foram comparadas por meio da técnica de análise de variância com medidas repetidas (Neter et al., 2005).

Posteriormente, considerando as observações nas três avaliações $(\mathrm{PA}(\mathrm{C}) 1, \mathrm{PA}(\mathrm{C}) 2$ e $\mathrm{PA}(\mathrm{C}) 3)$ nos grupos TAF e TAI, as médias nos dois grupos e nas três avaliações foram comparadas por meio da técnica de análise de variância com medidas repetidas, com o objetivo de comparar a média na terceira avaliação com as das avaliações anteriores, e comparar as médias dos dois grupos na terceira avaliação. Para localizar diferenças entre as médias foi utilizado o método de comparações múltiplas de Bonferroni.

No teste Gaps in Noise (GIN) não há observações do limiar no TAI na $1^{\text {a }}$ avaliação. Na análise do limiar foi adotada a seguinte estratégia: As distribuições do limiar nos grupos foram comparadas em cada avaliação por meio no teste de Kruskal-Wallis (Neter et al., 2005), e em cada grupo as distribuições nas avaliações foram comparadas por meio do teste de Friedman (Neter et al., 2005).

Nos testes de hipótese foi fixado nível de significância de 0,05. 
RESULTADOS 


\section{REsultados}

Para a descrição e análise dos resultados, com o intuito de facilitar a compreensão, optou-se por dividir este capítulo em duas partes, sendo a primeira para a caracterização da amostra e a segunda envolvendo os testes aplicados para a avaliação comportamental do $\mathrm{PA}(\mathrm{C})$ pré e pós-treino auditivo ${ }^{2}$ :

PARTE I - Caracterização da amostra;

PARTE II - Resultados obtidos nos testes aplicados para a avaliação do $\mathrm{PA}(\mathrm{C})$ pré e pós-treino auditivo;

${ }^{2}$ Embora os questionários tenham sido aplicados em caráter pré e pós TA, as respostas obtidas foram muito variadas limitando a análise. Deste modo, tais dados se encontram descritos nos anexos (ANEXO I e J - CD ANEXO 2), mas não foram discutidos. 


\section{PARTE I - Caracterização da amostra}

- Quanto à idade

A amostra consiste de 15 indivíduos com transtorno fonológico, cinco sem alteração do processamento auditivo (grupo Controle - C) e $10 \mathrm{com}$ alteração do processamento. Estes foram divididos em dois grupos: TAF e TAl, cada um com cinco indivíduos.

$\mathrm{Na}$ tabela 1 são apresentados valores de estatísticas descritivas para a Idade (anos).

Tabela 1 - Estatísticas descritivas para a Idade (anos)

\begin{tabular}{ccccccc}
\hline Grupo & $\mathbf{N}$ & Média & $\begin{array}{c}\text { Desvio } \\
\text { padrão }\end{array}$ & Mínimo & Mediana & Máximo \\
\hline C & 5 & 9,1 & 1,2 & 7,9 & 8,7 & 10,6 \\
TAF & 5 & 8,3 & 0,7 & 7,3 & 8,6 & 8,8 \\
TAl & 5 & 8,1 & 0,8 & 7,2 & 8,5 & 8,8 \\
\hline Total & 15 & 8,5 & 1,0 & 7,2 & 8,6 & 10,6 \\
\hline
\end{tabular}


- Quanto à análise do índice Percentage of Consonants Correct - Revised (PCC-R)

Na tabela 2 são encontrados valores de estatísticas descritivas para o PCC-R nas provas de nomeação e imitação. Os valores individuais e medianos do PCC-R estão representados nas figuras 2 (Imitação) e 3 (Nomeação).

Nota-se que as porcentagens no Controle tendem a ser maiores e mais homogêneas que no TAF e TAl, tanto na Imitação, quanto na Nomeação.

Tabela 2 - Estatísticas descritivas para o PCC-R (\%) na imitação e na nomeação

\begin{tabular}{cccccccc}
\hline & Grupo & N & Média & $\begin{array}{c}\text { Desvio } \\
\text { padrão }\end{array}$ & Mínimo & Mediana & Máximo \\
\hline \multirow{2}{*}{ PCC-R } & C & 5 & 98,5 & 1,2 & 97,2 & 99,0 & 100,0 \\
Imitação & TAF & 5 & 80,8 & 15,1 & 67,8 & 73,8 & 99,0 \\
& TAI & 5 & 78,3 & 15,3 & 63,6 & 74,8 & 95,3 \\
\cline { 2 - 8 } & Total & 15 & 85,9 & 14,8 & 63,6 & 95,3 & 100,0 \\
\cline { 2 - 8 } PCC-R & C & 5 & 96,8 & 2,6 & 92,2 & 97,8 & 98,1 \\
& TAF & 5 & 82,1 & 13,5 & 63,2 & 80,7 & 97,8 \\
& TAI & 5 & 75,1 & 15,1 & 58,9 & 70,0 & 92,2 \\
\cline { 2 - 8 } & Total & 15 & 84,6 & 14,4 & 58,9 & 92,0 & 98,1 \\
\hline
\end{tabular}


Figura 2 - Valores individuais e medianos do PCC-R (\%) na imitação nos grupos Controle, TAF e TAI

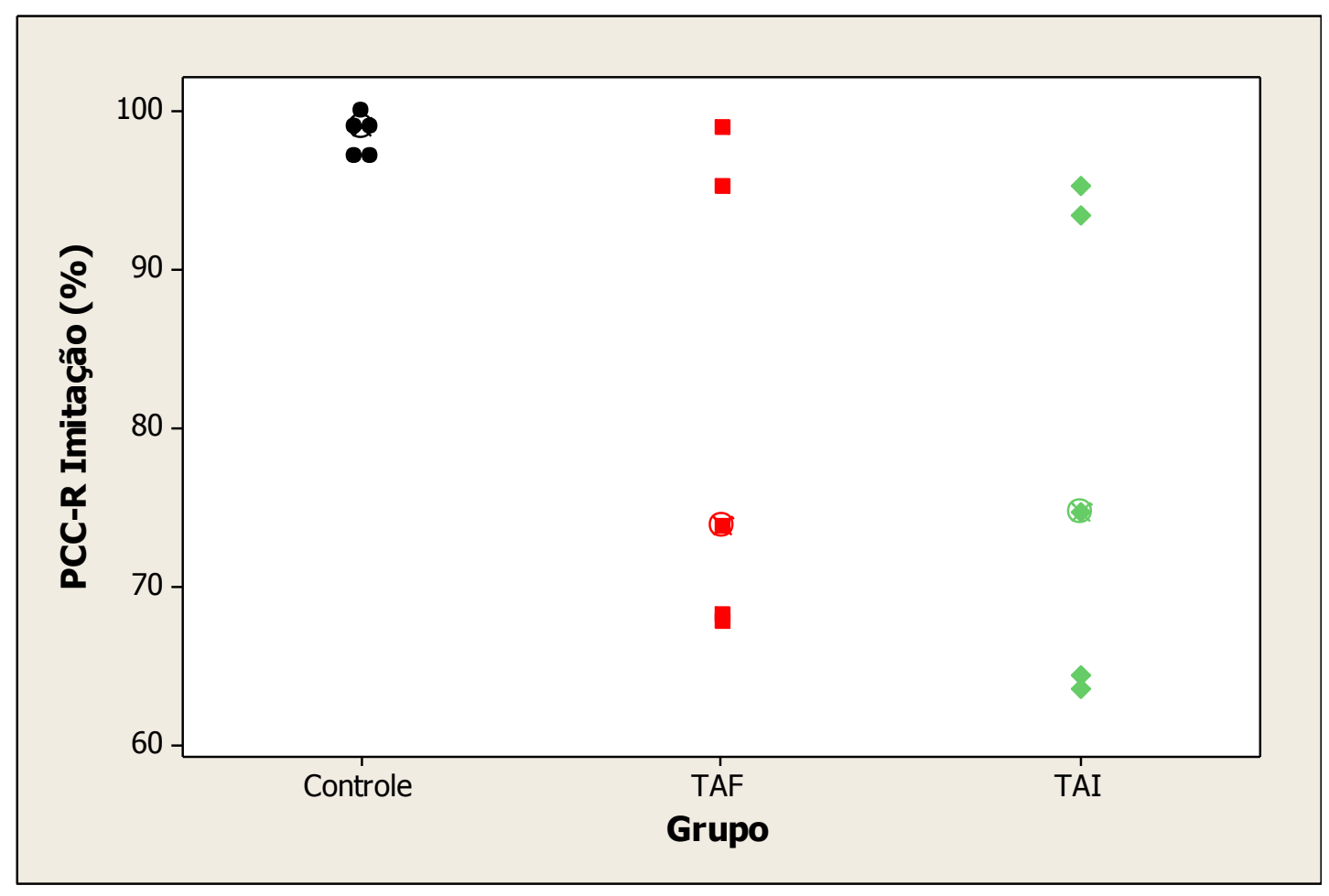

Figura 3 - Valores individuais e medianos do PCC-R (\%) na nomeação nos grupos Controle, TAF e TAI

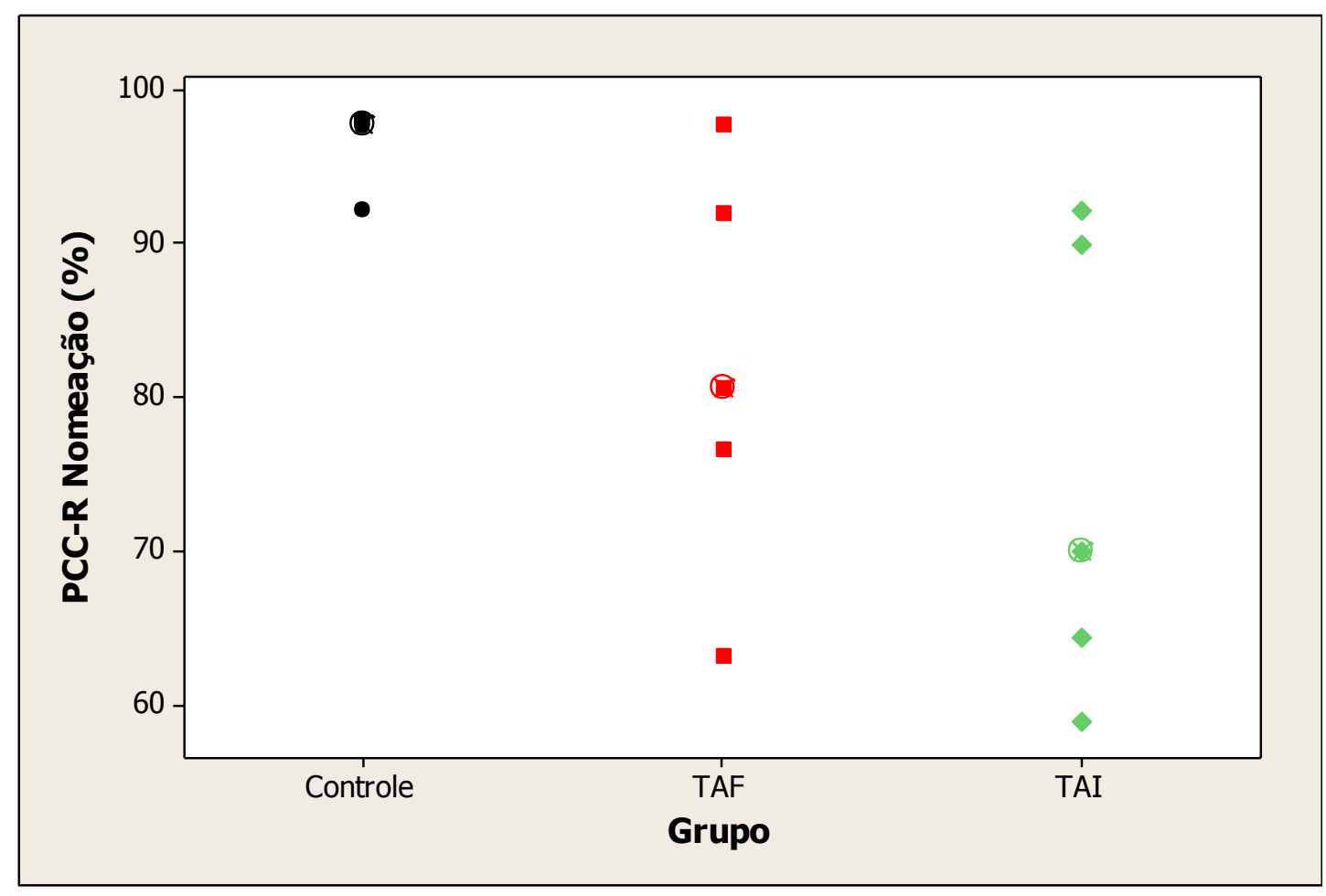


O teste de Kruskal-Wallis apontou que há diferença significativa entre as distribuições do PCC-R na imitação nos três grupos $(p=0,021)$. No prosseguimento da análise, as distribuições nos três grupos foram comparadas duas a duas, obtendo-se os p-valores apresentados na tabela 3. Nota-se que os valores do PCC-R tendem a ser maiores no Controle do que no TAI e o TAF é um grupo intermediário entre o Controle e o TAI.

$\mathrm{Na}$ análise do PCC-R na nomeação, obteve-se que há diferença significativa entre as distribuições do PCC-R nos três grupos $(p=0,021)$. Assim como na prova de Imitação, os p-valores na tabela 3 indicam que as porcentagens na nomeação tendem a ser maiores no Controle que no TAl, e o TAF é um grupo intermediário entre o Controle e o TAI.

Tabela 3 - P-valores obtidos na comparação das distribuições do PCC-R nos três grupos, duas a duas, ajustados pelo procedimento de Bonferroni

\begin{tabular}{ccc}
\hline Comparação & Imitação & Nomeação \\
\hline TAF x TAl & $>0,999$ & $>0,999$ \\
TAF x Controle & 0,128 & 0,131 \\
TAl x Controle & 0,023 & 0,024 \\
\hline
\end{tabular}

Na tabela 4 estão descritos os valores referentes às médias do PCCR na imitação e nomeação, comparando-se o grupo Controle (sem alteração do PA(C)) com os grupos TAF e TAI (com alteração do PA(C)). 
Tabela 4 - Estatísticas descritivas para o PCC-R (\%) na imitação e na nomeação reunindo os grupos com TPA(C) (TAF + TAl)

\begin{tabular}{llcccccc}
\hline \multirow{2}{*}{ Variável } & Grupo & N & Média & $\begin{array}{c}\text { Desvio } \\
\text { padrão }\end{array}$ & Mínimo & Mediana & Máximo \\
\hline \multirow{2}{*}{ PCC - R } & C & 5 & 98,5 & 1,2 & 97 & 99,0 & 100 \\
Imitação & TAF+TAI & 10 & 79,6 & 14,4 & 64 & 74,3 & 99 \\
\cline { 2 - 8 } & Total & 15 & 85,9 & 14,8 & 64 & 95,3 & 100 \\
\cline { 2 - 8 } PCC - R & C & 5 & 96,8 & 2,6 & 92 & 97,8 & 98 \\
Nomeação & TAF+TAI & 10 & 78,6 & 14,0 & 59 & 78,7 & 98 \\
\cline { 2 - 8 } & Total & 15 & 84,6 & 14,4 & 59 & 92,0 & 98 \\
\hline
\end{tabular}

O teste de Mann-Whitney apontou que:

- a distribuição do PCC-R na imitação não é a mesma nos dois grupos $(p=0,007)$ e a porcentagem tende a ser maior no $\mathrm{C}$;

- a distribuição do PCC-R na nomeação não é a mesma nos dois grupos $(p=0,007)$ e a porcentagem tende a ser maior no $C$. 


\section{PARTE II - Resultados obtidos nos testes aplicados para a avaliação do $\mathrm{PA}(\mathrm{C})$ pré e pós-treino auditivo}

\section{- Análise dos resultados obtidos no Teste Identificação de Figuras com Ruído Branco (IF)}

Nas tabelas 5 e 6 são apresentados valores de estatísticas descritivas para a porcentagem de acertos no IF por grupo e avaliação, nas orelhas direita e esquerda, respectivamente. As médias observadas no Controle são maiores que no TAF e no TAl nas duas primeiras avaliações. As médias observadas no TAF e no TAl na terceira avaliação são maiores que as observadas nas avaliações anteriores.

Tabela 5 - Estatísticas descritivas para a porcentagem de acertos no IF por grupo e avaliação - orelha direita

\begin{tabular}{|c|c|c|c|c|c|c|c|}
\hline Avaliação & Grupo & $\mathbf{N}$ & Média & Desvio padrão & Mínimo & Mediana & Máximo \\
\hline \multirow{4}{*}{$\mathrm{PA}(\mathrm{C}) 1$} & C & 5 & 86,0 & 11,4 & 70 & 90 & 100 \\
\hline & TAF & 5 & 64,0 & 21,9 & 30 & 70 & 90 \\
\hline & TAI & 5 & 46,0 & 11,4 & 30 & 50 & 60 \\
\hline & Total & 15 & 65,3 & 22,3 & 30 & 70 & 100 \\
\hline \multirow{3}{*}{$\mathrm{PA}(\mathrm{C}) 2$} & C & 5 & 90,0 & 7,1 & 80 & 90 & 100 \\
\hline & TAF & 5 & 64,0 & 24,1 & 30 & 70 & 90 \\
\hline & TAl & 5 & 58,0 & 23,9 & 30 & 60 & 90 \\
\hline \multirow{4}{*}{$\mathrm{PA}(\mathrm{C}) 3$} & Total & 15 & 70,7 & 23,4 & 30 & 80 & 100 \\
\hline & TAF & 5 & 86,0 & 11,4 & 70 & 90 & 100 \\
\hline & TAI & 5 & 64,0 & 15,2 & 40 & 70 & 80 \\
\hline & Total & 10 & 75,0 & 17,2 & 40 & 75 & 100 \\
\hline
\end{tabular}

O comportamento da porcentagem de acertos no IF em cada indivíduo no decorrer das avaliações em cada grupo pode ser visualizado nas figuras 4 (orelha direita) e 6 (orelha esquerda). Os perfis médios nas 
orelhas direita e esquerda em cada grupo estão representados nas figuras 5 e 7 respectivamente.

Figura 4 - Perfis individuais da porcentagem de acertos no IF por grupo e avaliação - orelha direita

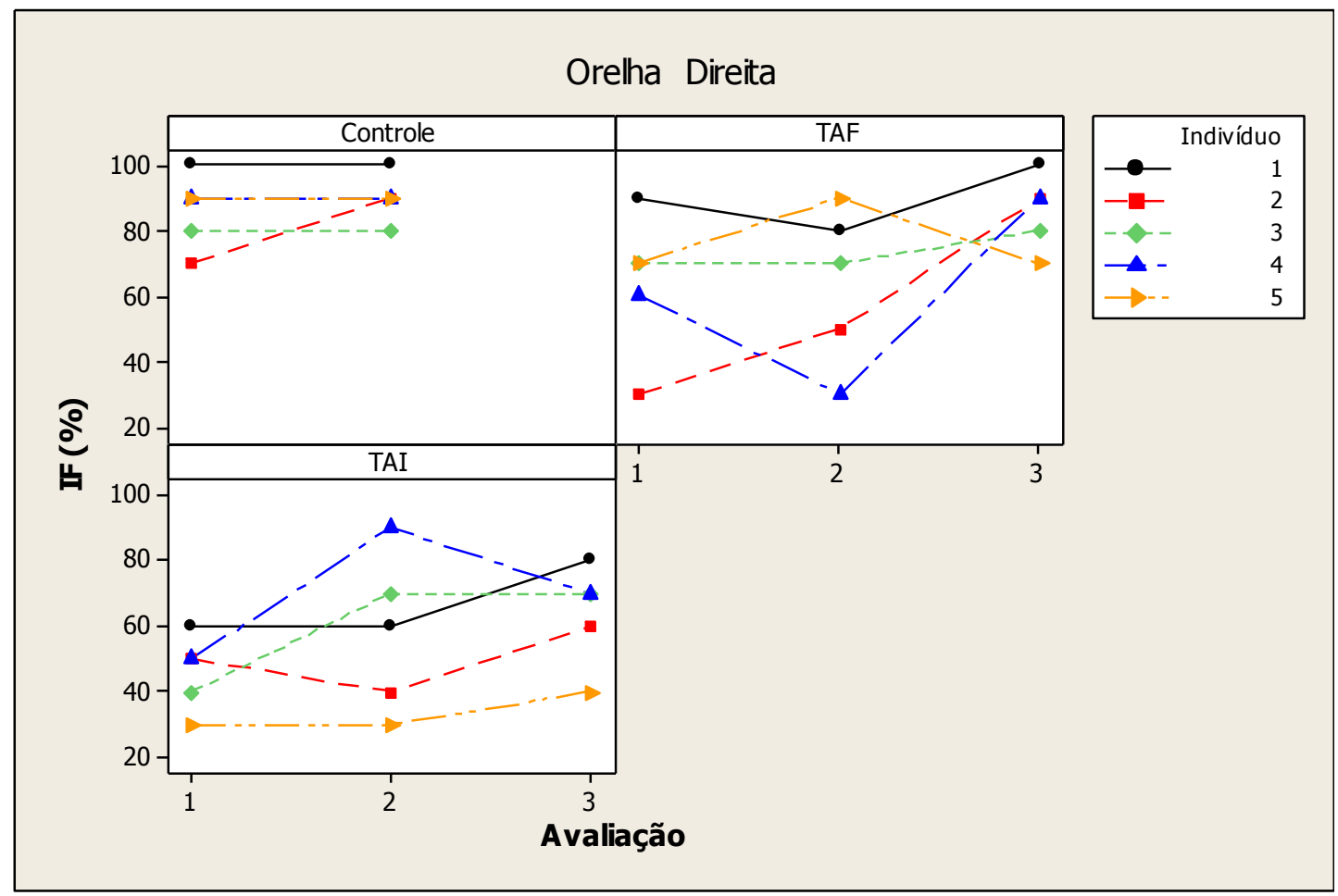

Legenda: $1=\mathrm{PA}(\mathrm{C}) 1 ; 2=\mathrm{PA}(\mathrm{C}) 2 ;$ e $3=\mathrm{PA}(\mathrm{C}) 3$ 
Figura 5 - Médias \pm erros padrão da porcentagem de acertos no IF por grupo e avaliação - orelha direita

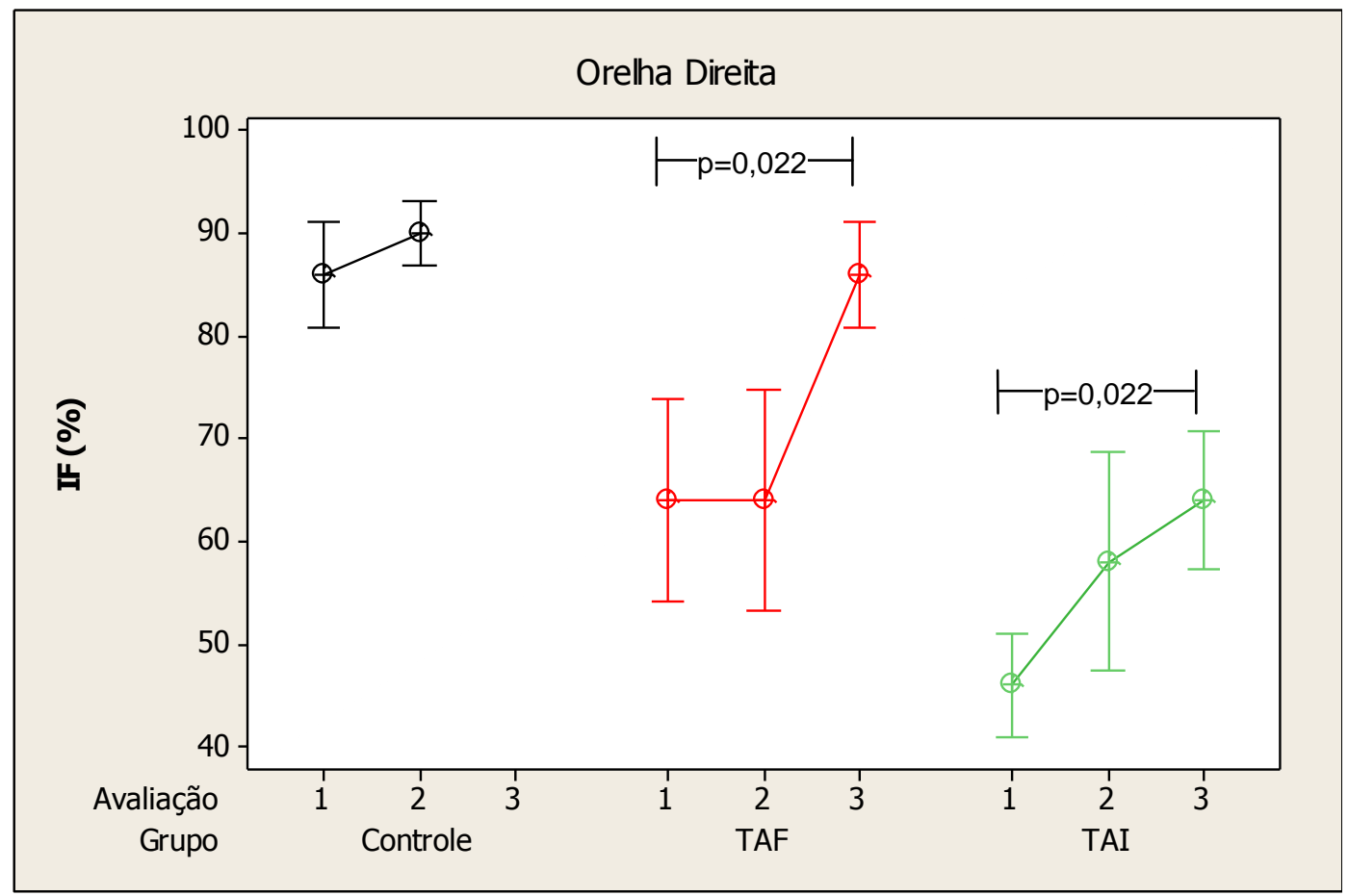

Legenda: $1=\mathrm{PA}(\mathrm{C}) 1 ; 2=\mathrm{PA}(\mathrm{C}) 2 ;$ e $3=\mathrm{PA}(\mathrm{C}) 3$

Tabela 6 - Estatísticas descritivas para a porcentagem de acertos no IF por grupo e avaliação - orelha esquerda

\begin{tabular}{cccccccc}
\hline Avaliação & Grupo & $\mathbf{N}$ & Média & Desvio padrão & Mínimo & Mediana & Máximo \\
\hline \multirow{4}{*}{ PA(C)1 } & C & 5 & 90,0 & 17,3 & 60 & 100 & 100 \\
& TAF & 5 & 72,0 & 16,4 & 60 & 70 & 100 \\
& TAI & 5 & 42,0 & 19,2 & 20 & 40 & 70 \\
\cline { 2 - 8 } & Total & 15 & 68,0 & 26,2 & 20 & 70 & 100 \\
\cline { 2 - 8 } PA(C)2 & C & 5 & 84,0 & 8,9 & 70 & 90 & 90 \\
& TAF & 5 & 72,0 & 14,8 & 50 & 70 & 90 \\
& TAI & 5 & 62,0 & 17,9 & 40 & 60 & 90 \\
\cline { 2 - 8 } & Total & 15 & 72,7 & 16,2 & 40 & 70 & 90 \\
\cline { 2 - 8 } PA(C)3 & TAF & 5 & 84,0 & 16,7 & 60 & 80 & 100 \\
& TAI & 5 & 70,0 & 15,8 & 50 & 70 & 90 \\
\cline { 2 - 8 } & Total & 10 & 77,0 & 17,0 & 50 & 80 & 100 \\
\hline
\end{tabular}


Figura 6 - Perfis individuais da porcentagem de acertos no IF por grupo e avaliação - orelha esquerda

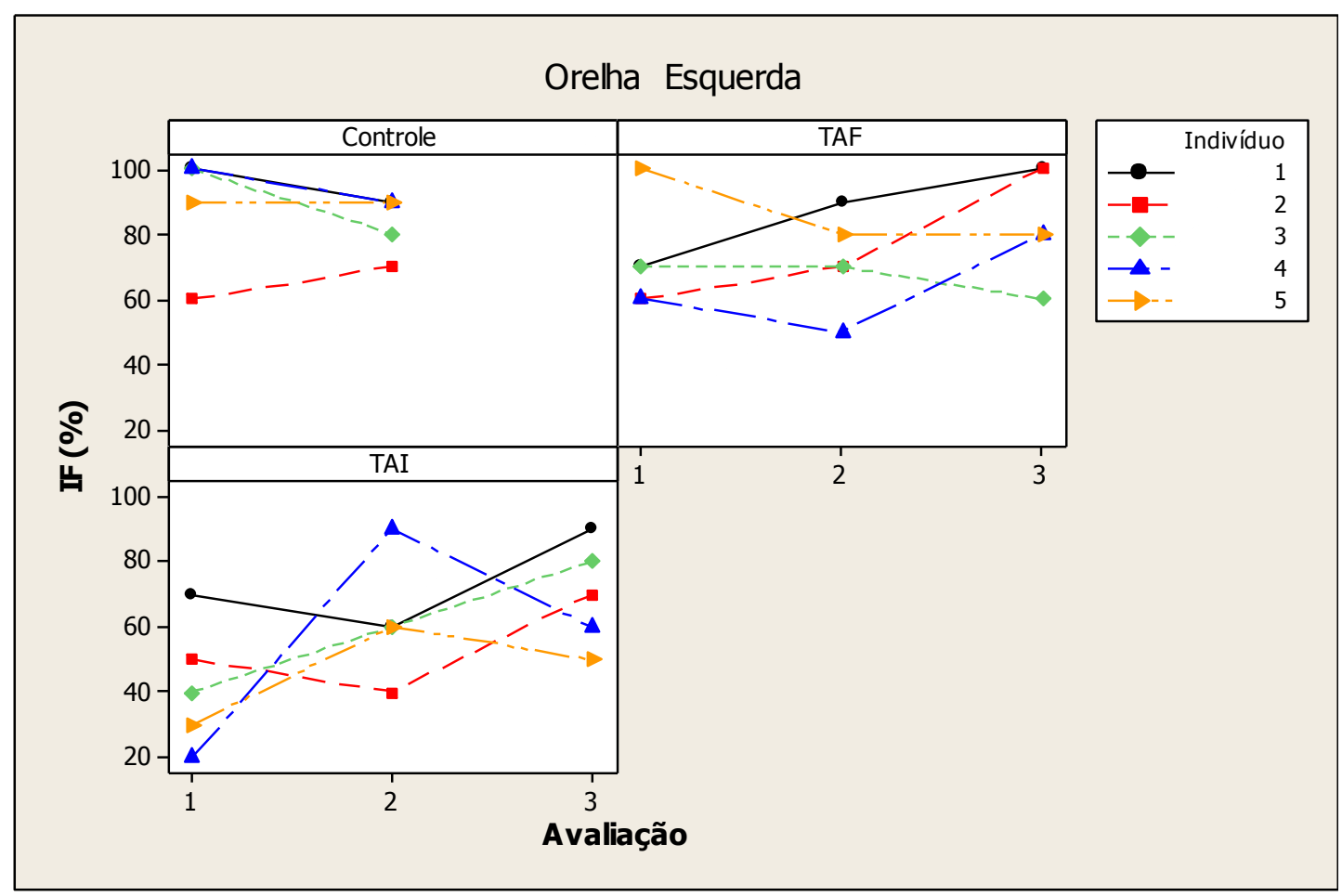

Legenda: 1 = $\mathrm{PA}(\mathrm{C}) 1 ; 2=\mathrm{PA}(\mathrm{C}) 2$; e $3=\mathrm{PA}(\mathrm{C}) 3$

Figura 7 - Médias \pm erros padrão da porcentagem de acertos no IF por grupo e avaliação - orelha esquerda

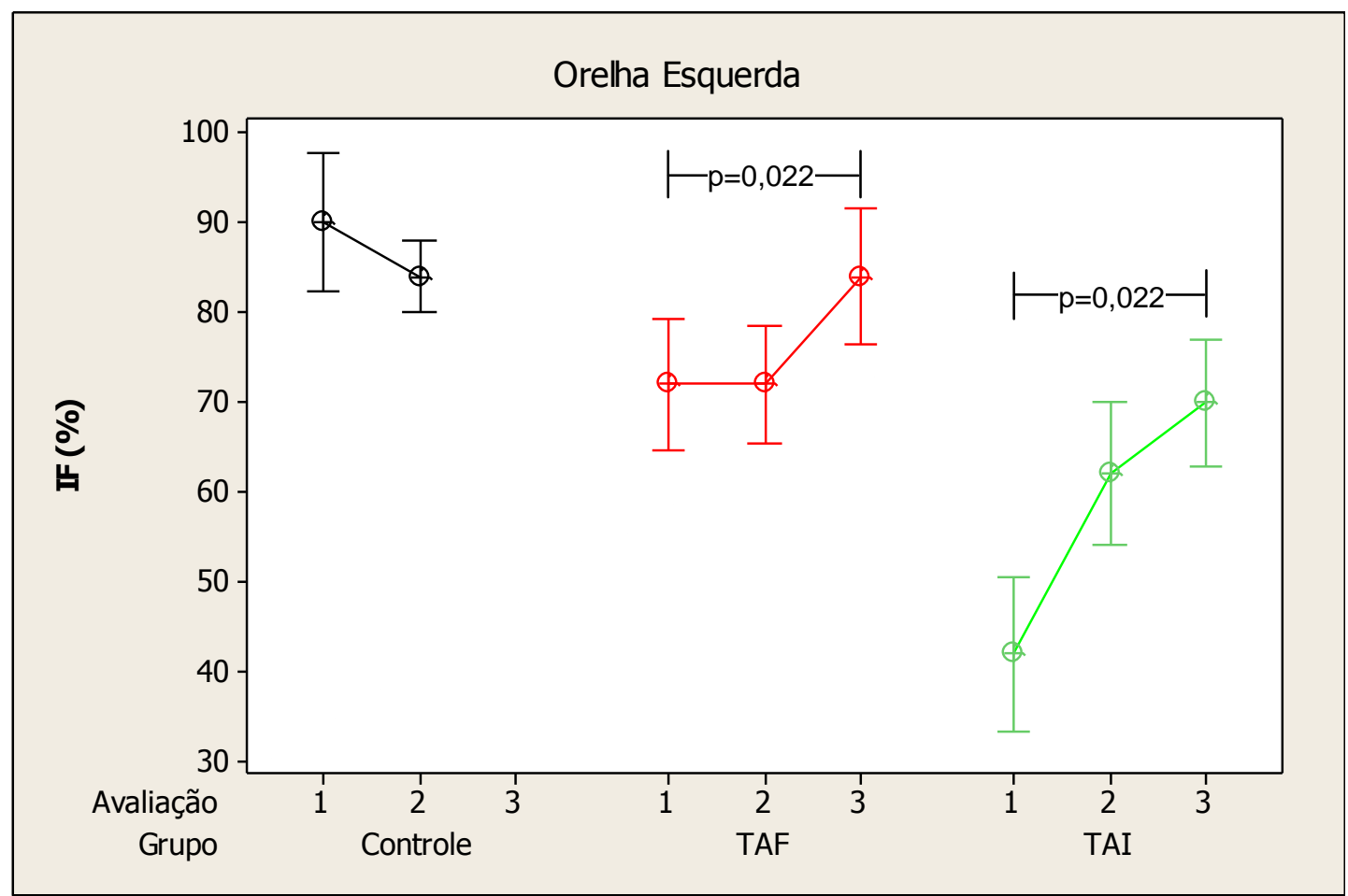

Legenda: $1=\mathrm{PA}(\mathrm{C}) 1 ; 2=\mathrm{PA}(\mathrm{C}) 2 ;$ e $3=\mathrm{PA}(\mathrm{C}) 3$ 
Considerando inicialmente as duas primeiras avaliações, as médias do IF nos três grupos e nas duas avaliações foram comparadas por meio da técnica de análise de variância com medidas repetidas. Obteve-se que:

- Não existe diferença significativa entre as médias do IF nas duas avaliações $(p=0,294)$, independentemente do grupo $(p=0,271)$ e da orelha $(p=0,900)$ (ou seja, não há interação entre avaliação e grupo e entre avaliação e orelha);

- Não existe diferença significativa entre as médias do IF nas duas orelhas $(p=0,419)$, qualquer que seja o grupo $(p=0,382)$ e qualquer que seja a avaliação $(p=0,900)$;

- As médias do IF não são iguais nos grupos ( $p=0,003)$, e a diferença entre as médias dos grupos é a mesma nas duas orelhas $(p=0,382)$ e nas duas avaliações $(p=0,271)$. No prosseguimento da análise, com o objetivo de localizar as diferenças entre as médias nos três grupos, obteve-se que não há diferença significativa entre as médias nos grupos Controle e TAF $(p=0,093)$, a média no Controle é maior que no TAI $(p=0,002)$ e não há diferença significativa entre as médias no TAF e no TAl $(p=0,204)$.

Considerando agora as observações nas três avaliações nos grupo TAF e TAI, as médias nos dois grupos e nas três avaliações foram comparadas por meio da técnica de análise de variância com medidas repetidas. O objetivo desta parte da análise é comparar a média na terceira avaliação com as das avaliações anteriores e comparar as médias dos dois grupos na terceira avaliação. Os resultados obtidos foram:

- As médias da porcentagem de acertos não são iguais nas três avaliações $(p=0,021)$, e a diferença entre as médias é a mesma nos dois 
grupos $(p=0,396)$ e nas duas orelhas $(p=0,599)$. Na comparação entre as avaliações obteve-se que a média na $3^{\underline{a}}$ avaliação é maior que na 1a $^{\text {a }}$ $(p=0,022)$, e não há diferença significativa entre as médias na $2^{\underline{a}}$ e $3^{\text {a }}$ avaliações $(p=0,367)$;

- Não há diferença significativa entre as médias da porcentagem de acertos nas duas orelhas $(p=0,366)$, independentemente do grupo $(p=0,693)$ e da avaliação ( $p=0,599)$;

- A média no TAF é maior que no TAl na $3^{\text {a }}$ avaliação $(p=0,048)$, independentemente da orelha $(p=0,693)$. 
- Análise dos resultados obtidos no Teste Dicótico de Dígitos (DD)

Valores de estatísticas descritivas para a porcentagem de acertos no DD por grupo e avaliação são apresentados nas tabelas 7 (orelha direita) e 8 (orelha esquerda). É possível observar que as médias no Controle são maiores que nos outros dois grupos em todas as avaliações. No TAF e no TAl é observado um aumento na média da primeira para a terceira avaliação.

Tabela 7 - Estatísticas descritivas para a porcentagem de acertos no DD por grupo e avaliação - orelha direita

\begin{tabular}{cccccccc}
\hline Avaliação & Grupo & N & Média & Desvio padrão & Mínimo & Mediana & Máximo \\
\hline \multirow{4}{*}{ PA(C)1 } & C & 5 & 93,5 & 4,9 & 90,0 & 90,0 & 100,0 \\
& TAF & 5 & 81,5 & 6,5 & 77,5 & 77,5 & 92,5 \\
& TAI & 5 & 63,5 & 19,4 & 45,0 & 57,5 & 95,0 \\
\cline { 2 - 8 } & Total & 15 & 79,5 & 17,0 & 45,0 & 82,5 & 100,0 \\
\cline { 2 - 8 } PA(C)2 & C & 5 & 97,0 & 4,5 & 90,0 & 100,0 & 100,0 \\
& TAF & 5 & 85,5 & 9,3 & 75,0 & 87,5 & 97,5 \\
& TAI & 5 & 72,0 & 11,5 & 60,0 & 70,0 & 90,0 \\
\cline { 2 - 8 } & Total & 15 & 84,8 & 13,4 & 60,0 & 90,0 & 100,0 \\
\cline { 2 - 8 } PA(C)3 & TAF & 5 & 90,5 & 12,3 & 70,0 & 92,5 & 100,0 \\
& TAI & 5 & 70,0 & 11,6 & 57,5 & 70,0 & 85,0 \\
\cline { 2 - 8 } & Total & 10 & 80,3 & 15,6 & 57,5 & 81,3 & 100,0 \\
\hline
\end{tabular}

Perfis individuais da porcentagem de acertos no DD no decorrer das avaliações em cada grupo são encontrados nas figuras 8 (orelha direita) e 
10 (orelha esquerda). Os perfis médios nas orelhas direita e esquerda em cada grupo estão representados nas figuras 9 e 11, respectivamente.

Figura 8 - Perfis individuais da porcentagem de acertos no DD por grupo e avaliação - orelha direita

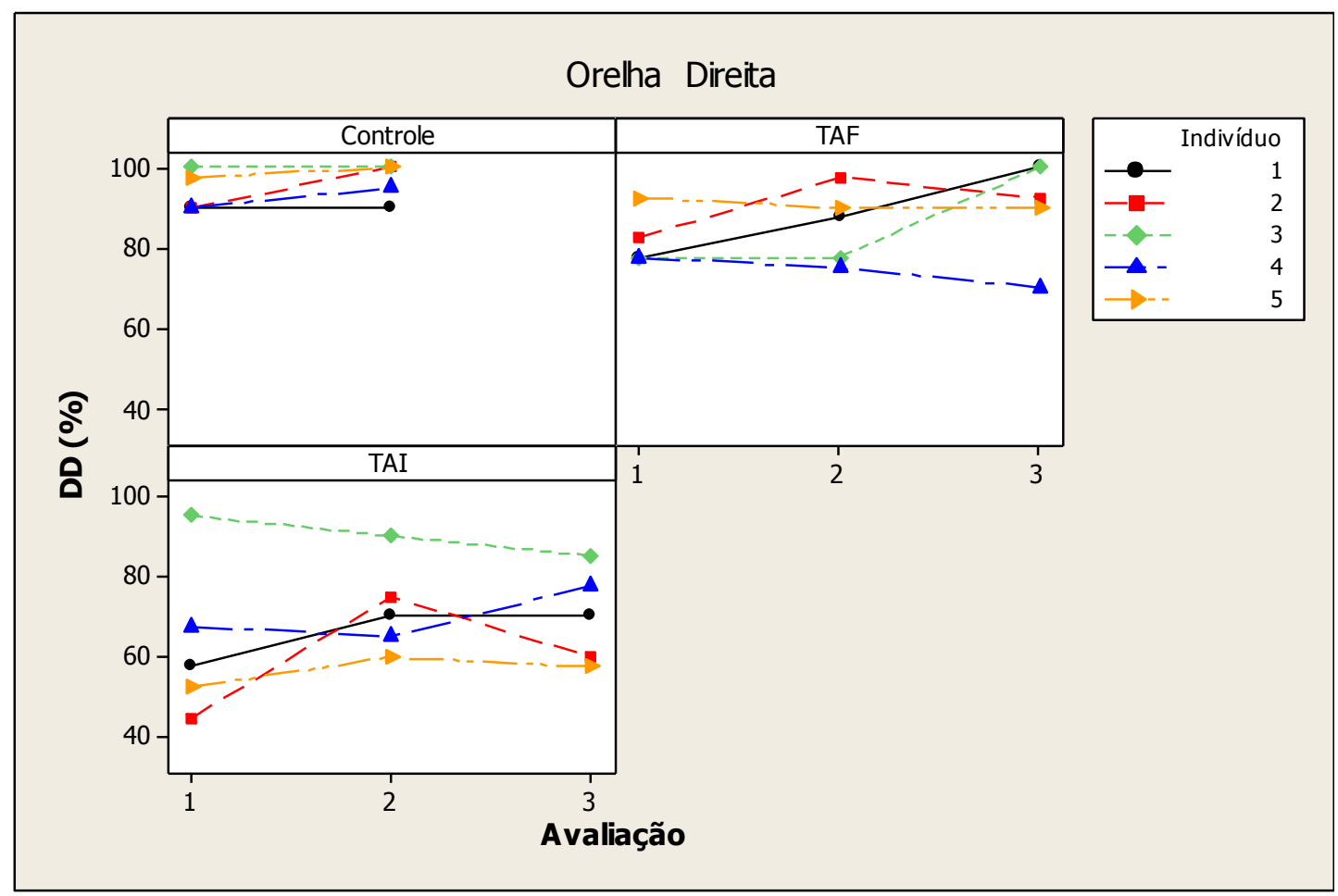

Legenda: $1=\mathrm{PA}(\mathrm{C}) 1 ; 2=\mathrm{PA}(\mathrm{C}) 2$; e $3=\mathrm{PA}(\mathrm{C}) 3$ 
Figura 9 - Médias \pm erro padrão da porcentagem de acertos no DD por grupo e avaliação - orelha direita

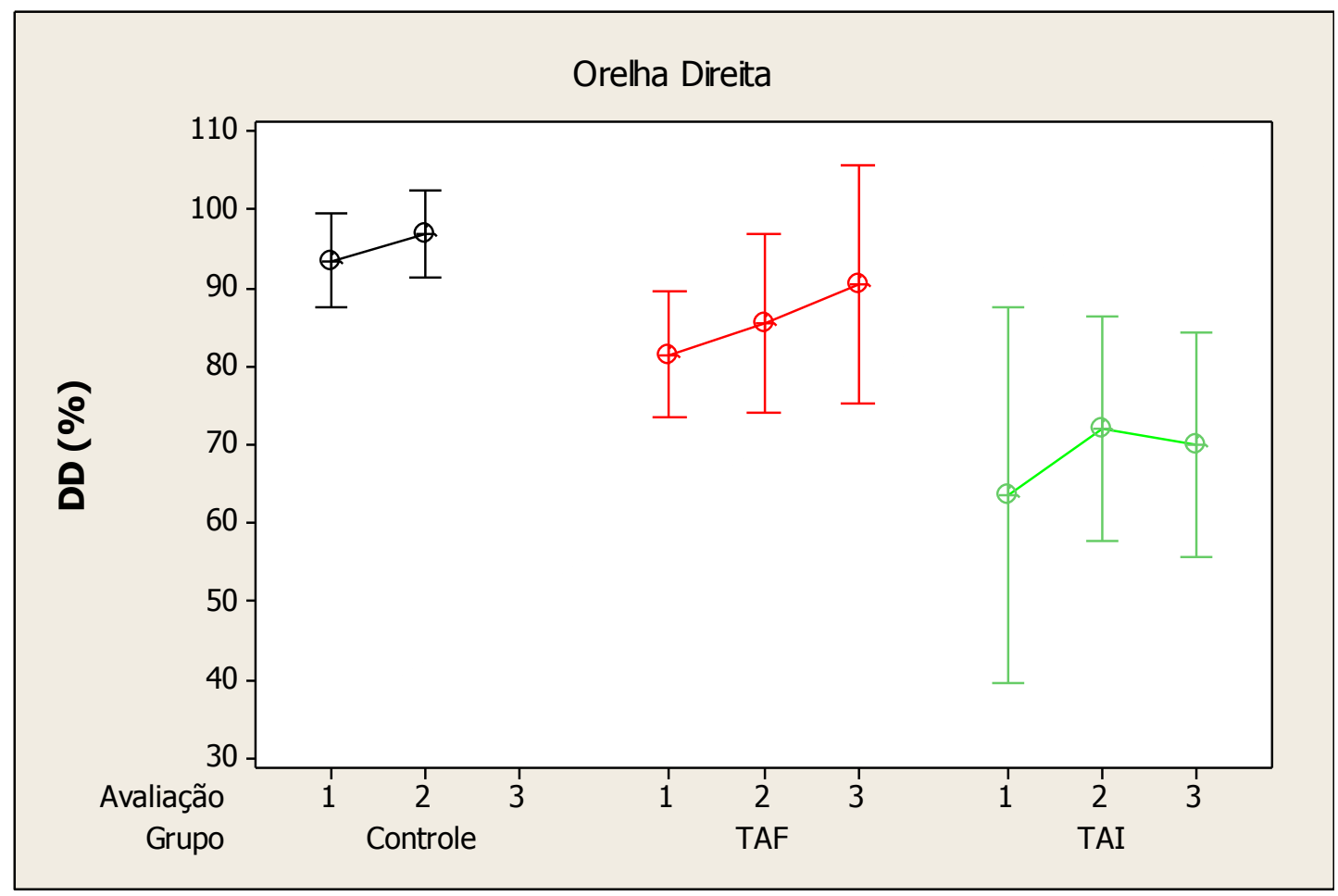

Legenda: $1=\mathrm{PA}(\mathrm{C}) 1 ; 2=\mathrm{PA}(\mathrm{C}) 2$; e $3=\mathrm{PA}(\mathrm{C}) 3$

Tabela 8 - Estatísticas descritivas para a porcentagem de acertos no DD por grupo e avaliação - orelha esquerda

\begin{tabular}{cccccccc}
\hline \multirow{3}{*}{ Avaliação } & Grupo & N & Média & $\begin{array}{c}\text { Desvio } \\
\text { padrão }\end{array}$ & Mínimo & Mediana & Máximo \\
\hline \multirow{4}{*}{ PA(C)1 } & C & 5 & 94,0 & 3,8 & 90,0 & 92,5 & 100,0 \\
& TAF & 5 & 69,0 & 11,8 & 55,0 & 72,5 & 85,0 \\
& TAl & 5 & 58,5 & 15,9 & 35,0 & 62,5 & 77,5 \\
\cline { 2 - 8 } & Total & 15 & 73,8 & 18,8 & 35,0 & 72,5 & 100,0 \\
\cline { 2 - 8 } PA(C)2 & C & 5 & 93,5 & 5,8 & 85,0 & 92,5 & 100,0 \\
& TAF & 5 & 87,5 & 8,8 & 72,5 & 90,0 & 95,0 \\
& TAl & 5 & 60,0 & 13,5 & 37,5 & 62,5 & 72,5 \\
\cline { 2 - 8 } PA(C)3 & Total & 15 & 80,3 & 17,6 & 37,5 & 87,5 & 100,0 \\
\cline { 2 - 8 } & TAF & 5 & 88,5 & 6,5 & 80,0 & 90,0 & 97,5 \\
& TAI & 5 & 64,0 & 15,5 & 45,0 & 65,0 & 82,5 \\
\cline { 2 - 8 } & Total & 10 & 76,3 & 17,1 & 45,0 & 81,3 & 97,5 \\
\hline
\end{tabular}


Figura 10 - Perfis individuais da porcentagem de acertos no DD por grupo e avaliação - orelha esquerda

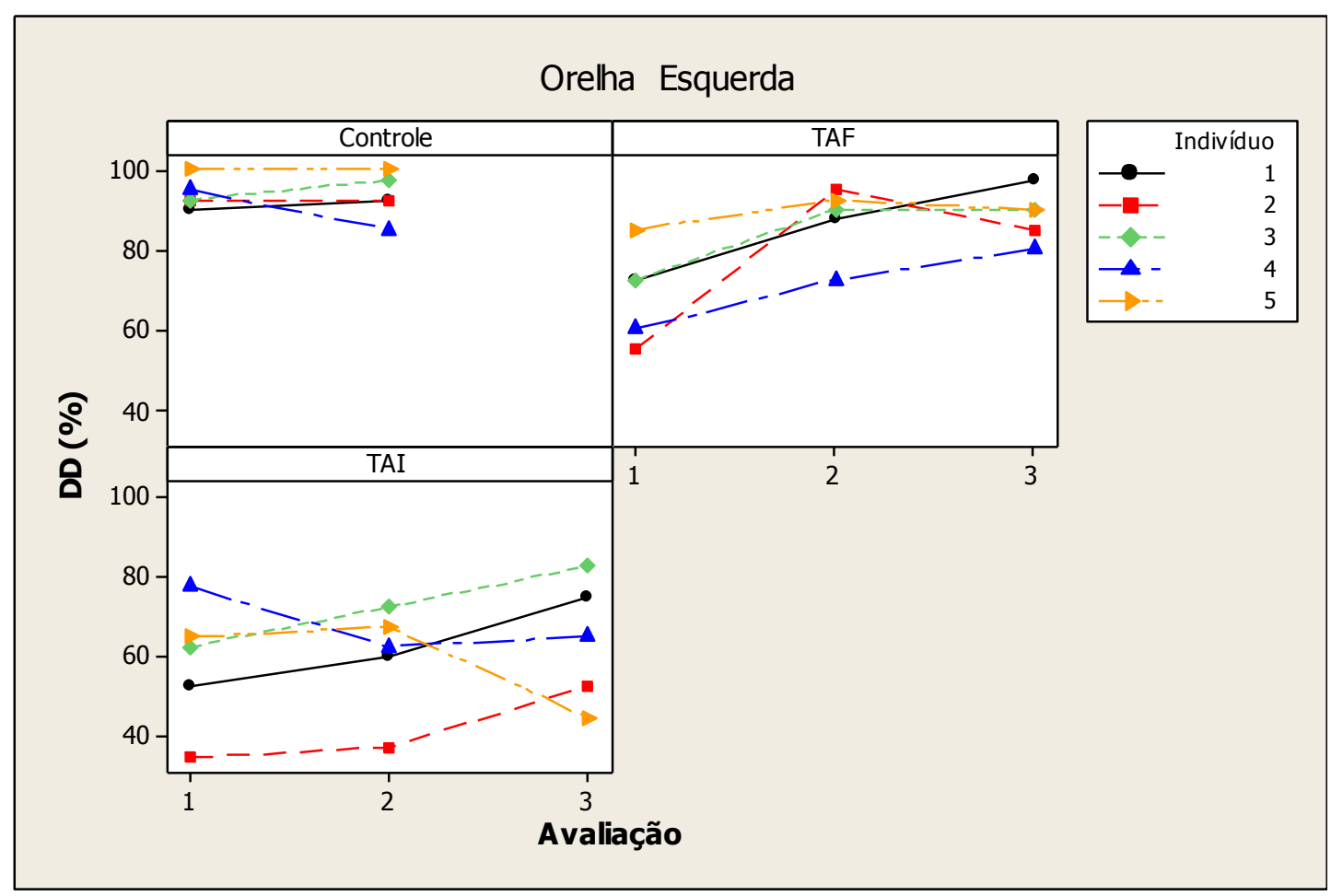

Legenda: $1=\mathrm{PA}(\mathrm{C}) 1 ; 2=\mathrm{PA}(\mathrm{C}) 2 ;$ e $3=\mathrm{PA}(\mathrm{C}) 3$

Figura 11 - Médias \pm erro padrão da porcentagem de acertos no DD por grupo e avaliação - orelha esquerda

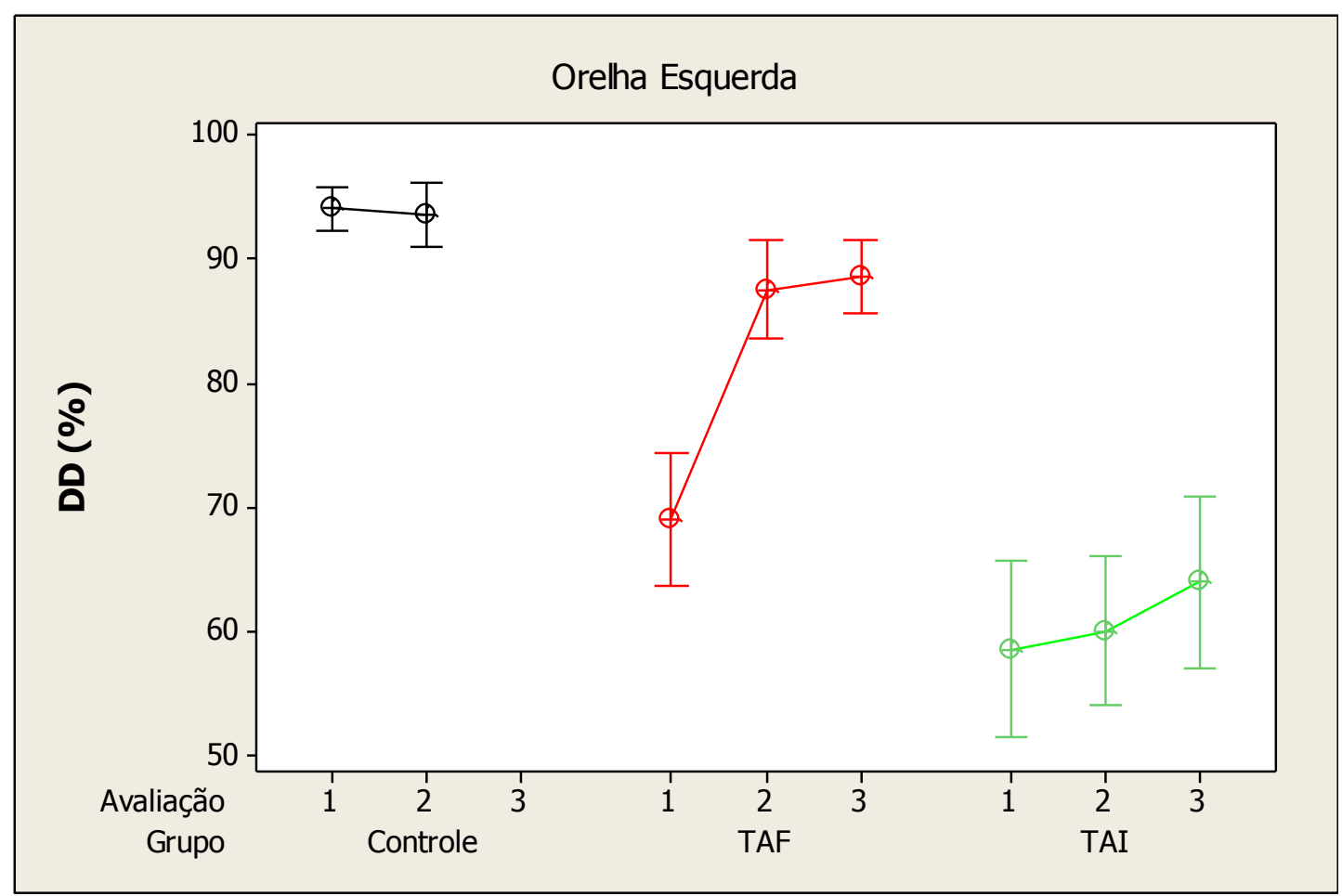

Legenda: $1=\mathrm{PA}(\mathrm{C}) 1 ; 2=\mathrm{PA}(\mathrm{C}) 2 ;$ e $3=\mathrm{PA}(\mathrm{C}) 3$ 
A análise de variância com medidas repetidas apontou que a diferença entre as médias dos grupos e entre as médias das avaliações depende da orelha $(p=0,019)$. Os resultados de cada orelha foram então analisados separadamente (isto é, para cada orelha foi feita uma análise de variância com medidas repetidas com dois fatores: grupo e avaliação).

$\mathrm{Na}$ análise da orelha direita obteve-se que:

- Não há diferença significativa entre as médias da porcentagem de acertos no DD nas duas avaliações $(p=0,053)$, independentemente do grupo $(p=0,673)$;

- As médias da porcentagem de acertos não são todas iguais nos três grupos $(p=0,002)$ e a diferença entre elas é a mesma nas duas avaliações $(\mathrm{p}=0,673)$. Prosseguindo a análise com o objetivo de localizar as diferenças entre as médias obteve-se que não há diferença significativa entre as médias dos grupos $C$ e TAF $(p=0,223)$ e entre TAF e TAl $(p=0,067)$, e a média no $C$ é maior que no TAI $(p=0,002)$.

$\mathrm{Na}$ análise da orelha esquerda obteve-se que há interação entre Avaliação e Grupo ( $p=0,018)$, isto é, a diferença entre as médias dos grupos não é a mesma nas duas avaliações, e a diferença entre as médias das duas avaliações depende do grupo. No prosseguimento da análise obtevese que:

- Não há diferença significativa entre as médias da porcentagem nas duas avaliações no $C(p=0,854)$ e no TAI $(p=0,749)$; no TAF, a média na segunda avaliação é maior que na primeira $(p=0,030)$; 
- Na primeira avaliação a média no Controle é maior que no TAF $(p=0,016)$ e maior que no TAI $(p=0,001)$; não há diferença significativa entre as médias no TAF e no TAl $(\mathrm{p}=0,537)$;

- Na segunda avaliação não há diferença significativa entre as médias no Controle e no TAF ( $p>0,999)$; a média no Controle é maior que no TAI $(p=0,001)$ e a média no TAF é maior que no TAI $(p=0,003)$.

A análise dos resultados dos grupos TAF e TAI nas três avaliações também foi feita por orelha.

$\mathrm{Na}$ orelha direita foram obtidos os seguintes resultados:

- Não há diferença significativa entre as médias da porcentagem de acertos nas três avaliações $(p=0,110)$, independentemente do grupo $(p=0,631)$

- A média no TAF é maior que no TAI na $3^{a}$ avaliação $(p=0,031)$.

Os resultados obtidos na orelha esquerda foram:

-Não há diferença significativa entre as médias da porcentagem de acertos nas avaliações $(p=0,073)$, e este resultado independe do grupo $(p=0,152)$

-A média do TAF é maior que no TAI na $3^{\text {a }}$ avaliação $(p=0,010)$. 
- Análise dos resultados obtidos no Teste Padrão Temporal de Frequência (PF)

Valores observados de estatísticas descritivas para a porcentagem de acertos no PF por grupo e avaliação são encontrados na tabela 9. As médias observadas no Controle são maiores que no TAF e no TAI nas duas primeiras avaliações. As médias observadas no TAl na terceira avaliação são maiores que as observadas nas avaliações anteriores.

Tabela 9 - Estatísticas descritivas para a porcentagem de acertos no PF por grupo e avaliação

\begin{tabular}{cccccccc}
\hline Avaliação & Grupo & N & Média & Desvio padrão & Mínimo & Mediana & Máximo \\
\hline \multirow{4}{*}{ PA(C)1 } & C & 5 & 89,0 & 8,9 & 80,0 & 90,0 & 100,0 \\
& TAF & 5 & 49,0 & 17,8 & 20,0 & 55,0 & 65,0 \\
& TAI & 4 & 32,5 & 34,0 & 0,0 & 25,0 & 80,0 \\
\cline { 2 - 8 } & Total & 14 & 58,6 & 31,5 & 0,0 & 62,5 & 100,0 \\
\cline { 2 - 8 } PA(C)2 & C & 5 & 86,0 & 16,7 & 60,0 & 90,0 & 100,0 \\
& TAF & 5 & 61,0 & 18,5 & 30,0 & 65,0 & 75,0 \\
& TAI & 5 & 40,0 & 25,7 & 15,0 & 30,0 & 70,0 \\
\cline { 2 - 8 } & Total & 15 & 62,3 & 27,3 & 15,0 & 65,0 & 100,0 \\
\cline { 2 - 8 } PA(C)3 & TAF & 5 & 57,0 & 23,1 & 30,0 & 65,0 & 80,0 \\
& TAI & 5 & 55,0 & 23,2 & 15,0 & 60,0 & 75,0 \\
\cline { 2 - 8 } & Total & 10 & 56,0 & 21,8 & 15,0 & 62,5 & 80,0 \\
\hline
\end{tabular}

O comportamento da porcentagem de acertos no PF em cada indivíduo no decorrer das avaliações em cada grupo pode ser visualizado na figura 12. Os perfis médios em cada grupo estão representados na figura 13. 
Figura 12 - Perfis individuais da porcentagem de acertos no PF por grupo e avaliação

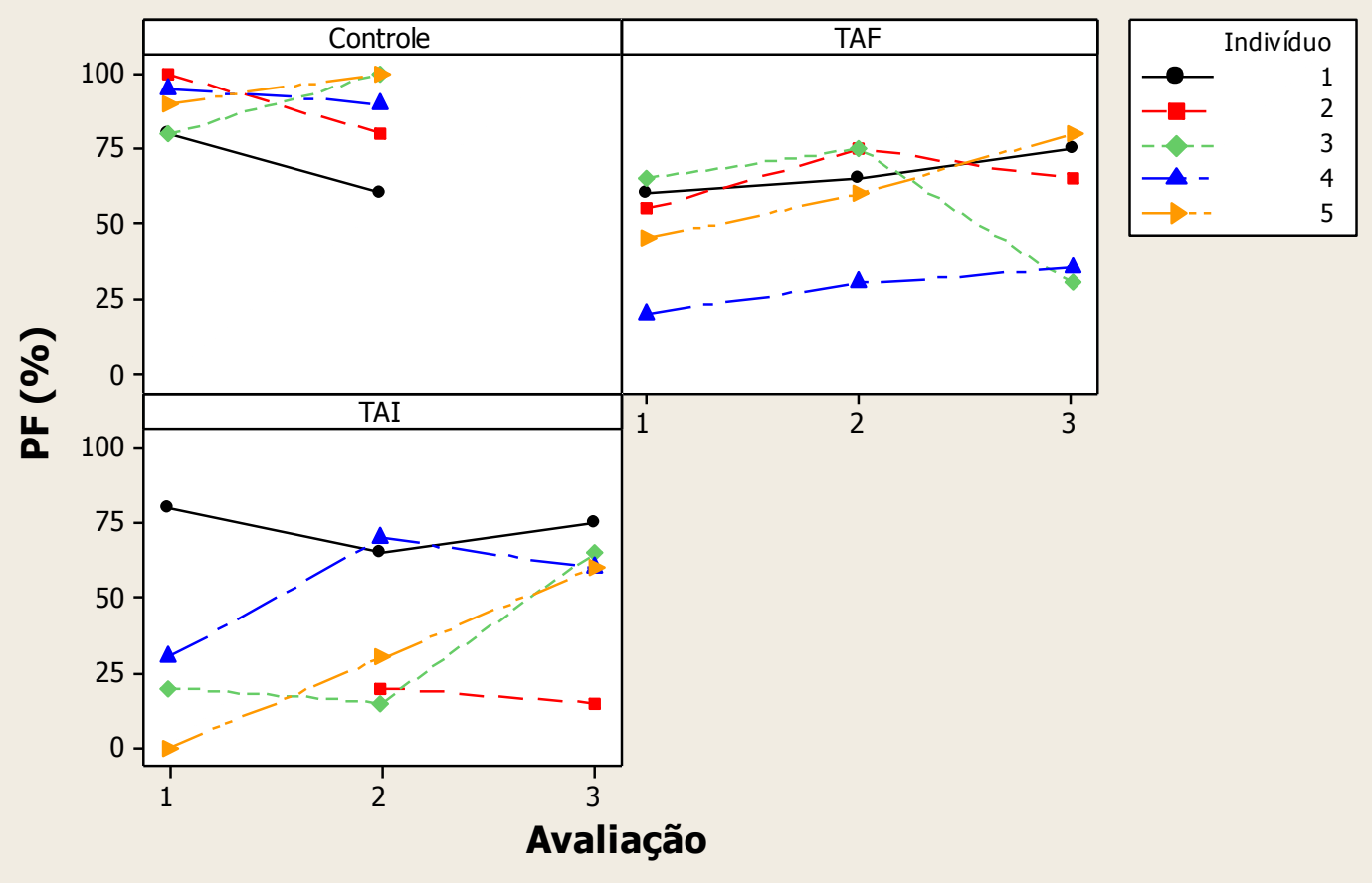

Legenda: $1=\mathrm{PA}(\mathrm{C}) 1 ; 2=\mathrm{PA}(\mathrm{C}) 2 ;$ e $3=\mathrm{PA}(\mathrm{C}) 3$

Figura 13 - Médias \pm erros padrão da porcentagem de acertos no PF por grupo e avaliação

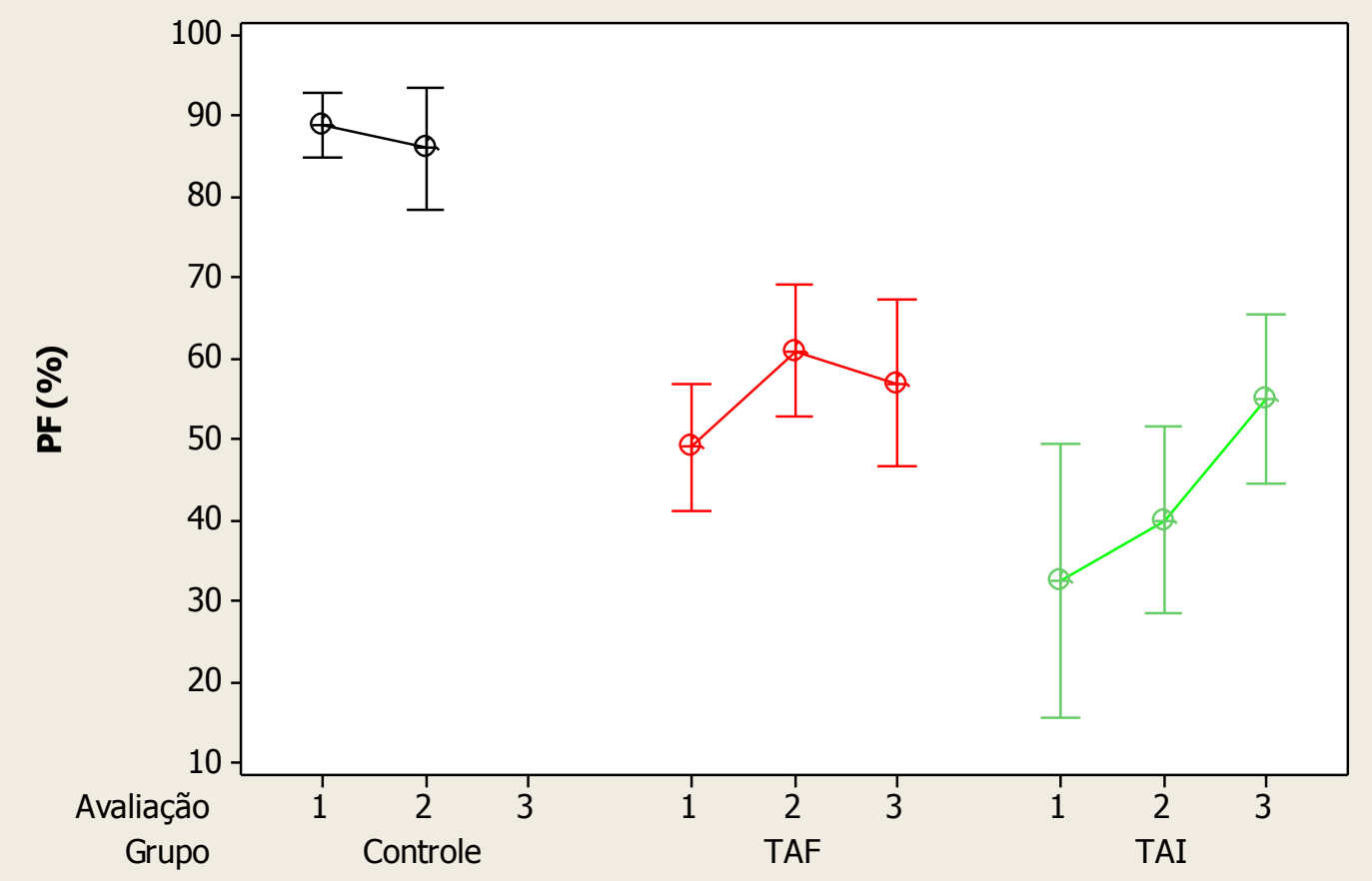

Legenda: $1=\mathrm{PA}(\mathrm{C}) 1 ; 2=\mathrm{PA}(\mathrm{C}) 2 ;$ e $3=\mathrm{PA}(\mathrm{C}) 3$ 
$\mathrm{Na}$ comparação dos três grupos e as duas primeiras avaliações obteve-se que:

- Não há diferença significativa entre as médias do PF nas duas avaliações $(p=0,165)$, independentemente do grupo $(p=0,349)$;

- As médias do PF não são iguais nos três grupos e a diferença entre os grupos independe da avaliação $(p=0,349)$. Na localização das diferenças entre as médias dos três grupos obteve-se que não há diferença significativa entre as médias do PF no $C$ e no TAF $(p=0,055)$, a média no $C$ é maior que no TAl $(p=0,003)$ e não há diferença significativa entre as médias no TAF e no TAI $(p=0,356)$. Nota-se que o $p$-valor obtido na comparação das médias no $C$ e no TAF foi próximo a 0,05 , e a falta de poder estatístico pode ser atribuída ao reduzido tamanho da amostra. Assim, pode-se concluir que não há diferença significativa entre as médias do PF no TAF e no TAI, e as médias nesses grupos são menores que no $\mathrm{C}$.

$\mathrm{Na}$ análise do TAF e TAI nas três avaliações os resultados obtidos foram:

- Não há diferença significativa entre as médias nas três avaliações $(p=0,076)$, independentemente do grupo $(p=0,323)$ (portanto não há diferença significativa entre a média na $3^{\underline{a}}$ avaliação e as médias nas duas primeiras);

- Não há diferença entre as médias dos grupos ( $p=0,243)$, independentemente da avaliação $(p=0,323)$ (portanto não há diferença significativa entre as médias no TAF e TAI na $3^{\text {a }}$ avaliação). 
- Análise dos resultados obtidos no Teste Padrão Temporal de Duração (PD)

Os valores das estatísticas descritivas na tabela 10 têm comportamento semelhante ao observado na análise dos testes anteriores: a média no Controle é maior que nos outros dois grupos e as médias no TAF e no TAI tendem a aumentar no decorrer das avaliações.

Tabela 10 - Estatísticas descritivas para a porcentagem de acertos no PD por grupo e avaliação

\begin{tabular}{cccccccc}
\hline Avaliação & Grupo & N & Média & Desvio padrão & Mínimo & Mediana & Máximo \\
\hline \multirow{4}{*}{ PA(C)1 } & C & 5 & 74,0 & 22,7 & 40,0 & 80,0 & 100,0 \\
& TAF & 4 & 29,1 & 20,3 & 1,5 & 32,5 & 50,0 \\
& TAl & 3 & 18,3 & 17,6 & 0,0 & 20,0 & 35,0 \\
\cline { 2 - 8 } & Total & 12 & 45,1 & 32,0 & 0,0 & 37,5 & 100,0 \\
\cline { 2 - 8 } PA(C)2 & C & 5 & 77,0 & 17,9 & 55,0 & 70,0 & 100,0 \\
& TAF & 5 & 41,0 & 18,8 & 10,0 & 45,0 & 60,0 \\
& TAl & 3 & 25,0 & 10,0 & 15,0 & 25,0 & 35,0 \\
\cline { 2 - 8 } & Total & 13 & 51,2 & 27,1 & 10,0 & 50,0 & 100,0 \\
\cline { 2 - 8 } PA(C)3 & TAF & 5 & 42,0 & 16,8 & 30,0 & 35,0 & 70,0 \\
& TAI & 5 & 37,0 & 14,0 & 25,0 & 30,0 & 60,0 \\
\cline { 2 - 8 } & Total & 10 & 39,5 & 14,8 & 25,0 & 32,5 & 70,0 \\
\hline
\end{tabular}


Perfis individuais da porcentagem de acertos no PD nos três grupos estão representados na figura 14. Os perfis médios podem ser visualizados na figura 15.

Figura 14 - Perfis individuais da porcentagem de acertos no PD por grupo e avaliação

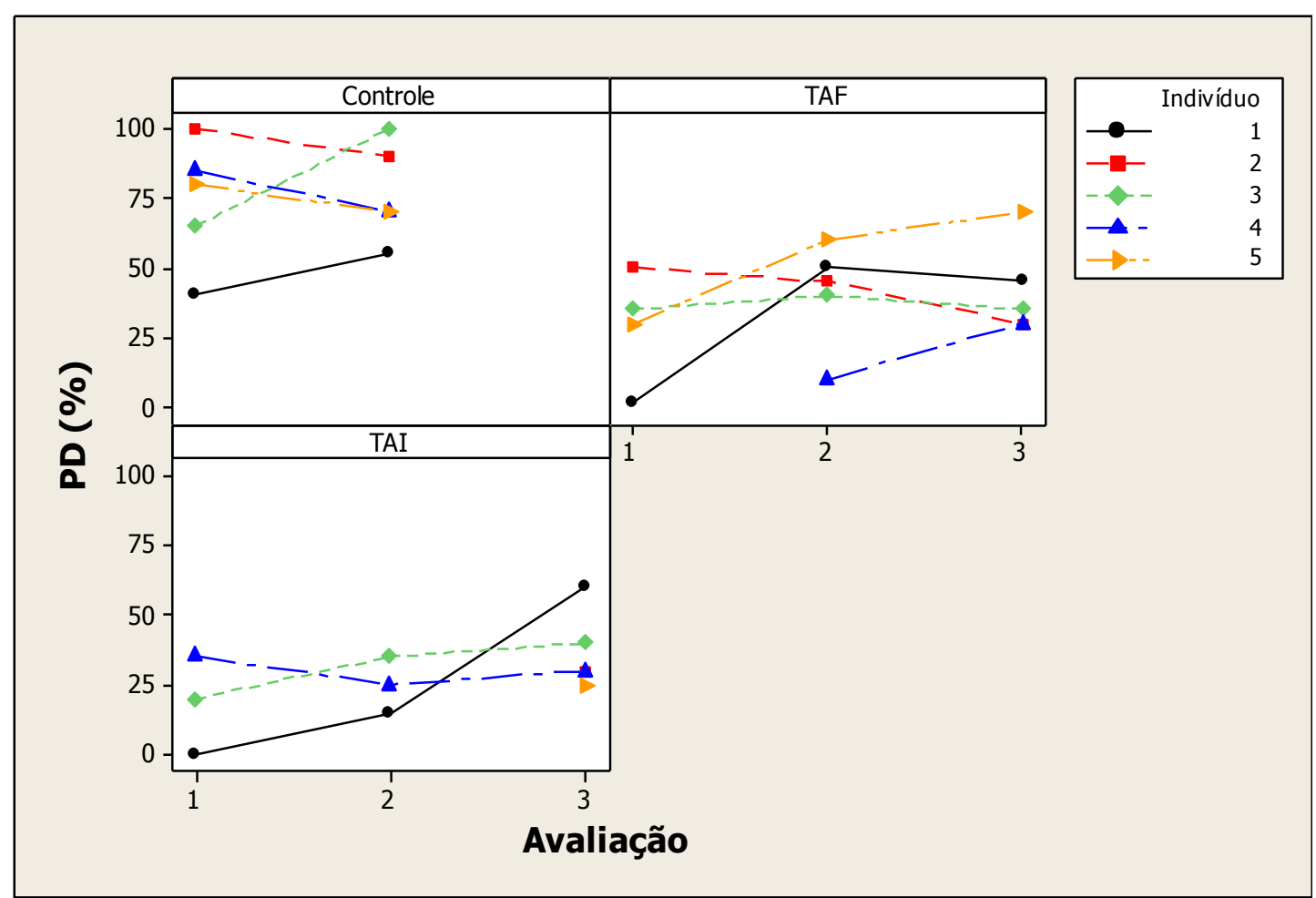

Legenda: $1=\mathrm{PA}(\mathrm{C}) 1 ; 2=\mathrm{PA}(\mathrm{C}) 2 ;$ e $3=\mathrm{PA}(\mathrm{C}) 3$ 
Figura 15 - Médias \pm erros padrão da porcentagem de acertos no PD por grupo e avaliação

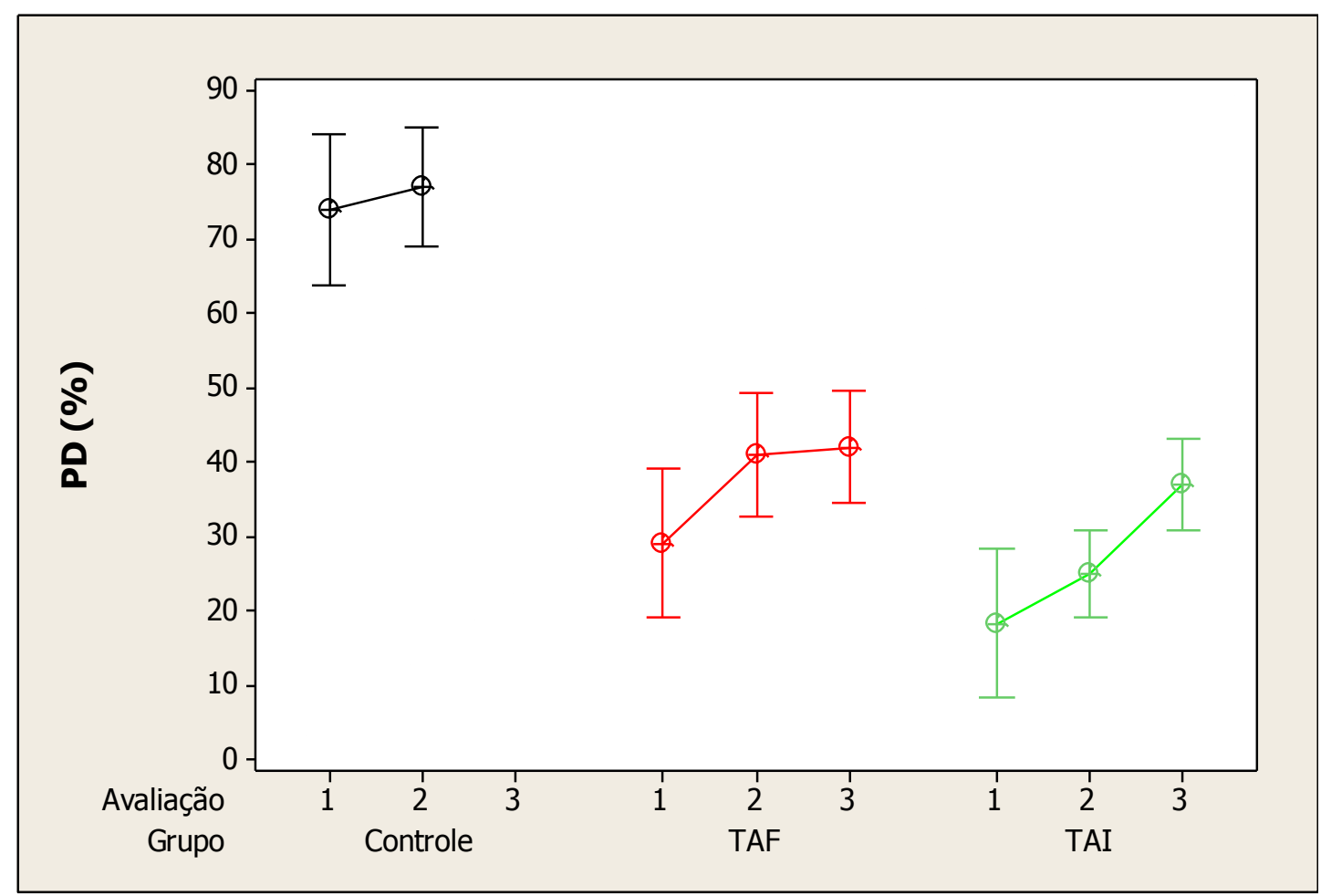

Legenda: $1=\mathrm{PA}(\mathrm{C}) 1 ; 2=\mathrm{PA}(\mathrm{C}) 2 ;$ e $3=\mathrm{PA}(\mathrm{C}) 3$

$\mathrm{Na}$ análise dos três grupos nas duas primeiras avaliações foram obtidos os seguintes resultados:

- Não há diferença significativa entre as médias da porcentagem de acertos nas duas primeiras avaliações $(p=0,151)$, independentemente do grupo $(p=0,511)$;

-As médias da porcentagem de acertos no PD não são todas iguais nos três grupos $(p=0,001)$, independentemente do grupo $(p=0,511)$. No prosseguimento da análise os resultados obtidos foram: a média no C é maior que no TAF $(p=0,012)$ e que no TAI $(p=0,002)$, e não há diferença significativa entre as médias no TAF e no TAl $(p=0,435)$. 
Os resultados obtidos na análise do TAF e TAI nas três avaliações foram:

-Não há diferença significativa entre as médias da porcentagem de acertos no PD nas três avaliações $(p=0,096)$, independentemente do grupo $(p=0,615)$ (portanto não há diferença significativa entre a média na $3^{\text {a }}$ avaliação e as médias nas duas primeiras);

-Não há diferença significativa entre as médias dos dois grupos $(p=0,131)$, independentemente da avaliação $(p=0,615)$ (portanto não há diferença significativa entre as médias no TAF e TAI na $3^{a}$ avaliação). 


\section{- Análise dos resultados obtidos no Teste Gaps in Noise (GIN)}

Valores de estatísticas descritivas para o Limiar no GIN (ms) por grupo e avaliação são apresentados na tabela 11. É possível observar que não há observações no TAI na 1aa avaliação. Na primeira avaliação a média e a mediana observadas são menores no Controle do que no TAF. Na segunda avaliação, as medianas observadas nos três grupos são iguais. As medianas observadas no TAF e no TAl na $3^{a}$ avaliação são iguais e os valores são os mesmos obtidos na $2^{2}$ avaliação.

Tabela 11 - Estatísticas descritivas para a Limiar no GIN (ms) por grupo e avaliação

\begin{tabular}{cccccccc}
\hline Avaliação & Grupo & N & Média & Desvio padrão & Mínimo & Mediana & Máximo \\
\hline \multirow{2}{*}{ PA(C)1 } & C & 5 & 3,8 & 0,8 & 3 & 4 & 5 \\
& TAF & 3 & 4,7 & 0,6 & 4 & 5 & 5 \\
\cline { 2 - 8 } & Total & 8 & 4,1 & 0,8 & 3 & 4 & 5 \\
\cline { 2 - 8 } PA(C)2 & C & 5 & 3,6 & 0,5 & 3 & 4 & 4 \\
& TAF & 4 & 3,8 & 0,5 & 3 & 4 & 4 \\
& TAl & 3 & 4,0 & 0,0 & 4 & 4 & 4 \\
\cline { 2 - 8 } PA(C)3 & Total & 12 & 3,8 & 0,5 & 3 & 4 & 4 \\
\cline { 2 - 8 } & TAF & 4 & 4,0 & 0,8 & 3 & 4 & 5 \\
& TAI & 3 & 4,0 & 0,0 & 4 & 4 & 4 \\
\cline { 2 - 8 } & Total & 7 & 4,0 & 0,6 & 3 & 4 & 5 \\
\hline
\end{tabular}

Perfis individuais do Limiar no GIN nos três grupos estão representados na figura 16. Valores individuais e medianos são encontrados na figura 17. 
Figura 16 - Perfis individuais do Limiar no GIN (ms) por grupo e avaliação

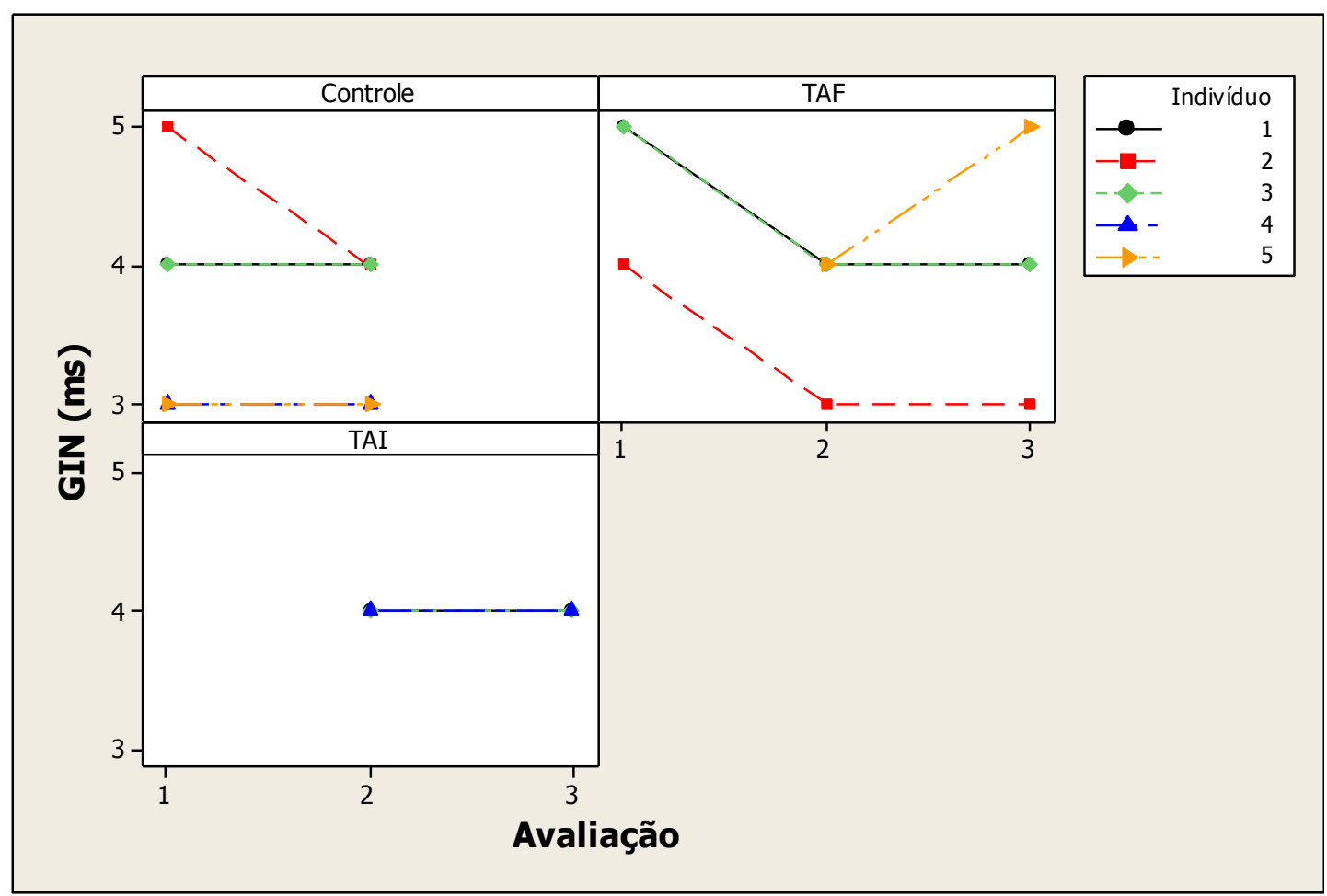

Legenda: $1=\mathrm{PA}(\mathrm{C}) 1 ; 2=\mathrm{PA}(\mathrm{C}) 2 ;$ e $3=\mathrm{PA}(\mathrm{C}) 3$

Figura 17 - Valores individuais e medianos do Limiar no GIN (ms) por grupo e avaliação

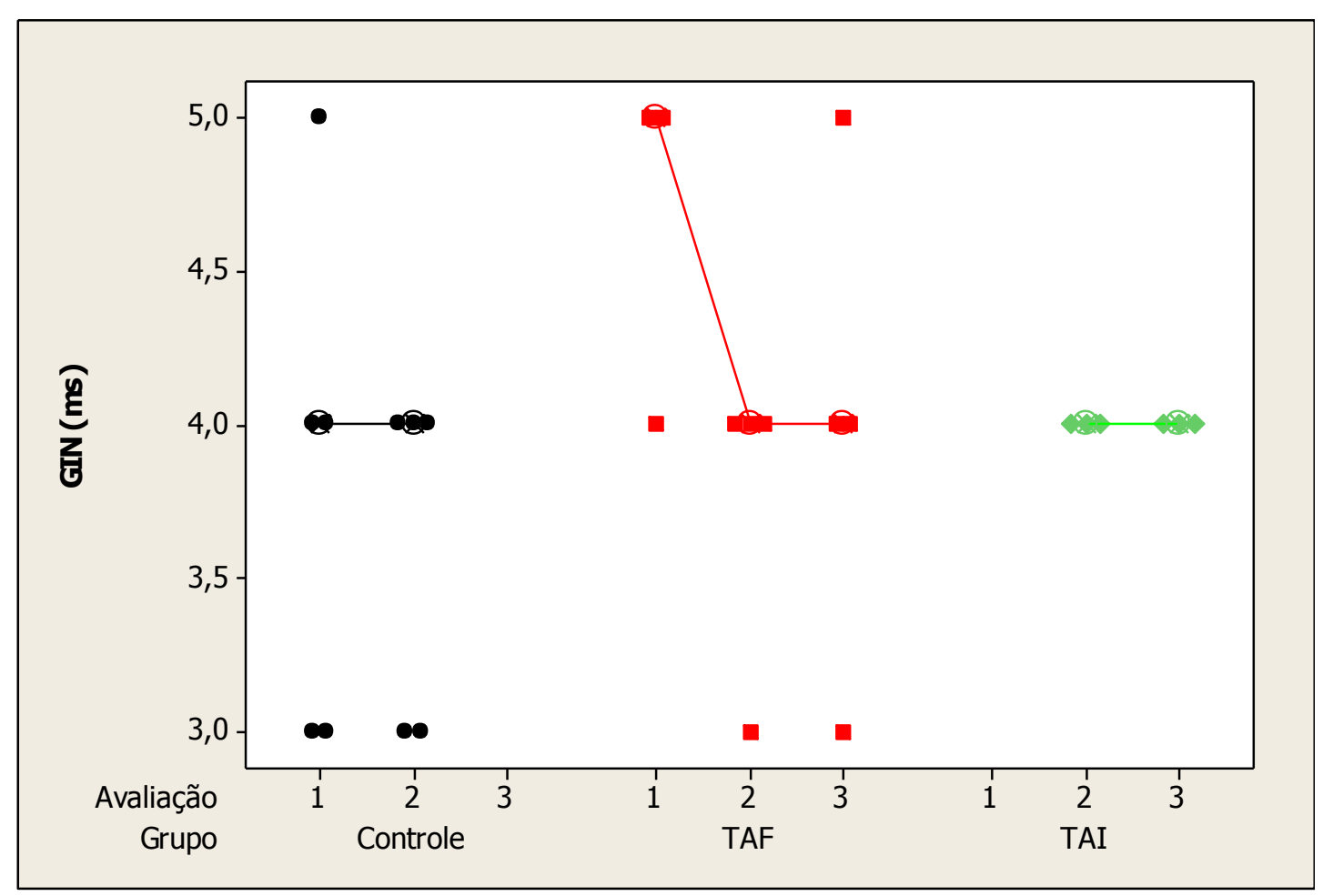

Legenda: $1=\mathrm{PA}(\mathrm{C}) 1 ; 2=\mathrm{PA}(\mathrm{C}) 2 ;$ e $3=\mathrm{PA}(\mathrm{C}) 3$ 
$\mathrm{Na}$ comparação dos grupos em cada avaliação foram obtidos os resultados:

- Não há diferença significativa entre as distribuições do TAF e do C na primeira avaliação $(p=0,156)$;

- Não há diferença significativa entre as distribuições dos três grupos na segunda avaliação $(p=0,480)$;

- Não há diferença significativa entre as distribuições do TAF e do TAI na terceira avaliação $(p>0,999)$.

$\mathrm{Na}$ comparação entre as avaliações em cada grupo, os resultados obtidos foram:

- No C não há diferença significativa entre as distribuições do Limiar nas duas avaliações $(p=0,317)$;

- No TAF não há diferença significativa entre as distribuições do Limiar nas três avaliações $(p=0,050)$;

- No TAI não há diferença significativa entre as distribuições do Limiar na $2^{\mathrm{a}}$ e $3^{\mathrm{a}}$ avaliações $(p=1,000)$. 
Discussão 


\section{DISCUSSÃO}

O primeiro aspecto que se pretende discutir envolve o índice PCC-R. A distribuição deste índice, tanto para a imitação como para a nomeação, ao levarmos em conta os três grupos da pesquisa, mostra diferença importante entre o grupo controle e os outros dois grupos (TAF e TAI). Embora tanto no grupo TAF como no TAI, haja havido indivíduos com valores de PCC-R próximos de $100 \%$, nota-se que a média do desempenho fonológico das crianças que apresentam TPA(C) foi menor do que o das crianças do grupo Controle (Figuras 2 e 3). Além disso, embora sem significância estatística, os índices de PCC-R (nomeação e imitação) foram menores no grupo TAI, do que no grupo TAF. Já na comparação entre o grupo Controle e o TAl houve diferença estatística no PCC-R imitação e nomeação.

Tal observação pode indicar relação entre o índice PCC-R e o TPA(C). Ou seja, se a criança apresenta índice de PCC-R muito baixo, a chance de apresentar $\operatorname{TPA}(C)$ pode ser maior. Isso não significa dizer que um índice de PCC-R próximo de $100 \%$ exclui por si só a possibilidade de a criança apresentar TPA $(\mathrm{C})$, mas o contrário parece ser um indício de haver comorbidade entre estes dois transtornos fonoaudiológicos. Tal observação corrobora as afirmações de vários autores que descrevem dificuldades de percepção auditiva em crianças que apresentam alterações de fala (Fey, 1992; Gierut, 1998; McArthur , Bishop, 2004 e 2005). McArthur et al. (2009), 
e também nos fornecem explicação para este achado ao defenderem a ideia de haver estreita relação entre o $\operatorname{TPA}(C)$ e a alteração de fala, pelo fato de o primeiro interferir na formação estável da representação fonêmica no cérebro e na percepção de fala, dificultando assim o aprendizado da fonologia, da sintaxe e semântica.

Além disso, assim como afirma Bellis (2002), aliar os resultados dos testes do $\mathrm{PA}(\mathrm{C})$ à avaliação de linguagem e cognição favorece um direcionamento mais adequado para a reabilitação. Neste sentido, uma sugestão para trabalhos futuros seria parear o índice de PCC-R das crianças acometidas pelo TPA $(\mathrm{C})$, com 0 intuito de estabelecer diretrizes mais específicas em relação ao melhor tratamento e, consequentemente, ao melhor prognóstico para estas crianças. De acordo com Wertz et al. (2002), a efetividade do tratamento está diretamente relacionada com a especificidade do diagnóstico.

Ao considerarmos os achados em relação ao teste Identificação de Figuras, é possível notar que nos grupos TAF e TAl, os resultados foram mais heterogêneos que no grupo Controle (Figuras 4 e 6). Embora entre o $\mathrm{PA}(\mathrm{C}) 1$ e o $\mathrm{PA}(\mathrm{C}) 2$, não haja havido qualquer intervenção fonoaudiológica, observa-se bastante variabilidade no desempenho das crianças, inclusive com desempenhos piores à segunda avaliação $(\mathrm{PA}(\mathrm{C}) 2)$. Para a piora de desempenho, tanto no $\mathrm{PA}(\mathrm{C}) 2$ (quando as crianças já haviam apresentado desempenhos melhores anteriormente), como no $\mathrm{PA}(\mathrm{C}) 3$ (que ocorreu após o treino auditivo), entendemos que a falta de motivação ou cansaço da criança são os fatores que melhor explicam estes achados. 
Ao compararmos as orelhas no teste Identificação de Figuras (Figuras 5 e 7), observa-se que a habilidade de fechamento está melhor na OE. Para os grupos C e TAI, os valores para o desempenho por orelha ficaram mais próximos.

O desempenho das crianças dos grupos TAl e TAF no teste IF parece indicar grande dificuldade na habilidade auditiva de fechamento auditivo. Desta maneira, enfocar tal habilidade no treino auditivo oferecido a crianças com TF e TPA(C) pode favorecer a reabilitação fonoaudiológica.

Em relação ao teste Dicótico de Dígitos (Figuras 8 e 10), para as duas orelhas, de forma semelhante ao teste Identificação de Figuras, o desempenho dos grupos TAF e TAl variou mais ao longo das três avaliações $(\mathrm{PA}(\mathrm{C}) 1,2$ e 3), do que o desempenho do grupo $C$ nas avaliações do $\mathrm{PA}(\mathrm{C}) 1$ e 2. Neste teste também foi observada piora de desempenho em algumas crianças nos três grupos, tanto ao compararmos os resultados das avaliações do $\mathrm{PA}(\mathrm{C}) 1$ e $\mathrm{PA}(\mathrm{C}) 2$, como do $\mathrm{PA}(\mathrm{C}) 2$ e $\mathrm{PA}(\mathrm{C}) 3$. As variáveis consideradas para explicar estes achados foram eventual cansaço ou falta de motivação por parte da criança. Considerando as médias de desempenho no teste Dicótico de Dígitos (Figuras 9 e 11), entre os grupos TAF e TAI, nota-se piora de desempenho para a OD, após o TAI. Este comportamento não foi observado no grupo TAF e tampouco na OE para ambos os grupos.

Ainda considerando o teste Dicótico de Dígitos, tanto para a OD, como para a OE, a diferença no desempenho das crianças na avaliação do $\mathrm{PA}(\mathrm{C}) 3$ foi significativa entre o grupo TAF e TAI. Como esta diferença não havia sido notada no $\mathrm{PA}(\mathrm{C}) 1$ e 2, pode-se dizer que, após o TAF, as 
crianças demonstraram melhora mais efetiva na habilidade de figura-fundo do que o grupo que foi submetido ao TAl.

Outra consideração que precisa ser realizada acerca do teste Dicótico de Dígitos é o fato de o TAl não envolver tarefas dicóticas em quaisquer das atividades propostas para este treino. A explicação para a ausência deste tipo de tarefa no treino informal se dá a partir da intenção em produzir uma situação de pesquisa que pudesse ser facilmente replicada no consultório ou em ambiente diverso da cabina acústica.

Considerando o desempenho das crianças no teste Padrão de Frequência, é preciso salientar que, no grupo TAl, uma criança não conseguiu compreender o teste durante a avaliação do $\mathrm{PA}(\mathrm{C}) 1$, apresentando respostas somente a partir do PA(C)2 (Figura 12).

Assim como nos testes anteriormente descritos, houve variação maior nos resultados dos grupos TAF e TAI. O grupo $\mathrm{C}$ apresentou desempenho mais homogêneo que os outros. Nos três grupos houve piora de desempenho em algumas crianças. Comparando a avaliação do PA(C)1 e $\mathrm{PA}(\mathrm{C}) 2$, observou-se piora em três crianças do grupo $\mathrm{C}$, e duas crianças do grupo TAl. Já na comparação do desempenho no $P A(C) 2$ e $P A(C) 3$, observou-se piora nos resultados em duas crianças do grupo TAF e em duas crianças do grupo TAl.

Mesmo após a realização do treino auditivo, o grupo TAF apresentou piora na média de desempenho para o teste Padrão de Frequência (Figura 13). Com isso, embora na avaliação inicial $(P A(C) 1)$ o desempenho dos grupos TAF e TAl tenha sido diferente ( $49 \%$ e $32,5 \%$, respectivamente), na 
avaliação do $\mathrm{PA}(\mathrm{C}) 3$, as médias destes dois grupos se aproximaram bastante $(\mathrm{TAF}=57 \%$ e $\mathrm{TAl}=55 \%)$.

Ao levarmos em conta o desempenho das crianças no teste Padrão de Duração (Figura 14) temos que inicialmente salientar que para este também houve crianças que não foram capazes de realizá-lo na avaliação do $\mathrm{PA}(\mathrm{C}) 1$ (uma criança do grupo TAF e duas do grupo TAI) e no $\mathrm{PA}(\mathrm{C}) 2$ (as mesmas duas crianças do grupo TAI). A análise deste dado, isoladamente, já nos dá a ideia de que houve aprendizado na tarefa de ordenação temporal e transferência inter- hemisférica das crianças que participaram da pesquisa, uma vez em que elas não eram capazes de realizar a tarefa e, posteriormente passaram a ser.

Diferentemente do que ocorreu para os outros testes (IF, DD e PF), o desempenho do grupo Controle no teste Padrão de Duração não pareceu mais homogêneo que nos outros grupos. Levando em conta a comparação da faixa de normalidade entre os testes Padrão de Frequência e Padrão de Duração (Balen, 2001), pode-se concluir que para crianças falantes do português, o teste Padrão de Duração é mais difícil que o teste Padrão de Frequência. Talvez por isso mesmo o desempenho do grupo Controle tenha sido também heterogêneo; tais achados parecem concordar com os resultados de Frederigue-Lopes et al. (2010). Além disso, como afirmam Muniz et al. (2007), crianças que apresentam desvios fonológicos podem apresentar alteração no processamento temporal.

De um modo geral, as respostas obtidas pelas crianças dos grupos TAF e TAl nas três avaliações do $\operatorname{PA}(C)$ (1, 2 e 3 ) foram bastante 
heterogêneas. Estes dados entram em concordância com os achados de Schochat et al. (2000) que também encontraram bastante variabilidade nas respostas de crianças entre 7 e 11 anos e 11 meses.

Ao levarmos em conta que os indivíduos em nosso estudo apresentavam TF e que este pode acarretar dificuldades escolares, é possível sugerir que as crianças participantes também apresentem atraso na maturação das habilidades auditivas, assim como sugerido por Neves (2005) em seu estudo.

Embora o desempenho do grupo TAl para o teste Padrão de Duração tenha sido pior que o do grupo TAF na avaliação do $P A(C) 1$, não houve diferença estatística entre estes dois grupos. No entanto, ambos os grupos se diferenciaram estatisticamente do grupo Controle (tabela 10). Após o TA, tanto o TAI como o TAF não apresentaram diferenças estatísticas, mas é possível observar que a diferença que havia entre as médias destes dois grupos diminuiu após o TA. Na avaliação do $\mathrm{PA}(\mathrm{C}) 1$ os grupos TAF e TAI apresentaram médias de acerto de 29,1\% e 18,3\%, respectivamente; após o TA, no entanto, as médias apresentadas pelo grupo TAF foi $42 \%$ e pelo TAI foi 37\%). O grupo TAF apresentou melhora de desempenho muito discreta após o TA (comparando-se com o do PA(C)2 que foi igual a 41\%), já o TAI, embora sem diferença estatística, demonstrou maior variação na capacidade de realizar a tarefa de ordenação temporal e transferência inter-hemisférica após o treino.

Ao se levar em conta o teste GIN, primeiramente é importante lembrar que o desempenho das crianças neste teste não influenciou sua participação 
em qualquer um dos grupos. Ou seja, independentemente do resultado alcançado pela criança neste teste, sua inclusão no grupo Controle ou TAF e TAI não se alterou. Foi o desempenho nos quatro outros testes que fizeram parte da bateria de avaliação (IF, DD, PF e PD) que estabeleceu se a participação seria no grupo C (crianças com alteração em no máximo um teste) ou nos grupos TAF e TAI (crianças com resultados alterados em pelo menos dois testes). Desta maneira, o interesse no teste GIN esteve voltado para a verificação de eventuais mudanças nos resultados dele após a realização do TA (tanto formal, quando informal). Somente para o grupo Controle, todas as crianças foram capazes de realizá-lo (Figura 16). Considerando as crianças que foram capazes de responder ao teste, houve diminuição do tempo necessário para a detecção de gaps em três crianças do grupo TAF do $\mathrm{PA}(\mathrm{C}) 1$ para o 2. Após o TAF, no entanto, o limiar se manteve em três crianças e aumentou em uma. Além disso, pode-se notar que, embora a compreensão do teste tenha sido excessivamente difícil para algumas crianças, a partir do momento em que a tarefa era entendida, os limiares de detecção já se mostravam dentro da faixa de normalidade estabelecida para faixas etárias inclusive maiores do que as deste estudo. Esta observação concorda com estudos anteriores em que não foram notadas diferenças significativas de desempenho com o aumento da idade (Balen et al., 2009; Perez , Pereira, 2010 e Amaral, Colella-Santos, 2010 e Barreira et al., 2011).

A partir dos dados obtidos com o teste GIN, pode-se supor não ter havido variação no desempenho após o TA (formal e informal). Além disso, 
uma criança pertencente ao grupo TAF apresentou limiar de detecção de gaps maior após o treino. Uma explicação possível para isso é o fato de a criança estar eventualmente cansada ou desmotivada durante o PA(C)3.

Outra observação pertinente é o fato de que, embora a diferença não tenha sido estatisticamente significante, a média do desempenho das crianças do grupo TAl, tanto na OD, quanto na $\mathrm{OE}$, foi sempre pior que a do grupo TAF ao considerarmos todos os testes aplicados para avaliar o desempenho auditivo.

Além disso, em relação ao grupo Controle, o grupo TAl apresentou diferença estatística significante no que se refere às médias do desempenho na avaliação do $\mathrm{PA}(\mathrm{C})$. O grupo TAF, embora tenha apresentado desempenho menor que o grupo $\mathrm{C}$, manteve-se sempre como intermediário entre o grupo Controle e o grupo TAl, com única exceção para o teste Padrão Temporal de Duração.

Em todos os testes aplicados, foi possível perceber que a avaliação comportamental do $\mathrm{PA}(\mathrm{C})$ diferenciou claramente os grupos entre normais e alterados, em todas as situações. Este fato reforça a importância da avaliação comportamental, mesmo considerando sua subjetividade em relação às respostas solicitadas.

Ambos os treinos auditivos aplicados nesta pesquisa (treino auditivo formal e informal) possibilitaram melhora de desempenho nos testes comportamentais do PA(C). Esta observação concorda com Gillam et al. (2008) que ao investigar diferentes abordagens terapêuticas em crianças com alterações de linguagem, apesar de ter notado melhora, não conseguiu 
identificar uma abordagem mais eficaz que outra. Vários são os autores que também identificaram melhora no desempenho auditivo de indivíduos submetidos a TA (Tallal, 1996; Beck et al., 1997; Tremblay et al., 1997; Musiek, Schochat, 1998; Kraus, 1999; Putter-Katz et al., 2002; Hayes et al., 2003; Zalcman, Schochat, 2007; Moncrief, Wertz, 2008; Murphy, 2008; Stevens et al., 2008; Samelli, Mecca, 2010; e Pinheiro, Cappellini, 2010). Desta maneira, o TA se apresenta como uma possibilidade eficaz de reabilitação de crianças com TPA(C) (Moore, Amitay, 2007 e Kricos, McCarthy, 2007).

Além disso, ao ser observada melhora nas respostas comportamentais dadas pelas crianças submetidas ao TA, supõe-se ter ocorrido aprendizagem e, portanto, plasticidade neural. Este fato também está em consonância com muitos autores (Kraus et al., 1995; AllumMecklenburg, 1996; Musiek, Berge, 1998; King, 1999; Grafman, 2000; Fujioka et al., 2006 e Tremblay, 2007).

O fato de o TAl também ter proporcionado melhora no desempenho auditivo é de extrema importância, por ampliar a possibilidade de aplicação em crianças com TPA $(C)$, uma vez que o TAl é menos dependente de equipamentos específicos.

A questão da motivação da criança também merece atenção. A avaliação comportamental do $\mathrm{PA}(\mathrm{C})$, assim como o treino auditivo (formal ou informal) depende do estado geral da criança e também de fatores como atenção, motivação, memória e linguagem. Desta forma, seus resultados precisam ser analisados levando-se em conta tais variáveis. Berlau e 
Weinberger (2008) referem que o aprendizado é diretamente afetado pela motivação. Para Bellis (2002), pelo fato de a eficácia da intervenção fonoaudiológica no TPA(C) ser acessada a partir de habilidades funcionais, mais do que por habilidades ou processos auditivos, é possível que a intensidade e frequência do tratamento e a motivação do indivíduo sejam mais eficientes do que a habilidade auditiva treinada especificamente.

Diferentemente da pesquisa realizada por Moncrieff e Wertz (2008), em nosso estudo não houve a intenção de realizar diferenciação do déficit por orelha. Além disso, a amostra era reduzida $(\mathrm{n}=$ cinco em cada um dos grupos) para comportar qualquer subdivisão além da previamente programada. Futuramente talvez seja interessante realizar a separação das crianças considerando o desempenho de cada orelha, na tentativa de especificar mais os resultados.

Outro aspecto que julgamos relevante refere-se à complementação do TA, que pode ser realizada na escola ou em casa. Em nossa pesquisa, optamos por realizar somente o TA controlado por nós e não incluir quaisquer atividades que pudessem ser realizadas por pais e professores, por entendermos que a falta de controle acerca da realização de tais atividades, poderia gerar viés em nossas análises. No entanto, concordamos com outros autores que referem ser esta uma importante complementação ao TA realizado pelo fonoaudiólogo (Musiek, Schochat, 1998; Chermak, Musiek, 2002; Chermak, 2002 e Samelli, Mecca, 2010).

Em função do TF, talvez as crianças submetidas ao TA (seja ele formal ou informal) necessitem mais que oito sessões para que os 
resultados possam mostrar-se mais consistentes, assim como verificado por Samelli e Mecca (2010).

O fato do número de sessões não ter sido suficiente para que os indivíduos alcançassem a faixa de normalidade estabelecida para cada teste, pode ser também explicado a partir de um paralelo com as considerações de Domínguez Ugidos et al. (2001) que, em seus estudos sobre a utilização de ruído branco durante o TA, destacaram que o tempo necessário para o treino e aprendizado se relaciona diretamente com a complexidade da tarefa. Considerando as crianças do grupo TAI, pelo fato de o desempenho à avaliação do $\mathrm{PA}(\mathrm{C}) 1$ ter sido muito abaixo do esperado, é possível supor que as tarefas do treino auditivo informal tenham sido demasiadamente complexas. Esta é uma limitação encontrada no presente estudo, uma vez que, se por um lado houve a tentativa de padronizar a estimulação com o intuito de favorecer a posterior análise, por outro, o fato de serem tarefas pré-fixadas dificultou a adequação do treino às necessidades de cada indivíduo. Neste sentido, autores salientam a necessidade de que a reabilitação do $\operatorname{TPA}(C)$ precisa ser direcionada às dificuldades de cada sujeito (Baran, 2002; e AAA, 2010).

A melhora mais efetiva observada no grupo TAF (embora sem diferença estatística) pode ser explicada pelo fato de o TAF se utilizar de estímulos e situações muito semelhantes à própria avaliação comportamental do PA(C), concordando com as colocações de DomínguezUgidos et al. (2001) que defendem que quanto maior a semelhança entre as características e condições de realização do treino e os testes, maior a 
chance de aprendizado. Ainda para estes autores, quanto maior a familiaridade com o estímulo, mais rápida é a aprendizagem. Para Berlau e Weinberger (2008) e Thibodeau (2007), quando o som adquire um significado, seu processamento se dá de forma diferenciada. Tais afirmações reforçam a importância do TAl que pode apropriar-se de situações bastante cotidianas da criança para ser realizado. Kraus e Chandrasekaran (2010) e Chermak (2010) também referem que o aprendizado musical também acarreta grande aprimoramento do processamento auditivo por reforçar funções como atenção, aprendizagem, comunicação e memória. Deste modo, a música também pode ser considerada como um recurso que auxilia o SNC em relação à aptidão auditiva.

Em função do extenso período de coleta, a reavaliação pós treino $(\mathrm{PA}(\mathrm{C}) 3)$ precisou ocorrer uma semana após o término do treinamento. Entendemos que, prever acompanhamento das crianças que realizaram TA em intervalos mais longos após o término deste pode trazer mais informações acerca dos benefícios alcançados.

O fato das crianças deste estudo terem passado por avaliação de linguagem é algo que pode auxiliar no direcionamento terapêutico da prática fonoaudiológica. Pelo fato de o $\operatorname{TPA}(\mathrm{C})$ atingir uma gama bastante inespecífica de pessoas e de apresentar comorbidades também de forma ampla, pesquisas que estabeleçam relação entre o $\operatorname{TPA}(C)$ e outras alterações podem trazer resultados que indiquem com maior especificidade o tratamento mais indicado nos diferentes casos. Em concordância com esta 
análise, Bellis (2002) refere que aliar os resultados dos testes do PA(C) à avaliação de linguagem e cognição promove um direcionamento mais adequado para a reabilitação, além de facilitar o entendimento sobre como esta alteração dificulta o aprendizado, a linguagem e a comunicação do indivíduo. Para ela, como a terapia envolve o investimento de tempo e dinheiro, são necessárias pesquisas para determinar qual a frequência necessária para atingir os resultados esperados.

A partir deste estudo e de acordo com afirmações de outros autores, pode-se supor que a intervenção no TPA(C) que leva em conta tanto o TAF, como o TAl aumenta as possibilidades de sucesso na reabilitação de sujeitos acometidos por tal alteração (Chermak et al., 1998; Chermak, Musiek, 2002 e Chermak, 2002). Além disso, a prática do TA em indivíduos com TF amplia a possibilidade de reabilitação destas crianças, podendo torná-la mais efetiva, ao se considerar que a relação entre estas duas alterações pode ser bastante estreita. (McArthur, Bishop, 2004 e 2005; McArthur et al. 2009; e Mota, Melo Filha, 2009).

Considerando a relação que existe entre TF e TPA(C) e conhecendo as dificuldades que ambos os transtornos podem acarretar no aprendizado da leitura e escrita, faz-se premente a necessidade de estudos que favoreçam a detecção e intervenção precoce destas crianças, com o intuito de minimizar os prejuízos escolares que podem enfrentar. Tal conceito reafirma as proposições de Chermak e Musiek (1992) e Carvallo (1997) que também acreditam que a intervenção abrangente e precoce são fundamentais para o desenvolvimento infantil. Além disso, identificar e tratar 
- TPA(C) antes que a criança seja alfabetizada, parece condição fundamental para evitar maiores dificuldades no aprendizado da leitura e escrita.

Neste sentido, a American Academy of Audiology (2010) publicou um manual de orientações para o diagnóstico e tratamento do TPA(C) enfatizando a necessidade de desenvolvimento e investigação sobre a validade e eficiência de testes do $\mathrm{PA}(\mathrm{C})$ em crianças menores que sete anos.

A partir deste estudo e de acordo com afirmações de outros autores, pode-se supor que a intervenção no TPA(C) que leva em conta tanto o TAF, como o TAl aumenta as possibilidades de sucesso na reabilitação de sujeitos acometidos por tal alteração (Chermak et al., 1998; Chermak, Musiek, 2002 e Chermak, 2002). Além disso, a prática do TA em indivíduos com TF amplia a possibilidade de reabilitação destas crianças, podendo torná-la mais efetiva, principalmente ao se considerar que a relação entre estas duas alterações pode ser bastante estreita. (McArthur, Bishop, 2004 e 2005; McArthur et al. 2009; e Mota, Melo Filha, 2009)

Em função dos questionamentos levantados sugere-se que estudos levando em conta um maior número de sujeitos sejam realizados.

A partir dos resultados encontrados neste estudo, sugere-se a realização de avaliação eletrofisiológica em trabalhos futuros, como maneira de complementar os achados e direcionar as pesquisas. 
Além disso, seria interessante também verificar se o treinamento Auditivo aplicado neste estudo (seja ele formal ou informal) foi capaz de causar impacto positivo nas alterações de fala apresentadas pelas crianças. 
Conclusões 


\section{CONCLUSÕES}

A partir dos resultados encontrados em nosso estudo é possível concluir que:

1) Houve relação entre o índice do PCC-R e o TPA(C);

2) Os testes comportamentais do $P A(C)$ foram eficazes em diferenciar o grupo Controle dos grupos TAF e TAI;

3) O treino auditivo informal proporcionou variação positiva no desempenho auditivo de crianças com TF e TPA $(C)$, gerando benefícios similares aos alcançados a partir do treino auditivo formal; 


\section{REFERÊNCIAS}

AAA - American Academy of Audiology. Clinical Practice Guidelines Guidelines for the Diagnosis, Treatment and Management of Children and Adults with Central Auditory Processing Disorder. 2010. Disponível no sítio: http://www.audiology.org/resources/documentlibrary/Pages/CentralAuditoryP rocessingDisorder.aspx

Almeida, CIR, Campos, MI e Almeida, RR. Logoaudiometria Pediátrica (PSI). Pediatric Intelligibility test. Rev Bras Otorrinolaringol. 1988; 54: 73 - 6.

Allum - Mecklenburg, D J e Babighian, G. Cochlear implant as an indicator of auditory plasticity in humans. In: Salvi, RJ, Henderson, D, Fiorino, F, Colleti, V. Auditory System Plasticity and Regenaration. New York: Thieme; 1996. p. $395-404$.

Amaral, MIR e Colella - Santos, MF. Temporal Resolution: performance of school-aged children in the GIN - Gaps-in-noise test. BJORL. 2010; 76(6): $745-752$.

Auditec. Evaluation manual of pitch pattern sequence and duration pattern sequence. St. Louis: Auditec; 1997.

ASHA - American Speech-Language-Hearing Association. Central Auditory Processing: Current Status of Research and implications for clinical practice. Am J Audiol.1996; 5: 41 - 54.

ASHA - American Speech-Language-Hearing Association. (Central) Auditory Processing disorders [Technical Report]. 2005. Recuperado através do sítio: http://www.asha.org/docs/html/TR2005-00043.html

Balen, SA. Reconhecimento de padrões auditivos de frequência e de duração: desempenho de crianças escolares de 7 a 11 anos [tese]. São Paulo: Universidade de São Paulo; 2001.

Balen, SA, Liebel, G, Boeno, MRM e Mottecy, CM. Resolução temporal de crianças escolares. Rev Cefac. 2009; 11(1): 52 - 61.

Baran, JA e Musiek, FE. Avaliação comportamental do Sistema Nervoso Auditivo Central. In: Musiek, FE e Rintelman, WF. Perspectivas atuais em avaliação auditiva. Barueri: Manole; 2001. p. 371 - 409.

Baran, JA. Managing Auditory Processing Disorders in Adolescents and Adults. Semin Hear. 2002; 23(4):327 - 35. 
Barreira, HAB, Silva, M, Branco-Barreiro, FC, Samelli, AG. Desempenho de escolares brasileiros de 7 a 12 anos no GIN. Rev Soc Br Fono. 2011 [no prelo].

Beck, CS, Calichman, F, Gandra, LPF, Machado, AH e Pereira, LD. Estimulação do Processamento Auditivo Central em escolares de 7 a 10 anos de idade. Pro Fono. 1996; 8(2): 45 - 50.

Bellis, TJ. Developing Deficit-Specific Intervention Plans for Individuals with Auditory Processing Disorders. Semin Hear. 2002; 23(4): 287 - 95.

Berlau, KM e Weinberger, NM. Learning stategy determines auditory cortical plasticity. Neurobiol Learn Mem. 2008; 89: 153 - 66.

Bocca, E, Calearo, C e Cassinari, V. A New Method for Testing Hearing in Temporal Lobe Tumours: Preliminary report. Acta Oto-Laryngol.1954; 44:3, $219-21$.

Borges, ACLC. Dissílabos alternados (SSW). In: Pereira, LD e Schochat, E. Processamento Auditivo Central - Manual de Avaliação. São Paulo: Lovise; 1997. p. 169-178.

Borges, CF. Processamento temporal auditivo em crianças com transtorno de leitura. [dissertação]. São Paulo: Faculdade de Medicina, Universidade de São Paulo; 2005.

Broadbent, DE. Listening to one of two synchronous messages. J Exp Psychol.1952; 44: 51 - 5 .

Broadbent, DE. The role of auditory localization in Attention and Memory span. J Exp Psychol. 1954; 47: 191 - 6.

Campbell, TF, Dollaghan, C, Janosky, JE e Adelson, PD. A performance curve assessing change in Percentage of consonants correct- revised (PCCR). J Speech Lang Hear Res. 2007; 50:1110 - 9.

Carvallo, RMM. Processamento Auditivo: Avaliação Audiológica Básica. In: Pereira, LD e Schochat, E. Processamento Auditivo Central - Manual de Avaliação. São Paulo: Lovise; 1997. p. 27 - 35.

Chermak, GD. Music and auditory training. Hear J. 2010, 63(4): 57 - 58.

Chermak, GD e Musiek, FE. Managing Central Auditory Processing Disorders in Children and Youth. Am J Audiol. 1992, 1(3): 61 - 65.

Chermak, GD, Musiek, FE e Craig, CH. Management: Auditory Training and Metalinguistic and Metacognitive Strategies. In: Chermak, GD, Musiek, FE e 
Craig, CH. Central Auditory Processing Disorders - New Perspectives. San Diego: Singular Publishing Group; 1998. p. 185 - 233.

Chermak, GD e Musiek, FE. Auditory Training: Principles and Approaches for Remediating and managing Auditory Processing Disorders. Semin Hear. 2002; 23(4): $297-308$.

Chermak, GD. Deciphering auditory processing disorders in children. Otolaryngol Clin North Am. 2002; 35: 733 - 749.

Dominguez - Ugidos, LJ, Morejon, CR, Varela, HV, Bolinaga, VI, Olmo, JR. Entrenamiento auditivo com ruído blanco de banda ancha. Acta Otorrinolaringol Esp. 2001; 52 (3): 111 - 9.

Fey, ME. Clinical Forum: Phonological assessment and treatment articulation and phonology: Inextricable constructs in speech pathology. Lang Speech Hear Serv Sch. 1992; 23: 225 - 32.

Frederigue-Lopes, NB, Bevilacqua, MC, Samishima, K e Costa, OA. Desempenho de crianças normais em testes temporais auditivos em campo livre. Pro Fono. 2010, 22(2): $83-8$.

Fujioka, T, Ross, B, Kakigil, R, Pantev, C, Trainor, L J. One year of musical training affects development of auditory cortical-evoked fields in young children. Brain. 2006; 129: 2593 - 608.

Gierut, JA. Treatment efficacy: Functional Phonological Disorders in children. J Speech Lang Hear Res.1998; 41: 85 - 100.

Gillam, RB, Loeb, DF, Hoffman, LM, Champlin, TBCA, Thibodeau, L, Brandel, JWJ, Friel - Patti, S. The Efficacy of Fast ForWord Language Intervention in School-Age Children with Language Impairement: A Randomized Controlled Trial. J Speech Lang Hear Res. 2008; 51: 97 - 119.

Grafman, J. Conceptualizing functional neuroplasticity. J Commun Disord. 2000; 33: $346-56$.

Hayes, EA, Warrier CM, Nicol, TG, Zecker, SG e Kraus, N. Neural plasticity following auditory in children with learning problems. Clin Neurophysiol. 2003; $114: 673-4$.

Hirsh, IJ. Auditory Perception of Temporal Order. J Acoust Soc Am. 1959; 31(6): $759-67$.

Ingram, D. Phonological Disability in Children. London: Edward Arnold, 1976. 
Jerger, S, Lewis, S, Hawkins, J e Jerger, J. Pediatric Speech Intelligibility Test. I. Generation of test materials. Int J Pediatr Otorhinolaryngol. 1980; 2: $217-30$.

Katz, J. The use of SSW for Assessing the Integrity of the Central Auditory Nervous System. J Aud Res. 1962; 2: 327 - 37.

Katz, J, Stecker, NA, Henderson, D. Central Auditory Processing: A Transdisciplinary View. Mosby-Yearbook, Chicago, 1992.

King, AJ. Auditory perception: does practice make perfect? Curr Biol. 1999; $9: 143-6$.

Kraus, N. Speech sound perception, neurophysiology, and plasticity. Int J Pediatr Otorhinolaryngol. 1999; 47:123 - 9.

Kraus, $\mathrm{N}$ e Chandrasekaran, B. Musik training for the development of auditory skills. Nat Rev Neurosci. 2010, 11: $599-605$.

Kraus, N, MCgee, T, Carrell, TD, King, C, Tremblay, K e Nicol, T. Central Auditory System Plasticity Associated with Speech Discrimination Training. J Cog Neurosci. 1995; 7(1): 25-32.

Kricos, PB e McCarthy, P. From Ear to There: A Historical Perspective on Auditory Training. Semin Hear. 2007, 28(2): 89 - 98.

McArthur , GM e Bishop, DVM. Which people with specific language impairment have auditory processing deficits? Cogn Neuropsychol. 2004; 21: $79-94$.

McArthur, GM e Bishop, DVM. Speech and non-speech processing in people with specific language impairment: a behavioral and electrophysiological study. Brain Lang. 2005; 94: 260 - 73.

McArthur, G, Atkinson, C e Ellis, D. Atypical brain responses to sounds in children with specific language and reading impairments. Dev Sci. 2009; 12(5): $768-83$.

Moncrieff, DW e Wertz, D. Auditory rehabilitation for interaural asymmetry: Preliminary evidence of improved dichotic listening performance following intensive training. Int J Audiol. 2008; 47:84 - 97.

Moore, DR e Amitay, S. Auditory Training: Rules and Applications - Semin Hear. 2007; 28(2): $99-109$.

Mota, HB e Melo Filha, MGC. Habilidade em consciência fonológica de sujeitos após realização de terapia fonoaudiológica. Pro Fono. 2009; $21(2): 119-24$. 
Muniz, LF, Roazzi, A, Schochat, E, Teixeira, CF, Lucena, JA. Avaliação da habilidade de resolução temporal, com uso do tom puro, em crianças com e sem desvio fonológico. Rev Cefac. 2007; 9(4): 550 - 62.

Murphy, CFB; Sschochat, E. Influência de paradigmas temporais em testes de processamento temporal auditivo. Pro Fono. 2007; 19(3): 259 - 66.

Murphy, CFB. Desenvolvimento de software para treinamento auditivo e aplicação em crianças com dislexia [tese]. São Paulo: faculdade de Medicina, Universidade de São Paulo; 2008, 158p.

Musiek, FE, Baran, JA e Schochat, E. Selected management approachs to central auditory processing disorders. Scand Audiol. 1999; 28(51): 63 - 76.

Musiek, FE e Berge, B. A neuroscience view of auditory training/stimulation and central auditory processing disorders. In: Masters MG, Stecker NA, Katz $\mathrm{J}$, editors. Central auditory processing disorders: mostly management. Boston: Allyn e Bacon; 1998. p. 15 - 32.

Musiek, FE, Chermak, GD, Weihing, J. Auditory Training. In: Chermak, GD e Musiek, FE, editors. Handbook of (Central) Auditory Processing Disorder. San Diego: Plural Publishing; 2007. v. 2; p. 77 - 103.

Musiek, FE, Shinn, J e Hare, C. Plasticity, Auditory Training, and Auditory Processing Disorders. Semin Hear. 2002; 23(4): 263 - 75.

Musiek, FE, Shinn, JB, Jirsa, R, Bamiou, DE, Baran, JA, Zaidan, E. GIN (Gaps in Noise) test performance in subjects with confirmed central auditory nervous system involvement. Ear Hear. 2005; 26(6): 608 - 18.

Musiek, FE e Schochat, E. Auditory training and central auditory processing disorders - A case study. Semin Hear. 1998; 19(4): 357 - 66.

Neves, I F. Maturação do Processamento Auditivo em crianças com e sem dificuldades escolares. Pro Fono. 2005; 17(3): 311 - 20.

Ortiz, KZ e Pereira, LD. Não-verbal de Escuta Direcionada. In: Pereira, LD e Schochat, E. Processamento Auditivo Central - Manual de Avaliação. São Paulo: Lovise; 1997. p. 151 - 157.

Pereira, LD e Schochat, E. Processamento Auditivo Central - Manual de Avaliação. Lovise, São Paulo, 1997.

Perez, AP e Pereira, LD. O teste Gap in Noise em crinaças de 11 e 12 anos. Pro Fono. 2010; 22(1): 7 - 12.

Phillips, DP. Central auditory system and central auditory processing disorders: some conceptual issues. Semin Hear. 2002; 23(4): 251 - 61. 
Pinheiro, FH e Capellini, AS. Treinamento auditivo em escolares com distúrbio de aprendizagem. Pro Fono. 2010, 22(1): 49 - 54.

Putter - Katz, H, Said, LA, Feldman, I, Miran, D, Kushnir, D, Muchnik, C, Hildesheimer, M. Treatment and evaluations indices of auditory processing disorders. Semin Hear. 2002; 23(4): 357 - 64.

Samelli, AG e Mecca, FFDN. Treinamento auditivo para transtorno do processamento auditivo: uma proposta de intervenção terapêutica. Rev Cefac. 2010; 12 (2): $235-41$.

Santos, MFC e Pereira, LD. Escuta com Dígitos. In: Pereira, LD e Schochat, E. Processamento Auditivo Central - Manual de Avaliação. São Paulo: Lovise; 1997. p. $147-150$.

Santos, TM e Russo, IP. Logoaudiometria. In: Santos, T. M. e Russo, I. P. A prática da audiologia clínica. 4ª ed. São Paulo: Cortez; 1986. p. 81 - 98.

Schochat, E. Sons Ambientais Competitivos (CES). In: Pereira, LD e Schochat, E. Processamento Auditivo Central - Manual de Avaliação. São Paulo: Lovise; 1997. p. 159 - 168.

Schochat, E, Rabelo, CM e Sanfins, MD. Processamento Auditivo central: testes tonais de padrão de frequência e duração em indivíduos normais de 7 a 16 anos de idade. Pro Fono. 2000; 12(2):1 - 7.

Shinn, JB, Chermak, GD e Musiek, FE. GIN (Gaps in Noise) Performance in the pediatric population. J Am Acad Audiol. 2009; 20: 229 - 38.

Shriberg, LD. Four new speech prosody voice measures for genetics research and other studies in developmental phonological disorders. $J$ Speech Lang Hear Res. 1993; 36, 105 - 40.

Shriberg, LD, Austin, D, Lewis, BA, McSweeny, JL, Wilson, DL. The percentage of consonants correct (PCC) metric: Extensions and reliability data. J Speech Lang Hear Res. 1997a; 40: 708 - 22.

Shriberg, LD, Austin, D, Lewis, BA, McSwenny, JL, Wilson, DL. The speech disorders classification system (SDCS): Extensions and lifespan reference data. J Speech Lang Hear Res. 1997b; 40: 723 - 40.

Shriberg, LD e Kwiatkowski, J. Phonological Disorders I: A diagnostic Classification System. JSLHD. 1982; 47: 226 - 241.

Stevens, C, Fanning, J, Coch, D, Sanders, L, Neville, H. Neural mechanisms of selective auditory attention are enhanced by computerized training: Electrophysiological evidence from language-impaired and typically developing children. Brain Res. 2008; 1205: 55 - 69. 
Tallal, P, Miller, SL, Bedi, G, Byma, G, Wang, X, Nagarajan, SS, Schreiner, $\mathrm{C}$, Jenkins, WM e Merzenich, MM. Language comprehension in language learning impaired children improved with acoustically modified speech. Science. 1996; 271: $81-4$.

Thibodeau, LM. Computer-Based Auditory Training (CBAT) for (Central) Auditory Processing Disorders. In: Chermak, GD e Musiek, FE, editors. Handbook of (Central) Auditory Processing Disorder - Comprehensive Intervention. San Diego: Plural Publishing; 2007. v 2; p. 167 - 205.

Tremblay, K. Training-related changes in the brain: Evidences from human auditory-evoked potencial. Semin Hear. 2007; 28: 120 - 32.

Tremblay, K, Kraus, N, Carrel, TD, McGee, T. Central auditory system plasticity: generalization to novel stimuli following listening training. J Acoust Soc Am. 1997; 102: 3762 - 73.

Wertz, D, Hall, JW, Davis, W. Auditory Processing Disorders: Management Approaches Past to Present. Semin Hear. 2002; 23(4): 277 - 86.

Wertzner, HF. O distúrbio fonológico em crianças falantes do português: descrição e medidas de severidade. [tese livre docência]. São Paulo: Faculdade de Medicina, Universidade de São Paulo, 2002. 228p.

Wertzner, HF. Fonologia. In: Andrade, CRF., Béfi - Lopes, DM, Fernandes, FDM., e Wertzner, HF. ABFW - Teste de Linguagem Infantil nas Áreas de Fonologia, Vocabulário, Fluência e Pragmática. 2aㅗ ed. Carapicuíba: Pro Fono. 2004. p. 5 - 31.

Wertzner, HF, Papp, ACCS., Galea, DE. Provas de nomeação e imitação como instrumentos de diagnóstico do TF. Pro Fono. 2006; 18(3): 303 - 12.

Wertzner, HF, Pagan, LO, Galea, DES., Papp, ACCS. Características fonológicas de crianças com transtorno fonológico com e sem histórico de otite média. Rev Soc Bras Fonoaudiol. 2007; 12(1): 41 - 7.

Zalcman, TE e Schochat, E. A eficácia do treinamento auditivo formal em indivíduos com transtorno do processamento auditivo. Rev Soc Bras Fonoaudiol. 2007; 12 (4): $310-4$. 